\title{
Assessing the Deinstitutionalization of Marriage Thesis: An Experimental Test ${ }^{*}$
}

\author{
Blaine G. Robbins \\ New York University Abu Dhabi \\ Aimée Dechter \\ University of Washington \\ Sabino Kornrich \\ New York University Abu Dhabi \\ Forthcoming in the American Sociological Review
}

November $24^{\text {th }}, 2021$

Word Count: 15,138 (text, references)

Key words: deinstitutionalization, marriage, social norms, factorial survey experiment

Corresponding author: Blaine G. Robbins, Division of Social Science, New York University Abu Dhabi, Building A5 1191, PO Box 129188, Abu Dhabi, United Arab Emirates.

Email: bgr3@nyu.edu

\footnotetext{
* This research was supported by a grant from the University of Washington's Royalty Research Fund (A74643). Partial support for this research came from a Eunice Kennedy Shriver National Institute of Child Health and Human Development research infrastructure grant to the Center for Studies in Demography \& Ecology at the University of Washington (R24 HD042828). We are indebted to Elisabeth Anderson, Paula England, Maria Grigoryeva, Edgar Kiser, Lake Lui, Ross Matsueda, John O’Brien, Michelle O’Brien, Karl-Dieter Opp, Steven Pfaff, Nora Schaeffer, Phi Su, three anonymous reviewers, and the editors of ASR for their advice and comments. We also benefited from the opportunity to present parts of this work to participants of the Social Research and Public Policy Writing Workshop at New York University Abu Dhabi, the workshop on The Future of Survey Experiments at New York University, and the 2020 Annual Meeting of the American Sociological Association. Finally, we would like to thank David Reisner and Magda Lasota from GfK for their research assistance.
} 


\begin{abstract}
This article seeks to experimentally evaluate the thesis that marriage is deinstitutionalized in the United States. To do so, we map the character of the norm about whether different-sex couples ought to marry, and identify the extent to which the norm is strong or weak along four dimensions: polarity, whether the norm is prescriptive, proscriptive, bipolar (both prescriptive and proscriptive), or nonexistent; conditionality, whether the norm holds under all circumstances; intensity, the degree to which individuals subscribe to the norm; and consensus, the extent to which individuals share the norm. Results of a factorial survey experiment administered to a disproportionate stratified random sample of U.S. adults $(N=1,823)$ indicate that the norm to marry is weak: it is largely bipolar, conditional, and of a low-to-moderate intensity with disagreement over the norm as well as the circumstances demarcating the norm. While the norm to marry is different for males and females and Black and White respondents, the amount of disagreement (or lack of consensus) within groups is comparable between groups. We find no significant differences across socioeconomic status (education, income, and occupation). Overall, our findings support key claims of the deinstitutionalization of marriage thesis.
\end{abstract}




\section{Introduction}

Where does the institution of marriage stand in the mind of the American public? There is growing consensus among family scholars that the institution of marriage is experiencing profound changes (Cherlin 2004, 2020; Coontz 2005; Knapp and Wurm 2019; Lundberg and Pollak 2007; Lundberg et al. 2016; Powell et al. 2010; Rosenfeld 2007; Thornton et al. 2007). In a programmatic statement, Andrew Cherlin (2004) refers to the sum of these changes as the deinstitutionalization of marriage, or “the weakening of the social norms that define people’s behavior in a social institution such as marriage (p. 848).” Cherlin’s (2004, 2020) deinstitutionalization of marriage thesis maintains that the institution of marriage is undergoing uneven declines across social groups. While marriage still plays a central role for White Americans and the college-educated, Cherlin (2020) contends that alternatives to marriage have become more acceptable and are more prevalent among Black Americans and the non-collegeeducated, suggesting that the norm about whether to marry has weakened. ${ }^{1}$

At the heart of the deinstitutionalization of marriage thesis are empirical questions about the "strength" of social norms governing marriage. Common definitions of a social norm conceptualize it as a rule, with some degree of consensus, that prescribes or proscribes a particular action (Coleman 1990; Hechter and Opp 2000; Horne 2009). Given this definition, what constitutes a strong or weak norm? For Cherlin, a norm is strong when it is "widely agreed upon (2020: 64)”, and a norm is weak when there is widespread disagreement. Yet the literature on social norms suggests that a norm can be strong or weak along four dimensions (Horne et al.

\footnotetext{
${ }^{1}$ The Second Demographic Transition characterizes the institution of marriage to be undergoing a similar decline or “retreat” in Western societies (Lesthaeghe 2014). The United States, however, is exceptional because of the race and class differences that exist in the institution of marriage (Ruggles 1994). Also note that the institution of marriage includes norms about how to be married, which have changed less in the United States than the norm about whether to marry (Cherlin 2020).
} 
2018; Jackson 1966; Jasso and Opp 1997; Rauhut and Winter 2010; Rossi and Berk 1985): polarity, whether a norm for a given individual is prescriptive (permit and endorse behavior), proscriptive (prohibit and oppose behavior), bipolar (both prescriptive and proscriptive), or nonexistent (an individual does not subscribe to the norm); conditionality, whether a norm for a given individual holds under all or some circumstances; intensity, the degree to which an individual subscribes to a norm; and consensus, the extent to which members of a population share a norm. Investigating each of these dimensions—particularly whether there is consensus across racial and socioeconomic lines-is necessary to assess the deinstitutionalization of marriages thesis.

The issue is that prior research examining norms about marriage has yet to measure all four dimensions in a single study, which makes it difficult to evaluate the strength of social norms surrounding the institution of marriage in general and the deinstitutionalization of marriage thesis in particular. In the current study, we address this gap by designing a factorial survey experiment (FSE) of different-sex marriage (Auspurg and Hinz 2015): a method that leading scholars of social norms argue is more systematic than and better suited to measuring social norms than conventional survey items or ethnographic methods (Horne et al. 2013; Horne et al. 2018; Jasso and Opp 1997; Jasso 2006). To test whether the norm to marry differs across social groups, we administer our FSE to a random sample of U.S. adults disproportionality stratified by race (Black, White), gender (male, female), and education (high school diploma, some college, Bachelor’s degree or higher).

With this design, we provide a comprehensive evaluation of Black and White Americans' approval of different-sex marriage, how conditional that approval is on the characteristics of those getting married, and how much consensus there is within and between demographic 
groups. Most importantly, the proposed FSE eliminates problems of internal validity inherent in observational studies via random assignment. Marriage conditions and preferences that are correlated in real life, such as education and earnings, are orthogonal by design in our experiment. We can, in other words, untangle effects of circumstances that commonly co-occur, permitting us to test and directly compare the independent effects of conditions that demarcate the norm to marry. Moreover, because we oversample specific demographic groups (e.g., Black Americans, college-educated), we can better test whether theorized differences exist between subpopulations, particularly Black Americans and White Americans and the non-collegeeducated and college-educated (Cherlin 2004, 2020). We can also draw population-based inferences for those randomly sampled subpopulations. In short, this paper makes two contributions. First, it contributes to family scholarship by directly measuring the four dimensions of the norm to marry; by investigating the extent to which the norm to marry varies across demographic groups; and by applying these methods and forms of investigation to a disproportionate stratified random sample of U.S. adults. Second, it extends the literature on social norms to a new area of study, illustrating how the conceptualization and measurement of social norms can provide novel insights in other fields like marriage and the family.

Our findings show that the majority of Black and White respondents in the United States embrace a different-sex marriage norm. Yet the norm to marry is weak: it is largely bipolar, conditional, and of a low-to-moderate intensity, with disagreement over the norm as well as the circumstances demarcating the norm. Our results buttress most claims of Cherlin's (2004, 2020) deinstitutionalization of marriage thesis: the norm to marry is weak and divided along racial and gender lines, though not socioeconomic status (SES).

\section{Social Norms and the Norm to Marry: Theoretical and Empirical Background}




\section{Four Aspects of a Social Norm}

A social norm is a rule about a particular behavior, with some degree of consensus, that is socially enforced (Coleman 1990; Hechter and Opp 2000; Horne 2009). Rules—-the backbone of social norms_-are statements "claiming that something ought or ought not to be the case (Opp 2013: 384)”. This implies that rules prescribe (permit) or proscribe (prohibit) particular actions (behaviors to which a social norm applies), and that individuals who subscribe to a norm tend to punish those who violate the rules, while rewarding those who follow the rules (Coleman 1990; Hechter and Opp 2000; Horne 2009). As Cristina Bicchieri (2006) writes: “Social norms prescribe or proscribe behavior; they entail obligations and are supported by normative expectations. Not only do we expect others to conform to a social norm; we are also aware that we are expected to conform, and both these expectations are necessary reasons to comply with the norm (p. 42)”.

These definitions highlight four key aspects of a social norm (Horne et al. 2018; Jackson 1966; Jasso and Opp 1997; Rauhut and Winter 2010; Rossi and Berk 1985). First, norms might vary in their polarity: they can be prescriptive, proscriptive, bipolar, and/or nonexistent. Second, norms might vary in their conditionality: they can hold under all (unconditional) or some (conditional) circumstances. Third, norms might vary in their intensity: individuals can differ in the degree to which they subscribe to a norm (e.g., low, moderate, or high). Fourth, norms might vary in their level of consensus: they can be shared by all or only a few members of society.

Polarity. The first step in establishing how strong or weak a social norm is in a population is to examine the norm's character for each individual. Mapping the character of a norm begins by identifying its polarity. Polarity means that for any given individual, a person can uniformly oppose a focal action or behavior regardless of the circumstances (proscriptive), 
uniformly endorse a behavior regardless of the circumstances (prescriptive), oppose and endorse a behavior depending on the circumstances (bipolar), or neither oppose nor endorse a behavior since there may not be a norm or rule guiding the focal action (nonexistent).

Conditionality. One should also evaluate whether the norm under study is unconditional_- “under no circumstance should an individual perform $X$ ” or "under all circumstances should an individual do $X$ "—and, if not, in which conditions does a social norm apply. Most norms are replete with conditions. Even a seemingly universal norm such as "thou shalt not kill” can have limits placed on the conditions in which it does or does not hold. Killing in some cultures is appropriate when in self-defense or when the victim is an outgroup member (e.g., White Americans lynching Black Americans in the U.S. South during Jim Crow). Conditionality, then, is the degree to which a social norm—-for any given individual—holds under all circumstances, where circumstances refer to characteristics of the situation and/or the situations' interactants. While polarity implies direction, conditionality identifies the degree to which an individual varies in their evaluation of a norm in light of shifting circumstances. For instance, individual A might uniformly prescribe marriage, but nonetheless vary the magnitude of their prescriptions depending on the circumstances. Individual B, in contrast, might uniformly prescribe marriage to the same degree regardless of the circumstances. In these examples, individual A subscribes to a conditional norm, while individual B subscribes to an unconditional norm. For any individual, an unconditional norm may be prescriptive or proscriptive, but never bipolar; a conditional norm, in contrast, may be prescriptive, proscriptive, or bipolar. Thus, a bipolar norm is always a conditional norm by definition.

Intensity. Whereas polarity identifies the direction of a social norm, intensity is the degree to which an individual subscribes to a norm. For instance, individuals A and B might both 
uniformly prescribe marriage, but the degree of this prescription could be "not very strong at all" for individual A and "very strong" for individual B. While individual A and individual B both feel obligated to conform to the norm to marry, the magnitude of each individual's personal obligations and expectations varies.

Consensus. Polarity, conditionality, and intensity are first established at the individual level, and then proportions and central tendencies can be used to map their distributions in the population. Consensus, by contrast, refers to the degree to which individuals in the population share a norm: degree of unanimity in the knowledge of a rule, common preferences to conform to a rule, and shared expectations of others' conformity to a rule. It can, in other words, "be described as the homogeneity of acceptance [emphasis added] concerning the validity of one particular norm within a population (Rauhut and Winter 2010: 1183).” Consensus is demonstrated by identifying the extent to which a norm is shared within and between subpopulations, and ultimately rests on the amount of between-individual variation in a norm (Jasso 2006).

Consensus is crucial for understanding the shared character of a norm in a population. Some norms vary between subpopulations but not within, while other norms vary to a great extent within and between subpopulations. Gaining knowledge of how a norm is shared in a population specifies how strong or weak a norm might be. For instance, if half of the individuals in a population uniformly prescribe marriage while the other half uniformly proscribe marriage, this would suggest disagreement (or a lack of consensus) in the norm to marry. Given disagreement in the population, the next step is to identify which traits or characteristics are common among subpopulations (e.g., upper-middle classes might be more likely to prescribe marriage than those in poverty). 
Theoretically, then, a strong norm is one with consensus about a rule that approves (or disapproves) of a particular behavior, where the strength of approval (or disapproval) is intense and the circumstances under which the rule applies are unconditional. One ideal-typical strong norm is a norm against incest: individuals widely believe, to a great degree, that incest is strictly prohibited regardless of the conditions. A weak norm, by contrast, is one with widespread disagreement in which (a) some people approve of a particular behavior, others disapprove, and still others might believe that the focal action is not guided by rules, (b) the strength of approval or disapproval is mild, and/or (c) the circumstances under which the rule applies are varied. The norm about whether and what to give on Valentine's Day is a contemporary example of a weak norm: some people feel obligated to give a gift, other people refuse to participate in the tradition out of principle, and most people do not care either way.

Despite their importance, these four dimensions are rarely used to shed light on topics of general interest to sociologists (see Horne et al. 2018; Jasso and Opp 1997; Rauhut and Winter 2010 for exceptions). The primary reason for this is methodological. Although sociologists have toolkits for inferring the representativeness of various attitudes, beliefs, and intentions—such as general social surveys — widespread measurement of the four dimensions of social norms is lacking. To properly measure polarity, conditionality, intensity, and consensus, respondents must assess a systematic set of counterfactual conditions, which is time consuming and costly for general population surveys. However, because norms undergird most social institutions, questions of broad sociological interest—such as the deinstitutionalization of marriage thesis (Cherlin 2004, 2020)—would benefit from theoretical insights and methodological tools developed by scholars of social norms. Our paper offers a template for incorporating the four 
dimensions of social norms into sociological research, and extends the empirical scope of the multidimensional approach to measuring norms.

\section{The Norm to Marry in the United States}

In the United States, social norms have long played a part in individual decisions to marry (Edin and Kefalas 2005; Powell et al. 2010; Rosenfeld 2007). Measuring the norm about whether different-sex couples ought to marry is thus important for the resolution of debates that exist over the polarity, intensity, conditionality, and consensus of the norm. Below, we briefly review these major debates and findings. ${ }^{2}$

Polarity and Intensity. Although we cannot document change over time, we contextualize our work by noting that throughout much of the $20^{\text {th }}$ century prior to the 1960 s, only about 5 percent of people in the United States ever cohabited and couples would typically marry after roughly six months of dating (Coontz 2005; Cott 2002). This suggests that social norms at the time were prescriptive of marriage following a narrow dating period. Individuals today, however, are less likely to think that couples should marry than in the past, and have a greater tolerance for behaviors that were once forbidden socially (Powell et al. 2010). Americans’ attitudes toward marriage have also grown more negative and they view marriage as more restrictive (Gubernskaya 2010; Thornton and Young-DeMarco 2001; Treas et al. 2014). Despite shifts in attitudes and behavior, the literature suggests that norms still govern marriage in the

\footnotetext{
${ }^{2}$ While there are several axes along which norms about marriage differ, the present paper focuses on Black-White differences in norms about different-sex marriage rather than same-sex marriage (as well as differences by gender and SES). We focus on different-sex marriage because the deinstitutionalization of marriage thesis is largely concerned with changes to different-sex marriage in the United States (Cherlin 2004), and our interest is in testing these classic arguments about the normative state of different-sex marriage. We also focus on Black-White differences because these two subpopulations have been described as having the most divergent patterns of marriage. As Cherlin (2020: 70) notes, Hispanic Americans occupy a middle position between Black and White Americans when it comes to marriage, divorce, and non-marital childbearing. We further discuss the implications of our research design, and potential studies of other subpopulations, in the discussion and conclusion.
} 
contemporary United States (Cherlin 2020; Lauer and Yodanis 2010; Knapp and Wurm 2019), though norms may be less prescriptive, less intense, and more conditional than they were in the past. In other words, the normative pressure to marry may still exist, but be less absolute, applying to fewer situations and couples than before.

What we are able to offer empirically is a thorough assessment of whether individuals in the contemporary United States_-particularly Black Americans and White Americans, and the non-college-educated and college-educated —-think that different-sex couples should or should not marry. Unlike previous work, we can answer the following questions: Is the contemporary norm to marry in the United States prescriptive, proscriptive, bipolar, nonexistent, or some combination of the four? Among those who subscribe to a norm (be it prescriptive, proscriptive, or bipolar), what is the magnitude or intensity of their devotion? Finally, how important are conditions for understanding these norms?

Conditionality: Economic bar to marriage. One important circumstance serving as a boundary of different-sex marriage, revealed by both quantitative and qualitative research, is that individuals need to meet a set of economic goals in order to marry (Edin 2000; Edin and Kefalas 2005; Gassman-Pines et al. 2017; Gibson-Davis et al. 2018; Ishizuka 2018; Rackin and GibsonDavis 2017; Schneider 2011; Watson and McLanahan 2011). While some research finds that men's and women's earnings and financial contributions are both important for entry to marriage (Ishizuka 2018; Kuo and Raley 2016; Gibson-Davis et al. 2018), earlier research suggests that men’s financial position and economic prospects are more important than women's (GibsonDavis 2009; Smock et al. 2005). Beyond earnings and employment prospects, assets have also been tied to marriage (Schneider 2011). The idea here is that couples should have the necessary capital or wealth in order to afford various “capstone” events such as a wedding or 
homeownership (Edin and Kefalas 2005; Smock et al. 2005; Gibson-Davis 2018). An economic bar to marriage is one potential explanation for why low-income individuals are less likely to marry than other socioeconomic groups (Watson and McLanahan 2011). Our research can help clarify how important features of the economic bar are relative to other relationship features, and whether men's and women's financial achievements are similarly important for prescribing different-sex marriage.

Conditionality: Pregnancy status. A strong norm forbidding non-marital childbearing existed in the United States until the last third of the $20^{\text {th }}$ century. This norm is still observed in the United States, albeit in a weakened state with variation in the strength of the norm across subpopulations (Barber et al. 2015; Cherlin et al. 2008; Daughterty and Copen 2016). That being said, there has been relative stability in the prevalence of "shotgun marriages" over time (Gibson-Davis et al. 2016), and the majority of adults in the United States agree that people who want children should marry (Thornton and Young-Demarco 2001). Although research on lowincome parents suggests that this norm has declined, ethnographic research shows that lowincome individuals without children view marriage and childbearing as strongly coupled (Rackin and Gibson-Davis 2017). It is thus an open question about how strong prescriptions to marry are when couples face a pregnancy. Our research can help answer this question.

Conditionality: Relationship quality. What constitutes relationship quality, and the level required for entry into marriage, has likely shifted. Marriage in the United States has moved from companionate marriages (in which quality meant emotional satisfaction from playing marital roles well) to individualized marriages (in which quality meant self-fulfillment, openness, and communication) (Cherlin 2004, 2010; Lesthaeghe 2014). These shifts suggest that whether people should marry depends on the quality of their relationship. Brown (2004) found 
that relationship quality did not increase the likelihood of marriage among cohabiting couples, but other research finds that distrust and conflict reduces the likelihood of marriage (Waller and McLanahan 2005). One goal of our study is to identify the extent to which relationship quality matters as a circumstance demarcating who should or should not marry.

Consensus: Race, gender, and socioeconomic status. A central goal for family scholars has been to understand the growing divergence in the institution of marriage across subpopulations (Pagnini and Morgan 1996; Wilson 1987, 1996, 2009). White Americans and the college-educated are more likely to marry and hold favorable attitudes toward marriage than Black Americans and the non-college-educated, respectively (Gubernskaya 2010; Kuo and Raley 2016; Lundberg and Pollak 2007; Raley et al. 2015; Sassler and Schoen 1999; South 1993; Torr 2011). ${ }^{3}$ Women are also more likely than men to prefer marriage, and are more certain about their desire to get married (Thornton and Young-DeMarco 2001), although other research shows that women report stronger negative attitudes toward marriage than men (Autor and Wasserman 2013; Gubernskaya 2010; Sassler and Schoen 1999).

Finally, a sizable body of research suggests that Black Americans and White Americans as well as the non-college-educated and college-educated disagree over the circumstances demarcating marriage, namely the economic bar, pregnancy status, and relationship quality (Cherlin et al. 2008; Edin 2000; Edin and Kefalas 2005; Gibson-Davis et al. 2005; Rackin and Gibson-Davis 2017; Smock et al. 2005; Waller 2002; Wilcox and Wolfinger 2016). In short, divergences along racial, gender, and socioeconomic lines have created disagreement over the institution of marriage in the United States. Our research design allows us to assess whether there

\footnotetext{
${ }^{3}$ It is important to note that Black-White differences in attitudes toward marriage vary from attitude-to-attitude (e.g., see Bulcroft and Bulcroft 1993; Sweeney 2002).
} 
is, in fact, a lack of consensus in the norm to marry, as well as the circumstances governing the norm.

\section{Research Questions}

The goal of this study is to evaluate the strength of the norm about whether different-sex couples ought to marry in the United States. We do so by mapping the character of the norm and by establishing whether divergent subsystems of the norm exist across race (Black, White), gender (male, female), and SES (education, income, occupation).

We follow Jasso and Opp’s (1997) method of mapping the character of a social norm; that is, we investigate the polarity, conditionality, intensity, and consensus of the norm to marry. Given the results, we then investigate the circumstances in which the norm to marry holds and whether these circumstances vary by subgroups in the U.S. population. This includes measuring the existence of the following conditions: different-sex couples ought (or ought not) to marry (a) unless they have achieved a certain economic status, (b) when they are expecting a child, and (c) when the quality of their relationship is good. Given the goals specified above, we use the following questions to orient our study:

Question 1. What is the character (polarity, conditionality, intensity, consensus) of the norm to marry among Black and White Americans in the United States, and what does it imply for the deinstitutionalization of marriage thesis?

Question 2. What are the circumstances demarcating, or serving as boundaries of, the norm to marry among Black and White Americans in the United States?

Question 3. Are individual tendencies to proscribe or prescribe marriage universal or specific to subpopulations based on race (Black, White), gender (male, female), and SES (education, income, occupation)?

Question 4. Are circumstances demarcating the norm to marry universal or specific to subpopulations based on race (Black, White), gender (male, female), and SES (education, income, occupation)? 


\section{Data and Methods}

To measure the character of the norm to marry, we employed a FSE design (Auspurg and Hinz 2015; Jasso 2006). The typical FSE presents respondents with hypothetical scenarios (vignettes) that reflect real-life situations and stimuli. Within each scenario or vignette, experimenters manipulate attributes of the situation (dimensions) by randomly assigning attribute values (levels) to elicit judgments, decisions, or intentions with one or more dependent variables (evaluation task). In this study, we presented a disproportionately stratified random sample of U.S. adults with ten vignettes describing a fictive couple, Mike and Jessica. ${ }^{4}$ We used a number of norm-relevant dimensions, such as Mike’s and Jessica’s individual earnings, to characterize their circumstances. Each dimension consisted of two or more manipulated levels (e.g., \$20,000 versus \$50,000 in earnings) that we randomly assigned to respondents. We then asked respondents to evaluate and judge whether the protagonists in each vignette ought to or ought not to marry.

\section{The Respondent Sample}

The sample consisted of respondents drawn from a nationally representative web panel collected by GfK (formerly Knowledge Networks). Participants for the study came from a random subset of the GfK web panel, which was recruited using a combination of list-assisted random-digit dial and address-based sampling methods. The study was fielded in January 2017 and targeted English speaking, non-institutionalized adults age 18 and older residing in the

\footnotetext{
${ }^{4}$ Although overrepresented among Whites, we selected the names “Mike” (78.3\% White, 10.6\% Black, 6.2\% Hispanic origin, 2.8\% Asian or Pacific Islander, and 2.1\% Other) and “Jessica” (71.1\% White, 10.5\% Black, 14.0\% Hispanic origin, 2.5\% Asian or Pacific Islander, and 2\% Other) since they are common names that exhibit representation across the major ethnoracial groups in the United States (mynamestats.com). Tzioumis (2018), by contrast, reports greater overrepresentation among Whites (“Mike” is 81.5\% White, “Jessica” is 88.9\% White).
} 
United States. GfK contacted 3,181 web panel participants. 1,823 participants completed the study, yielding a 57 percent completion rate.

One goal of our study was to investigate whether the norm to marry is universal or specific to subpopulations based on race, gender, and SES. We thus designed our sample to create twelve different demographic cells cross-classified by race, gender, and SES, with roughly 150 observations per cell. We restricted the sample to non-Hispanic Whites and non-Hispanic Blacks (henceforth White and Black, respectively), with an oversample of Blacks. We measured and restricted gender to males and females. Highest educational attainment was categorized as high school diploma, some college, and Bachelor's degree or higher. The "high school diploma" category consisted of respondents who received a high school diploma, GED, or high school equivalence certification. The "some college" category consisted of respondents who received an Associate's degree or completed some college courses but did not receive a degree. The "Bachelor’s degree or higher" category consisted of individuals who had graduated with a Bachelor's, Master's, Professional, or Doctorate degree. Our sample excluded respondents without a high school diploma because GfK was unable to guarantee a sufficient number of Black males or Black females with only some high school. ${ }^{5}$ Given our stratified sample design and budget constraints, we chose to maximize sample size—and consequently statistical power-for those cells that GfK was able to guarantee a sufficient number of observations. In all, our survey included 911 male, 912 female, 913 Black, 910 White, 609 HS diploma, 608 some college, and 606 Bachelor's degree or higher respondents. The result was twelve different demographic cells (e.g., Black male with a HS diploma) with roughly 150

\footnotetext{
${ }^{5}$ The U.S. Current Population Survey reports that approximately 10 percent of the population has less than a high school diploma.
} 
observations per cell. Other key demographic characteristics—such as age, census region, and metropolitan area-were representative of the U.S. population.

\section{Demographic Characteristics}

Socioeconomic status. We utilized two additional indicators to measure SES. First, we used the household income of respondents. To measure household income, we took the midpoints of closed income categories provided by GfK. We then adjusted for household size (divided midpoint values by total household size) and natural log the adjusted values. This produced a logged per capita household income adjusted for household size.

Second, we used the occupation of respondents, and employed a modified version of the EGP class schema to measure occupation (Erikson and Goldthorpe 1992): class one (higher- and lower-grade professionals, administrators, managers, and officials), class two (routine nonmanual and service employees, higher- and lower-grade), class three (high-grade technicians and repairers, public safety workers, performers, and supervisors of manual workers), class four (skilled manual workers, lower-grade technicians, installers, and repairers), class five (semiskilled and unskilled manual workers, not in agriculture), class six (agricultural), class seven (military), other occupation (occupation unknown), not working (layoff, looking for work, and other not working), retired, and disabled.

Control variables. To account for possible confounding at the individual-level, we controlled for various attitudes and demographic characteristics: age, marital status, cohabitation status, housing type, ownership of living quarters, MSA status, region, religious affiliation, religiosity, religious attendance, a short-form GSS vocabulary test, and marriage judgments. We omitted estimates of the control variables from all tables to conserve space since our focus is on testing whether the norm to marry varies by race, gender, and SES. But given the centrality of 
some control variables in debates about marriage (e.g., religion), we included estimates of all control variables in the Supplemental Materials online.

Summary statistics and descriptions of all individual-level variables used in the present study are in the Appendix (Table A1).

\section{The Vignette Samples}

Vignette dimensions and levels. In an FSE, "the choice of vignette characteristics is based on the conjecture that the characteristics may be relevant in the eyes of some respondents” and that the vignette characteristics capture “potentially normatively relevant information” (Jasso and Opp 1997: 951). Thus, the first step in constructing our FSE was to select circumstances relevant to setting the norm's boundaries. Our decision was based on three separate sources of information. First, we followed recent prescriptions offered by FSE methodologists who suggest that the number of dimensions to include in an FSE should be greater than four but less than ten (Auspurg and Hinz 2015). This nine-to-five range undermines order effects (i.e., bias that results from the order in which a dimension is presented in a vignette), reduces respondent boredom and fatigue effects, and facilitates unbiased evaluation of vignettes for respondents of higher age (> 60 years old), lower educational background, and little familiarity with the topic under evaluation. Second, we were also informed by a pretest administered to undergraduate students at a large public university $(N=75)$, a focus group of undergraduate honors students $(N=15)$, and a pilot study of Amazon.com Mechanical Turk workers $(N=530) .{ }^{6}$ Third, and most

\footnotetext{
${ }^{6}$ The pilot studies were particularly informative. A prior version of our design manipulated the race of Mike and Jessica. In open-ended responses inquiring about our study, respondents repeatedly questioned the necessity of including race (the race dimension was also statistically non-significant). To avoid demand and reverse demand effects, we excluded the race dimension from our experiment. Despite this change, findings were largely consistent across the Mechanical Turk and GfK samples.
} 
importantly, we were guided by the previously reviewed literature on the norm to marry in the United States.

Given the literature and our extensive pretesting, seven vignette dimensions were manipulated (see Table 1), consisting of pecuniary and non-pecuniary characteristics of Mike, Jessica, and their relationship. To avoid number-of-level effects (see Auspurg and Hinz 2015, p. 20), we restricted the number of levels manipulated per dimension to no more than three. And following convention (Wallander 2009), our manipulated levels included high and low values or the presence and absence of vignette characteristics.

Research consistently finds that an economic bar must be met before marriage is judged desirable (Edin 2000; Edin and Kefalas 2005; Gassman-Pines et al. 2017; Gibson-Davis et al. 2018; Ishizuka 2018; Rackin and Gibson-Davis 2017; Watson and McLanahan 2011). The most basic characteristics behind the economic bar to marriage are the earnings, employment, and education of male and female partners. For earnings and employment, we distinguished between unemployment ("she/he has been unemployed for 2 years”) and two earnings levels ("she/he has a full-time job and earns about $\$ 20,000 / \$ 50,000$ a year”) for both Mike and Jessica. ${ }^{7}$ The control level (i.e., unemployment) described situations of relatively low economic standing, while the middle (i.e., “earns about \$20,000”) and upper levels (i.e., “earns about \$50,000”) represented roughly the $1^{\text {st }}$ quartile and median income, respectively, for male householders (no wife present) in the United States (DeNavas-Walt et al. 2012). Building from the same literature, the education of Mike and Jessica included three levels roughly corresponding to SES in the United States: “Mike/Jessica... does not have a high school diploma/...has a high school diploma/...has a 4year college degree”. While higher levels of education can be achieved, we manipulated these

\footnotetext{
${ }^{7}$ Our operationalization of "unemployed” is intentionally ambiguous with respect to looking for work. We made this design choice to avoid conflating motivation for employment with the state of not being employed.
} 
three levels as they constituted the bulk of education levels observed in the U.S. population. Taken together, earnings and employment consisted of two dimensions (one for Mike and one for Jessica), as did education (one for Mike and one for Jessica).

The final pecuniary characteristic, assets, was used to capture the money needed to be in place for individuals to marry (Edin and Kefalas 2005; Smock et al. 2005; Schneider 2011). For our assets dimension, one level was mentioned in the vignettes ("Mike and Jessica recently inherited \$5,000 each from a mutual, elderly friend”), while the other level was not (i.e., a blank level). We settled on this operationalization of assets to reduce measurement confounding. Assets that are accrued exogenously (i.e., inheritance from a friend) are not correlated with other features of Mike or Jessica such as motivations to save money or the accrual of debt.

There are many non-pecuniary characteristics that inform decisions to marry, including control over household decisions, fear of domestic violence, and drug use (Edin 2000; Edin and Kefalas 2005; Smock et al. 2005). For the current study, we focus on two classic characteristics: relationship quality and pregnancy status. Relationship quality is often viewed as a multidimensional construct that consists of objective and subjective characteristics, such as levels of companionship, communication, affection, trust, and conflict, as well as satisfaction and happiness with the relationship (Wilcox and Nock 2006). Investigating several aspects of relationship quality would require too many vignette dimensions. Instead, we focus on communication and conflict. Therefore, two levels that emphasize (a lack of) communication and conflict resolution operationalized relationship quality (see Table 1).

To see whether unmarried couples are expected to marry given a pregnancy, we distinguished between not pregnant ("Mike and Jessica are not thinking of having a child at this time”) and pregnant ("Mike and Jessica were not thinking of having a child at this time, but they 
just found out that Jessica is pregnant”). The goal of our operationalization was to provide the respondent with Mike and Jessica’s preferences for children (not now, but possibly later) as well as their pregnancy status (not pregnant versus pregnant).

Population of vignettes. With the vignette dimensions and levels outlined in Table 1, we constructed the factorial object universe or vignette population (i.e., all possible combinations of dimensions and levels). The number of possible vignettes $(V)$ is $2^{3} \times 3^{4}=648$. Since all possible vignettes were plausible and logical, the resulting factorial object universe did not result in impossible combinations of dimensions and levels. We, as a result, retained the full population of 648 vignettes.

Drawing vignette samples. The final two design-based choices involved the number of vignettes to present to respondents and the sampling procedure used to assign vignette dimensions and levels to respondents.

With respect to the number of vignettes, the methodological literature suggests that respondents should evaluate no more than ten vignettes to avoid cognitive overload, fatigue, and learning effects (Auspurg and Hinz 2015). While evaluating more than one vignette increases statistical efficiency and power (Jasso 2006), the assumption of temporal stability and causal transience must be maintained. Empirical support of this assumption, as well as other assumptions central to causal inference, are in the Supplemental Materials Online. In short, we follow recent methodological suggestions and restrict the number of vignettes evaluated per respondent to ten.

To randomly assign vignette dimensions and levels, we used a randomized block design (RBD) with replacement. Given the respondent sample size $(N=1,823)$, the size of the vignette object universe $(V=648)$, and the total number of vignettes evaluated per respondent $(n=10)$, 
we were able to achieve a full-factorial between-subjects design. The RBD yielded an average of 28 evaluations for each unique vignette $(\min =14$, $\max =47)$. No respondent evaluated the same vignette twice. In terms of blocks, our block randomization procedure generated roughly equal distributions of Mike's earnings and employment, Jessica's earnings and employment, and pregnancy status within race (Black, White), gender (male, female), and education (high school diploma, some college, Bachelor's degree or higher). We used an RBD to increase the statistical efficiency of higher-order interaction terms between characteristics of respondents and manipulated characteristics of Mike and Jessica.

For each evaluated vignette $(1, \ldots, 10)$, the number of blocked cells to fill was $216(3 \times 3$ $\times 2 \times 2 \times 2 \times 3$ ). Our RBD was effective at producing balance between the three key vignette dimensions within the demographic characteristics of race, gender, and education. Illustrating the distribution of all cell combinations is difficult. Tables S1 through S12 in the Supplemental Material Online, however, summarize the number of vignettes in each vignette condition evaluated by the race, gender, and SES (education) of respondents pooled across the ten vignettes. A simple random sample with replacement (SRS) was used to randomly assign the remaining vignette dimensions and levels to respondents (i.e., Mike’s education, Jessica's education, assets, and relationship quality). Like the RBD, the SRS was effective at producing balance between the remaining vignette dimensions.

\section{The Evaluation Task}

Ten vignettes were presented successively to each respondent at the beginning of a webbased survey. Prior to assessing the vignettes, respondents were shown a coversheet providing details about Mike and Jessica: 
"Mike and Jessica have been together for a year and a half. Each is 33 years old. Neither one has been married. Neither one has a child. And neither of them has a criminal record or an addiction to drugs or alcohol.”

This information was subsequently provided at the top of each vignette to remind the respondents of these characteristics. ${ }^{8}$ Respondents were then told that they would be shown ten scenarios, and that each scenario would have different details about Mike and Jessica.

A vignette is presented below as an illustration (bolded portions were manipulated based on the level randomly assigned to respondents):

"Mike does not have a high school diploma. He has been unemployed for 2 years. Jessica has a 4-year college degree. She has a full-time job and earns about $\mathbf{\$ 5 0 , 0 0 0}$ a year. Mike and Jessica recently inherited \$5,000 each from a mutual, elderly friend.

Mike and Jessica are attracted to one another and treat each other well. But when they have disagreements with each other they argue and feel hurt and misunderstood afterward.

\section{Mike and Jessica are not thinking of having a child at this time.”}

After respondents read each scenario, they were instructed to think about their personal normative beliefs: "Based on your personal values about marriage, should Mike and Jessica marry or not marry in this scenario?” Since social norms range in polarity, respondents were asked to rate each vignette with a 9-point bipolar scale. Instead of showing respondents a horizontal rating scale with all nine response values, we employed a branching technique to simplify the complex decision task. With this technique, respondents were shown an initial four-

\footnotetext{
${ }^{8}$ We chose to fix various characteristics of Michael and Jessica to features of the median person or different-sex couple who gets married in the United States (Powell et al. 2010): a couple in their thirties, without children, who have been together for one-and-a-half years, and who have not been married previously. While this strategy increases measurement equivalence and the precision of our estimates, it also decreases the generalizability and scope of our findings. There is, in other words, a "tight correspondence" (Jasso 2006: 340) between estimates of a social norm and elements of the research design. Estimates of consensus and conditionality, for instance, may vary as a function of age differences between Mike and Jessica, or whether Mike and Jessica are abusive divorcees with criminal records. While these characteristics are important to explore in future research, the goal of our study is to see whether people approve of (or support) different-sex marriage under commonplace marriage conditions. Our study, then, is a conservative test of the deinstitutionalization of marriage thesis. We thank an anonymous reviewer for bringing these issues to our attention.
} 
option question (Should not marry, Neutral, Should marry, and Don't know). After selecting one of the endpoints, respondents were shown four levels of intensity: "Based on your personal values about marriage, how strong is your belief that Mike and Jessica [should not marry | should marry] in this scenario?”, with Not strong at all, Not very strong, Somewhat strong, and Very strong as response options $(M=4.04, S D=2.63, N=16804, \min =0, \max =8)$. The order of the initial four-option question was randomized between respondents, but remained fixed for each of the ten vignettes within respondents. This was done to undermine rating scale order effects. The 9-point scale ranges from should not marry $(0=$ very strong, $1=$ somewhat strong, 2 = not very strong, $3=$ not strong at all $)$ to neutral (4) to should marry $(5=$ not strong at all, $6=$ not very strong, 7 = somewhat strong, 8 = very strong).

We thus measured social norms as "personal normative beliefs" (Bicchieri 2016), or the extent to which individuals believe that others should (or ought to) follow a rule under various circumstances. We selected personal normative beliefs as our operationalization of social norms for three reasons. First, personal normative beliefs, along with empirical and normative expectations, undergird most social norms (Bicchieri 2006). Although some types of social norms can exist in the absence of personal normative beliefs, Opp (2013) contends that evaluations and judgments about what others ought to or ought not to do are core features of a social norm. As Hechter and Opp (2001) write: "the most common element in [definitions of a social norm] is ‘oughtness’ (p. 403).” Second, it is common for scholars of social norms to measure personal normative beliefs in FSEs (Diefenbach and Opp 2007; Jasso and Opp 1997), especially as bipolar scales probing degrees of “oughtness”. Third, behavioral intentions or selfreported preferences could have been used as alternative measures of social norms. These alternatives, however, require the respondent to imagine being in a relationship with either Mike 
or Jessica. Such a first-person design would have (a) created situations difficult for respondents to imagine, and (b) increased various response biases like social desirability (Auspurg and Hinz 2015).

Measuring the Character of a Norm: Averages, Dispersion, and Multilevel Models

Polarity. We differentiated between nonexistent, proscriptive, prescriptive, and bipolar norms. If a respondent assigns a rating of 4 (neutral rating) to all evaluated vignettes, we interpreted this as a "nonexistent” norm for that individual. That is, the respondent did not subscribe to a proscriptive, prescriptive, or bipolar marriage norm. If a respondent's ratings include neutral values and values less than 4, then we interpreted this as a proscriptive norm. Conversely, we identified a prescriptive norm when a respondent's ratings include neutral values of 4 and values greater than 4 . If a given respondent's ratings include values greater than 4 for some vignettes and less than 4 for other vignettes, then we interpreted this as a bipolar norm.

Conditionality. We also differentiated between unconditional and conditional norms. If a respondent assigns the same non-neutral rating to all evaluated vignettes, then the respondent's norm was interpreted as unconditional (e.g., a rating of 5 for all ten vignettes). In all other cases, the norm was treated as a conditional norm.

Intensity. We assess the intensity of an individual's norm by calculating the numerical "distance” of each rating from the neutral value of 4 (e.g., a rating of 4 would generate a distance of 0 , a rating of 3 would generate a distance of 1 , a rating of 6 would generate a distance of 2, etc.). We then estimate an individual-specific mean of the distances. For instance, a respondent who subscribes to a prescriptive norm with an individual-specific mean of 3.50 would have a greater intensity (or a stronger devotion to the norm) than a respondent with an individualspecific mean of 1.25. Finally, we take an average of the individual-specific means to estimate 
the intensity of the norm to marry in the population for each type of norm (e.g., unconditional proscriptive norm, conditional prescriptive norm, etc.). In this sense, measures of intensity will always be greater than 0 but less than or equal to 4 , where higher values equal greater intensity. ${ }^{9}$

Consensus. To assess consensus, we first summarize the proportion of respondents who vary in the polarity and conditionality of the norm. If some respondents subscribe to a conditional bipolar norm while others subscribe to an unconditional proscriptive norm, then there is disagreement over the norm. But if all respondents subscribe to an unconditional prescriptive norm of similar intensity, then there is consensus regarding the norm. Heterogeneity of acceptance characterizes the first example, while homogeneity of acceptance describes the second example (Rauhut and Winter 2010). Statistical estimates of consensus, then, quantify the degree of respondent heterogeneity in normative judgments (Jasso 2006).

Following Jasso (2006), we quantified the degree of consensus (or respondent heterogeneity) by estimating random intercept and random slope hierarchical linear models (HLM), and compared these models to models in which random intercepts and/or random slopes were fixed, or constrained to zero (see also Jasso and Opp 1997). Improvements to model fit would suggest that respondents differed in their "mean” views of the norm to marry (i.e., random intercept) and that respondents differed in their views of the circumstances demarcating the norm to marry (i.e., random slopes). Lack of statistical improvements to model fit, by contrast, would suggest inter-respondent homogeneity in intercepts and slopes, indicating consensus among respondents in their views of the norm to marry. Thus, standard deviations of the random effects provide metrics for the degree of consensus about the norm to marry.

\footnotetext{
${ }^{9}$ Measuring intensity is not straightforward: it is difficult to differentiate intensity from measurement error or response style. For this reason, we assume that measurement error and response biases are minimal, which is a weak assumption given our experimental design and survey format.
} 
If random intercepts and/or random slopes were observed, then the next step is to investigate which subpopulations — if any-accounted for the random variation in intercepts and/or slopes (Jasso 2006). To do this statistically, we estimated models in which race, gender, and SES predicted random intercepts and random slopes (i.e., cross-level interaction effects).

If we observe mean differences between groups (e.g., Black and White respondents), the final step is to identify whether within group differences (or variances) are the same for each subpopulation (e.g., Black respondents have greater or lesser consensus than White respondents). To do this statistically, we estimated equality of variances across race, gender, and education.

We thus estimated a series of nested two-level HLMs with robust standard errors in which $i$ vignettes $(i=1, \ldots, 10)$ were nested within $j$ individuals $(j=1, \ldots, 1823)$. Even though our dependent variable was a 9-point bipolar scale, we chose to model the scale within a linear framework (rather than treat the scale as a limited dependent variable). We did this for a number of reasons. First, the interpretation of estimates from linear models is more intuitive than ordered logit models, especially for higher-order interaction terms. Second, HLM fitted values produced estimates within the lower and upper bounds of the dependent variable ( 0 and 8 respectively). Third, we found little to no difference in estimates of main effects from linear and ordered logit regression models. The statistical models we estimated along with various tests of modeling assumptions are in the Supplemental Materials online.

\section{Results}

The Character of the Norm to Marry: Polarity, Intensity, Conditionality, and Consensus

Of the 1,823 respondents in our sample, slightly over 2 percent (46 respondents) did not rate any of the vignettes, and slightly over 22 percent (403 respondents) rated between one and 
nine vignettes. Our analyses use all available data, and include respondents who rated ten or fewer vignettes by answering “don’t know” or refusing to answer $(N=1,777)$.

Polarity of the norm to marry. 8.16 percent of the respondents did not subscribe to a marriage norm by providing neutral ratings of 4 for all evaluated vignettes (see Table 2). In contrast, 15.08 percent of the respondents subscribed to a prescriptive norm, and 13.96 percent subscribed to a proscriptive norm. A majority of the sample endorsed a bipolar norm to marry: 62.80 percent of the respondents vacillated between proscribing and prescribing marriage as a result of Mike and Jessica’s changing circumstances. ${ }^{10}$

Conditionality of the norm to marry. Beyond the 62.80 percent of respondents who subscribed to a bipolar norm— which, by definition, is a conditional norm—24.09 percent of the respondents subscribed to a conditional proscriptive norm or a conditional prescriptive norm, for a total of 86.89 percent. Altogether, the norm to marry in the United States is overwhelmingly conditional.

Intensity of the norm to marry. The norm to marry is intense among respondents who subscribed to an unconditional marriage norm, as they were relatively far from the neutral rating. For unconditional proscriptive norms $(N=33)$, the average distance (of the individual-specific mean ratings) from the neutral value was 3.24, while the average distance was 3.38 for unconditional prescriptive norms $(N=55)$. The small number of respondents (4.95 percent) who subscribed to an unconditional norm to marry favored extreme values, and the level of intensity was statistically equivalent for proscriptive and prescriptive norms, $b=0.139, S E=0.203, p=$ .495. ${ }^{11}$

\footnotetext{
${ }^{10}$ Robustness checks confirmed that respondents who uniformly proscribed or prescribed marriage did not randomly receive ten vignettes that were (un)favorable to marriage.

${ }^{11}$ Results from an OLS regression with cluster-robust standard errors by individuals ( $\left.N=88, n=880\right)$.
} 
Among conditional norms, the average distance was 1.72 for conditional proscriptive norms $(N=215)$ and 1.89 for conditional prescriptive norms $(N=213)$. The intensity of the norm to marry was statistically equivalent for respondents who subscribed to either a conditional proscriptive or prescriptive norm, $b=0.171, S E=0.103, p=.100 .{ }^{12}$ For individuals who subscribed to a bipolar marriage norm $(N=1,116)$, the average distance was 2.35 , or moderately intense ratings.

Taken together, the majority of the sample subscribed to a bipolar marriage norm where the average level of intensity was between "not very strong” and "somewhat strong”. The patterns in the data thus indicate that the overall intensity of the marriage norm was low-tomoderate.

Consensus about the norm to marry. The analysis of polarity, conditionality, and intensity indicates disagreement among respondents (see Figure A1 in the Appendix for histograms of individual-specific mean ratings of the norm to marry by norm type). To investigate consensus formally, we estimated the two-level HLMs outlined above. A likelihood ratio test rejected a model of fixed intercepts and slopes for each vignette dimension in favor of random intercepts and fixed slopes, $\chi^{2}(1)=4114.92, p<.001$. In addition, significant variation was observed around the intercept as indicated by the level-2 error term, $S D$ (intercept) $=1.427$ (see Table 3, model 1). This indicates differences across individuals in their tendencies to proscribe or prescribe marriage, thereby demonstrating respondent heterogeneity and a lack of normative consensus (Jasso 2006). ${ }^{13}$

\footnotetext{
${ }^{12}$ Results from an OLS regression with cluster-robust standard errors by individuals $(N=428, n=4,004)$.

${ }^{13}$ A null HLM yielded a moderate intra-class correlation (ICC) of .289. The ICC tells us that 28.9 percent of the variation in the norm to marry occurred between individuals, while 71.1 percent of the variation was within individuals; suggesting that ratings of vignettes by the same individual tended to be different.
} 
Next, we relaxed the assumption of fixed slopes, so that each respondent had a unique intercept and a unique slope for each vignette dimension. The results of a likelihood ratio test rejected a model of random intercepts and fixed slopes in favor of both random intercepts and random slopes, $\chi^{2}(11)=1134.83, p<.001$. Stated differently, respondents differed with one another in their tendencies to proscribe or prescribe marriage and respondents placed different weights on the pecuniary and non-pecuniary circumstances demarcating the norm to marry. Thus, there is disagreement among the respondents over the norm to marry.

\section{The Circumstances Demarcating the Norm to Marry}

We now investigate respondents' views about which circumstances demarcate, or serve as boundaries of, the norm to marry. We begin with a descriptive analysis that collapses the 9point evaluation task into three categories: Proscriptive (should not marry), Nonexistent (neutral), and Prescriptive (should marry). In Figure 1, we present histograms of the distribution of the collapsed dependent variable by levels of each respective vignette dimension.

For education, the percentage of responses was roughly equivalent when either Mike or Jessica had no high school diploma or a high school diploma. However, 35 percent of responses—a plurality—prescribed marriage when either Mike or Jessica had a 4-year college degree. Mike and Jessica's earnings produced slightly different, albeit expected, results. When Mike or Jessica was unemployed, a plurality of responses prohibited marriage (between 42 and 48 percent). But when Mike or Jessica was employed and earning money, the plurality switched from proscriptive to prescriptive, with the size of the plurality increasing as the amount of earnings increased. This shift was most noticeable for Mike’s earnings: only 23 percent of responses proscribed marriage, while 43 percent prescribed marriage when Mike was earning 
$\$ 50,000$ a year. Unlike education and earnings, assets generated only minor differences in the percentage of responses.

With respect to non-pecuniary circumstances, we observed a shift from a plurality of responses proscribing marriage (43 percent) to a plurality prescribing marriage (43 percent) as Mike and Jessica’s relationship quality went from bad to good. Pregnancy status generated similar results. When Mike and Jessica were not pregnant, 37 percent of the evaluations proscribed marriage. But when Mike and Jessica were pregnant, 40 percent of the evaluations prescribed marriage. Overall, Figure 1 shows that responses varied dramatically between vignette dimensions and levels.

Table 3 presents results of two-level HLMs in which random slopes were fixed (model 1) versus freely estimated (model 2). In model 1, we observed strong statistical support for all seven vignette dimensions. The pecuniary circumstances (Mike and Jessica’s education, Mike and Jessica's earnings and employment) affected views of marriage as expected: the greater the education and earnings, the more prescriptive the norm to marry. Familywise tests of each dimension were statistically significant (see Table 3 ), as were pairwise tests between the $2^{\text {nd }}$ and $3^{\text {rd }}$ levels of each dimension (save for the $2^{\text {nd }}$ and $3^{\text {rd }}$ levels of Jessica's education). Interestingly, the effect of earnings was not equal for Mike and Jessica. Mike’s earnings had stronger effects on the norm to marry than Jessica's earnings. Overall, our experimental design and sample finds evidence of an economic bar to marriage (Gibson-Davis et al. 2005; Gibson-Davis et al. 2018) that weighs men's labor force characteristics more heavily than women’s (Gibson-Davis 2009; Smock et al. 2005).

The non-pecuniary circumstances in model 1 yielded similar dynamics: a pregnancy and a good quality relationship elicited stronger prescriptions to marry than no pregnancy or a bad 
quality relationship, respectively. In the contemporary United States, pregnancy continues to guide views about the necessity of marriage (Cherlin et al. 2008). Likewise, a bad quality relationship leads to opposition to marriage, likely due to beliefs about the futility of marriage (Wilcox and Nock 2006). Interestingly, relationship quality—as operationalized here—had a stronger effect on the norm to marry than pregnancy. The higher-order needs of both individuals are thus more relevant to setting the norm's boundaries than a premarital conception.

Table 4 reports select linear predictions (and 95 percent CIs) by profiles of Mike and Jessica's pecuniary (rows 1, 2, and 3) and non-pecuniary (columns 1 through 4) circumstances calculated from Table 3, model 1 estimates. Starting with a low economic standing profile (i.e., Mike and Jessica did not have a HS diploma, were unemployed, and had no assets), respondents proscribed marriage between "not very strong” and "somewhat strong” (a linear prediction of 1.548) when Jessica was not pregnant and the quality of their relationship was bad. Only when Mike and Jessica achieved a moderate economic standing (i.e., both had a HS degree, earned $\$ 20,000$ a year, and had assets) and were pregnant or had a good quality relationship did respondents prescribe marriage. Respondents prescribed marriage to the greatest extentbetween "not very strong" and "somewhat strong" (a linear prediction of 6.405)—when Mike and Jessica achieved a high economic standing (i.e., both had a 4-year college degree, earned \$50,000 a year, and had assets), when Jessica was pregnant, and when the quality of their relationship was good. Taken together, the linear predictions illustrate how strong the average treatment effects of the circumstances were in motivating respondents to proscribe or prescribe marriage.

Returning to Table 3, we relaxed the assumption of fixed slopes in model 2 to investigate which vignette dimensions varied in their magnitude. Of the pecuniary circumstances, only the 
effect of Mike earning \$50,000 and Jessica earning \$50,000 varied to a great extent between respondents (see Figure 2 for an illustration). There was generally consensus among respondents over the effects of Mike’s education, Jessica’s education, Mike earning \$20,000, Jessica earning $\$ 20,000$, and their shared assets on the norm to marry. In contrast, both pregnancy status and the quality of relationship varied to a great degree between respondents in their effects on the norm to marry. As Figure 2 shows, most respondents were prescriptive of marriage (to varying degrees) when Mike and Jessica were expecting a child, while a small minority of respondents (roughly a quarter) were proscriptive of marriage under the same conditions. Similar dynamics were observed for the quality of Mike and Jessica's relationship.

In short, both pecuniary and non-pecuniary circumstances served as boundaries between who should and should not marry. Moreover, circumstances demarcating the norm to marry exhibited more consensus in some cases (education and assets) and less consensus in others (earnings, pregnancy status, and quality of relationship). Overall, however, we observed relatively little consensus.

Consensus Within and Between Subpopulations: Race, Gender, and SES

In the next subsection, we identify whether individual-level tendencies to proscribe or prescribe marriage are a function of the race, gender, and SES of respondents. After that, we investigate whether variation in the weights placed on the circumstances driving the norm to marry is a function of the race, gender, and SES of respondents. ${ }^{14}$

The character of the norm to marry within and between subpopulations. We now present estimates from a two-level HLM that includes the race, gender, and SES of respondents as

\footnotetext{
${ }^{14}$ Excluding the individual-level control variables (e.g., religious affiliation, religiosity, religious attendance, etc.) did not alter the substantive results presented in Tables 5 and 6.
} 
predictors of normative differences. The model, in Table 5, controlled for vignette dummies, vignette dimensions, and the individual-level control variables outlined in the Data and Methods section. These results show that White respondents and male respondents prescribed marriage more strongly than Black respondents and female respondents, respectively. There were weak effects for SES: a familywise test for the effect of education was statistically non-significant, $\chi^{2}(2)=1.99 p>.10$; the effect of income was statistically non-significant, $b=-0.070, S E=$ $0.040, p=.082$; and a familywise test for the effect of occupation was statistically nonsignificant, $\chi^{2}(10)=12.69, p>.10$. Next, we investigate whether within-group variation was the same between subpopulations (e.g., consensus is greater or lesser among White respondents than Black respondents). First, in Figure 3, kernel density plots of individual-specific mean ratings of the norm to marry revealed that the amount of disagreement (or lack of consensus) within subpopulations was comparable between subpopulations (e.g., disagreement among Black and White respondents was comparable). Second, tests of equality of variances across race, gender, and education yielded statistically non-significant results, providing statistical support for the visualized patterns in Figure $3 .{ }^{15}$ In short, male and female respondents, and Black and White respondents differed in their tendencies to prescribe marriage, but the amount of disagreement (or lack of consensus) within groups was comparable between groups.

The circumstances demarcating the norm to marry between subpopulations. Earlier, we found that some circumstances demarcating the norm to marry exhibited greater disagreement than other circumstances. We next investigate how much race, gender, and SES account for this disagreement by estimating a two-level HLM with cross-level moderation in which the race,

\footnotetext{
${ }^{15}$ Black vs White: $F(2,1777)=1.134, p=.060$. Female vs male: $F(2,1777)=0.993, p=.925$. HS diploma vs some college: $F(2,1181)=0.895, p=.178$. HS diploma vs BA+: $F(2,1185)=0.977, p=.779$. Some college vs BA+: $F(2,1188)=1.091, p=.285$.
} 
gender, and education of respondents interacted with each vignette dimension. ${ }^{16}$ This model controlled for vignette dummies, the individual-level control variables, and the other measures of SES (income and occupation) outlined in the Data and Methods section. The model in Table 6 shows that the majority of cross-level interaction effects were statistically non-significant, and those that were statistically significant yielded trivial substantive differences in the slopes (see Figures S1 and S2 in the Supplemental Materials online). The two cross-level interaction effects that did yield practical and substantive differences were between race and quality of relationship as well as race and pregnancy status. The cross-level interaction effects show that the quality of relationship dimension had a stronger positive effect on the norm to marry for White respondents than for Black respondents (see Figure 4, panel A). The pregnancy status dimension had a weaker positive effect on the norm to marry for Black respondents than for White respondents (see Figure 4, panel B). Overall, we found evidence that Black and White respondents placed different levels of importance on how relationship quality and pregnancy status affect the norm to marry. All other circumstances yielded relatively consistent effects regardless of race, gender, or SES.

To provide a sense of the magnitude of disagreement across demographic groups, Table 7 reports select linear predictions (and 95 percent CIs) by the race and gender of respondents as well as Mike and Jessica’s non-pecuniary circumstances (estimates calculated from model 1 in Table 6). When Jessica was not pregnant and the quality of Mike and Jessica’s relationship was bad, predicted values differed, at most, by 1 point (or a standardized mean difference of 0.379 ). ${ }^{17}$ But when Jessica was pregnant and the quality of Mike and Jessica’s relationship was good,

\footnotetext{
${ }^{16}$ See Tables S14 and S15 in the Supplemental Materials online for cross-level interactions between income and the vignette dimensions (Table S14) as well as occupation and the vignette dimensions (Table S15). A statistically significant cross-level interaction was not consistently observed across the different operationalizations of SES. ${ }^{17}$ Standardized mean difference calculated as follows: $\frac{\text { difference in predicted values }}{\text { pooled standard deviation }}$
} 
predicted values differed to a moderate extent, with Black females and White males, for instance, differing by 1.383 points (or a standardized mean difference of 0.526).

\section{Robustness and Sensitivity Checks}

Robustness and sensitivity checks are in the Supplemental Materials Online. First, we estimated nested models with all possible higher-order interactions between vignette dimensions (i.e., two-way interactions, three-way interactions, etc.). According to the Bayesian information criterion, model 1 in Table 3 was the best fitting model (Table S16). Second, characteristics of subpopulations may intersect in compelling ways to pattern norms about marriage in the United States. Poor Black Americans, for instance, exhibit different marriage patterns than middle-class Black or White Americans (Raley et al. 2015). To investigate intersectionality, we estimated a series of models predicting random intercepts and random slopes by interacting the race, gender, and SES of respondents. Overall, models suggest that race, gender, and SES did not interact in complex (or consistent) ways to influence ratings of who should or should not marry (Tables S17 and S18). Third, the main effects were robust to alternative modeling procedures, namely twolevel ordered logit (Tables S19 through S21) and multinomial logit regression (Tables S22 and S23). Fourth, the estimates were robust to models that excluded nonexistent norm followers (Tables S24 through S26) as well as models that restricted the analysis to respondents who evaluated all ten vignettes (Tables S27 through S29). Fifth, we estimated all models found in the present manuscript using post-stratification survey weights provided by GfK (Tables S30 through S33). Weighted and unweighted models yielded substantively similar results.

\section{Discussion and Conclusion}

The primary goal of the present study was to evaluate the strength of the norm about whether different-sex couples ought to marry in the contemporary United States. By turning our 
attention to the measurement of social norms within an experimental context, this article addresses a gap in our understanding of whether the norm to marry is weak and/or unevenly deinstitutionalized across race (Black, White), gender (male, female), and SES (education, income, and occupation). In returning to our four original questions, we provide the following answers.

What is the Character (Polarity, Intensity, Conditionality, Consensus) of the Norm to Marry among Black and White Americans in the United States, and What Does it Imply for the

\section{Deinstitutionalization of Marriage Thesis?}

While all four types of polarities—-proscriptive, prescriptive, bipolar, and nonexistentwere observed in the sample, the majority of respondents subscribed to a bipolar marriage norm, indicating that the norm to marry was overwhelmingly conditional. In terms of intensity, respondents' overall magnitude of devotion to the marriage norm was low-to-moderate. Regarding consensus, individuals differed in their tendencies to proscribe or prescribe marriage, and placed different weights on the circumstances governing marriage; thus, there is little consensus about the norm to marry.

Taken together, our results support Andrew Cherlin’s (2004) observation that “social norms [defining] people’s behavior in a social institution such as marriage (p. 848)” are weak in the United States. Despite this key finding, our results provide a nuanced picture of the contemporary institution of different-sex marriage: individuals still hold opinions about whether different-sex couples should or should not get married. Only a small minority of individuals are unwilling to state whether others should get married, suggesting a nonexistent norm. The remaining 92 percent of individuals subscribe to a norm, although the nature of the norm is conditional and does not exhibit consensus. Because different standards for action abound, these 
findings imply that individuals will be more prone to conflict, negotiation, and debate over who and why people should or should not get married (Cherlin 2004). This is what family scholars have observed in contemporary American marriage for some time, as evidenced by debates over same-sex and interracial marriage (Powell et al. 2010). Yet, it remains to be seen whether more individuals in the United States will come to view the norm to marry as nonexistent and treat marriage as one of many possible family forms, driven by individual choices independent of what one (or others) should or should not do. Or, whether the norm to marry is in a transitional phase, moving from one normative system to another as it absorbs and layers on new types of unions - and represents new types of goals — under the umbrella of marriage.

What are the Circumstances Demarcating, or Serving as Boundaries of, the Norm to Marry among Black and White Americans in the United States?

The majority of respondents subscribed to a conditional norm. One goal of the present study was to map the specific circumstances that predicted variation in—or accounted for the conditionality of-the norm to marry. As expected, pecuniary and non-pecuniary circumstances acted as the norm's boundaries. The education and earnings of Mike and Jessica, their shared assets, as well as their pregnancy status and quality of relationship all drove respondents' willingness to proscribe or prescribe marriage, with Mike’s earnings and employment having the strongest relative impact.

These findings align with Cherlin's (2010) view of contemporary marriage in the United States, where marriage requires "a decent job, a good education, and the ability to attract a partner who is likely to treat you fairly, be loyal, and stay with you indefinitely (p. 133).” Our findings support Cherlin's view of marriage — but also add depth of understanding to the circumstances surrounding the institution of marriage—-in two ways. First, we found that an 
economic bar is normative in the United States (Gassman-Pines et al. 2017; Gibson-Davis et al. 2018; Ishizuka 2018; Watson and McLanahan 2011), and that the earnings of men (Mike) have stronger positive effects on attitudes toward different-sex marriage than the earnings of women (Jessica) (Gibson-Davis 2009; Smock et al. 2005). Second, pregnancy status and relationship quality have dramatic effects on views of different-sex marriage in the United States (Cherlin et al. 2008; Gibson-Davis et al. 2016; Rackin and Gibson-Davis 2017; Waller and McLanahan 2005). When Mike and Jessica were expecting a child or when the quality of their relationship was good, the relative majority of responses prescribed marriage. The opposite occurred when Mike and Jessica were not pregnant or when their relationship quality was bad: the relative majority of responses proscribed marriage. In short, pregnancies and good quality relationships do engender beliefs that different-sex couples ought to marry, but economic considerations remain principal drivers of the approval of marriage. Still, some economic considerations, like education and assets, were of little practical significance. In the case of assets, this could be because the asset manipulation was relatively small rather than because assets are unimportant: larger amounts of wealth may have proven more persuasive.

Are Individual Tendencies to Proscribe or Prescribe Marriage Universal or Specific to Subpopulations Based on Race (Black, White), Gender (Male, Female), and SES (Education, Income, Occupation)?

The tendency to proscribe or prescribe different-sex marriage was not universally shared. Instead, the (dis)approval of marriage was specific to particular subgroups. Race and gender have unique additive effects on tendencies to proscribe or prescribe marriage (with gender exhibiting a slightly larger effect than race), while SES was statistically unrelated to the norm to marry. Many of these findings support prior research. Women frequently report stronger negative 
attitudes toward marriage than men (Sassler and Schoen 1999; Thornton and Young-DeMarco 2001) — which some argue is a function of sharp declines in the earning power of non-collegeeducated men coupled with gains in the economic self-sufficiency of women (Autor and Wasserman 2013)—while Black Americans are much less likely to marry than White Americans, and, when they do, it is at an older age (Raley et al. 2015; Tucker and MitchellKernan 1995). Black Americans also harbor stronger negative attitudes toward marriage than White Americans (South 1993). Our results, nevertheless, diverge from this literature in two important respects.

First, individual tendencies to proscribe or prescribe marriage were different between Black and White respondents but this effect was neither amplified nor dampened by gender. In other words, we did not find that the Black-White difference among males was significantly larger or smaller than the difference among females. With additive inequalities, linear predictions yielded ratings for White males $>$ Black males $>$ White females $>$ Black females. These inequalities, especially the difference between White males and Black females in attitudes toward different-sex marriage, have been observed in the literature (Wilcox and Wolfinger 2016), but contradict prior Black-White gender differences in attitudes toward marriage (Bulcroft and Bulcroft 1993; South 1993).

Second, we discovered weak support for differences in the norm to marry across levels of SES. Individual tendencies to proscribe or prescribe marriage were similar regardless of respondents' education, income, and occupation. Yet, previous research finds that class is tightly coupled with marriage patterns and attitudes toward marriage (Daugherty and Copen 2016; Gubernskaya 2010; Kuo and Raley 2016; Raley et al. 2015; Torr 2011). 
These seemingly conflicting findings can be reconciled by underscoring the SES of the focal couple and not the SES of respondents. What we find is that the economic conditions in which a specific marriage takes place demarcates who should and should not get married. Respondents, in other words, endorsed marriage to a greater extent when Mike and Jessica met an economic bar and achieved financial security prior to marriage. This observation was made possible because our experiment disentangled the SES of respondents from the financial and economic status of the couple under evaluation. Even more compelling, we found that the effects of the economic bar and financial security on the norm to marry were the same regardless of the SES of respondents. Below, we discuss in greater detail the relationship between respondent characteristics and their assessments of the conditions in which marriage should occur.

\section{Are Circumstances Demarcating the Norm to Marry Universal or Specific to Subpopulations}

Based on Race (Black, White), Gender (Male, Female), and SES (Education, Income, Occupation)?

We found that the effects of some circumstances varied statistically across the race, gender, and SES of respondents, but many effects were of small practical significance, save for Black-White differences in the effects of relationship quality and pregnancy status on the norm to marry. These results contribute to the literature in two important ways. First, our findings support the idea that Black-White differences in marriage patterns stem from compositional factors. Compositional arguments contend that marriage patterns differ between Black and White Americans because the pool of eligible partners is more constrained for Black Americans than White Americans (Lichter et al. 1992; Schoen and Kluegal 1988; Wilson 1987), not because Black Americans place a greater emphasis on having economic supports in place prior to marriage than White Americans (Bulcroft and Bulcroft 1993; Edin and Kefalas 2005). Our 
experiment reveals that Black and White respondents view economic resources similarly: Mike and Jessica's education, earnings and employment, and assets affect prescriptions of marriage the same way regardless of the race or SES of respondents. It is not that Black respondents view the economic bar or financial status differently than White respondents, it is that Black respondents, on average, prescribe different-sex marriage to a lesser extent than White respondents. We interpret this to mean that Black Americans may have-as Wilson (1987, 1996, 2009) contends_-rejected marriage norms due to facing decades of institutional racism and economic dislocations unique to the Black population. In other words, economic and structural cleavages between Black and White Americans may have produced various cultural shifts such as the deinstitutionalization of marriage in the Black community.

Second, we found that non-pecuniary circumstances demarcating the norm to marry did vary by the race and — to a lesser extent—-the SES of respondents. Although strongly positive for both racial groups, the effect of relationship quality on prescriptions of different-sex marriage was stronger for White respondents than Black respondents. Qualitative and quantitative research shows that fears of infidelity and distrust of romantic partners is a common roadblock to marriage in the Black community (Anderson 1999; Carlson et al. 2004; Edin 2000; Estacion and Cherlin 2010; Edin and Kefalas 2005; Wilcox and Wolfinger 2016). Given these barriers, a potential interpretation of our findings is that Black Americans may be more skeptical of signifiers of relationship quality than White Americans. Like relationship quality, research observes Black-White differences in the relation between childbearing and marriage, with Black Americans interpreting pregnancy and childbearing as calling for marriage less than White Americans (Barber et al. 2015). Our study corroborates these findings: pregnancy status yields stronger prescriptions of marriage for White respondents than Black respondents. The results, 
overall, buttress findings from the literature and lend experimental evidence in support of prior ethnographic observations.

\section{Limitations and Directions for Future Research}

Our research is not without limitations. First, future research should oversample individuals with less than a high school diploma. While Cherlin (2020) distinguishes between non-college educated and college-educated, including respondents without a high school diploma is important given the rich ethnographic research probing views of marriage among individuals in extreme poverty who often drop-out or fail to complete their high school education (Edin and Kefalas 2005). Having respondents without a high school diploma would allow us to better generalize our results to those subpopulations even though we observe variation on income and occupation.

Second, future research should feature a comprehensive range of ethnoracial groups in the sampling frame. Research shows that Latino and Asian Americans exhibit different marriage and family patterns than Black and White Americans (Raley et al. 2015). Latino Americans, for instance, have lower rates of marriage, higher rates of divorce, and higher rates of non-marital childbearing than White Americans (Cherlin 2020; Manning et al. 2015; U.S. National Center for Health Statistics 2018). We chose to limit our sample to Black and White respondents given Cherlin's (2004, 2020) focus on Black-White differences, but our FSE would yield compelling discoveries if administered to other ethnoracial groups. An application of our FSE to a representative sample of U.S. adults is a key goal for future research.

A third stream of research might extend our FSE to hypothetical different-sex and samesex couples. A number of interesting questions could be addressed with this research: What is the character of the norm to marry for same-sex couples? Does the character of this norm vary by the 
gender of the couple? How does the character of the norm vary according to the sexual orientation of respondents? Research shows that attitudes toward same-sex marriage are changing in the United States but still exhibit divides along race, gender, SES, and especially religion (Powell et al. 2010). By addressing such questions with an FSE, we could experimentally test whether marriage as an institution has expanded to account for new types of romantic partnerships or has become increasingly obsolete in the face of same-sex unions.

Fourth, we investigated a limited number of circumstances demarcating the norm to marry, which may have affected estimates of conditionality and consensus. This route was taken to see whether people (dis)approve of different-sex marriage under commonplace marriage conditions and to offer a conservative test of the deinstitutionalization of marriage thesis, but other circumstances likely drive views of marriage. It would be useful for future research to investigate the impact of these alternative conditions. For instance, there are a number of other non-pecuniary circumstances that might govern the norm to marry, including control over household decisions, fear of domestic violence, drug use, and multipartner fertility (Edin 2000; Edin and Kefalas 2005; Cherlin et al. 2008; Gibson-Davis et al. 2005; Smock et al. 2005; Waller 2002). Likewise, it would be beneficial to explore the bounds or limits of Mike's and Jessica's earnings and employment. We restricted our analysis to median incomes, but FSEs in the future should introduce and manipulate higher income earning couples. Investigating the impact of these alternative conditions would supply further revelations about the character of the norm to marry.

Despite these limitations, our findings should be of interest to scholars broadly concerned with social norms and institutions. By crafting a novel FSE and using it to probe the character of norms about marriage, this research presents evidence on how measurement tools can shine new 
light on established areas of study—beyond collective action (Jasso and Opp 1997), bridewealth (Horne et al. 2018), and inequality (Rauhut and Winter 2010)—where institutions loom large as antecedent and consequent conditions. Following Cherlin's (2020) recent theoretical considerations, we suggest that future work focus on integrating the measurement of social norms with models of institutional change that underscore processes of institutional "layering" and "absorbing” (see Lauer and Yodanis 2010). This union between measurement and theory could fundamentally alter what we know about marriage and the family.

In conclusion, the present article extends our understanding of the deinstitutionalization of marriage by subjecting it—and other arguments found in the marriage and family literatureto gold standards of research: experimental methods and random samples. By using a FSE, the present article unearthed important observations about the increasingly stratified character of different-sex marriage in the United States (Cherlin 2020). We found that the norm about whether different-sex couples ought to marry is weak, that it varies across certain social groups, and that the relation between (non)pecuniary circumstances and views of marriage are causal. Future research can extend this work by tracking temporal variation in the norm to marry with an experimental design similar to our own. This would grant marriage and family scholars traction on the dynamics of deinstitutionalization. Researchers could follow trends in how the norm to marry is weakening: Is the norm becoming more bipolar, more conditional, less intense, or all three? Or, conversely, is the norm becoming more proscriptive or prescriptive, more unconditional, or more intense? The continued use of FSEs will help sociologists answer these sorts of questions. 
Table A1. Summary Statistics and Descriptions of Individual-Level Variables

\begin{tabular}{|c|c|c|c|c|c|c|}
\hline Name & Definition & Mean & SD & Min. & Max. & $N$ \\
\hline \multicolumn{7}{|l|}{ Dependent variable } \\
\hline Marriage norms scale & Should Mike and Jessica marry or not marry? & 4.03 & 2.62 & 0 & 8 & 16804 \\
\hline DK & Don't know & $6.76 \%$ & --- & --- & --- & 1232 \\
\hline Refused & Refused to answer & $1.06 \%$ & --- & --- & --- & 194 \\
\hline \multicolumn{7}{|l|}{ Individual-level independent variables } \\
\hline \multicolumn{7}{|l|}{ Race } \\
\hline Black (omitted) & Non-Hispanic Black respondent & $50.08 \%$ & --- & --- & --- & 913 \\
\hline White & Non-Hispanic White respondent & $49.92 \%$ & --- & --- & --- & 910 \\
\hline \multicolumn{7}{|c|}{ (1) } \\
\hline Female (omitted) & Female respondent & $50.03 \%$ & --- & --- & --- & 912 \\
\hline Male & Male respondent & $49.97 \%$ & --- & --- & --- & 911 \\
\hline \multicolumn{7}{|l|}{ Education } \\
\hline High school diploma (omitted) & High school diploma & $33.41 \%$ & --- & --- & --- & 609 \\
\hline Some college & Some college (no degree) or an Associate's degree & $33.35 \%$ & --- & --- & --- & 608 \\
\hline Bachelor's degree or higher & Bachelors, Masters, Professional, or Doctorate degree & $33.24 \%$ & --- & --- & --- & 606 \\
\hline Household income per capita & & 38859.99 & 41159.70 & 357.14 & 365397 & 1823 \\
\hline $\ln ($ household income per capita) & & 10.08 & 1.11 & 5.87 & 12.80 & 1823 \\
\hline \multicolumn{7}{|l|}{ Occupation } \\
\hline Class 1 & Higher- and lower-grade professionals, administrators, managers, and officials & $27.70 \%$ & --- & --- & --- & 505 \\
\hline Class 2 & Routine non-manual and service employees, higher- and lower-grade & $13.43 \%$ & --- & --- & --- & 245 \\
\hline Class 3 & $\begin{array}{l}\text { High-grade technicians and repairers, public safety workers, performers, and } \\
\text { supervisors of manual workers }\end{array}$ & $2.02 \%$ & --- & --- & --- & 37 \\
\hline Class 4 & Skilled manual workers, lower-grade technicians, installers, and repairers & $2.63 \%$ & --- & --- & --- & 48 \\
\hline Class 5 (omitted) & Semi-skilled and unskilled manual workers, not in agriculture & $7.40 \%$ & --- & --- & --- & 135 \\
\hline Class 6 & Agricultural & $0.32 \%$ & --- & --- & --- & 6 \\
\hline Class 7 & Military & $0.60 \%$ & --- & --- & --- & 11 \\
\hline Class other & Occupation unknown & $7.56 \%$ & --- & --- & --- & 138 \\
\hline Not working & layoff, looking for work, and other & $9.81 \%$ & --- & --- & --- & 179 \\
\hline Retired & & $23.03 \%$ & --- & --- & --- & 420 \\
\hline Disabled & & $5.10 \%$ & --- & --- & --- & 93 \\
\hline Refused to answer & & $0.32 \%$ & --- & --- & --- & 6 \\
\hline \multicolumn{7}{|l|}{ Individual-level control variables } \\
\hline Age & Age in years & 51.55 & 16.47 & 18 & 91 & 1823 \\
\hline \multicolumn{7}{|l|}{ Marital status } \\
\hline Married (omitted) & & $52.98 \%$ & --- & --- & --- & 966 \\
\hline Widowed & & $5.70 \%$ & --- & --- & --- & 104 \\
\hline Divorced & & $12.01 \%$ & --- & --- & --- & 219 \\
\hline Separated & & $1.75 \%$ & --- & --- & --- & 32 \\
\hline Never married & & $27.53 \%$ & --- & --- & --- & 502 \\
\hline \multicolumn{7}{|l|}{ Cohabitation status } \\
\hline Present cohabitation (omitted) & Presently cohabitating with partner & $6.96 \%$ & --- & --- & --- & 127 \\
\hline Married cohabitation & Married and presently cohabitating with partner & $3.73 \%$ & --- & --- & --- & 68 \\
\hline
\end{tabular}


Past cohabitation

Never cohabitation

DKPNS

Refused

Head of household

Household size

Housing type

One-family house, detached (omitted)

One-family house, attached

Apartment building

A mobile home

Boat, RV, van, etc.

Ownership status of living quarters

Owned or being bought (omitted)

Rented for cash

Occupied without payment of rent

MSA Status

Metro (omitted)

Non-metro

Region

Northeast

Midwest

South

West (omitted)

Marriage judgments

GSS vocabulary test

\section{Religious affiliation}

Mainline protestant (omitted)

Pentecostal

Evangelical protestant

Black protestant

Non-traditional fundamentalist

Catholic

Jewish

Christian, non-denominational

Other denomination

Atheist-agnostic

Affiliation not listed

Religiously unaffiliated (i.e., none)

DKPNS

Refused

Religiosity

Not at all religious (omitted)

Not very religious

Somewhat religious
Cohabited with a partner in the past

Never cohabited with a partner in the past

Don't know or prefer not to say

Refused to answer

Head of household ( 1 = yes, $0=$ no)

Number of people in the respondent's household

Type of house in which respondent resides

Proportion of panel respondents living in metro areas

Proportion of panel respondents living in non-metro areas

Proportion of panel respondents living in the Northeast region

Proportion of panel respondents living in the Midwest region

Proportion of panel respondents living in the South region

Proportion of panel respondents living in the West region

Appropriate to judge whether people should marry $(0=$ no, $8=$ yes $)$

5-item GSS vocabulary test (space, broaden, emanate, edible, animosity). Scale indicates number of correct items.

Panel respondent identifies as mainline protestant (e.g., Lutheran, Methodist)

Panel respondent identifies as Pentecostal (e.g., Pentecostal, Assemblies of God)

Panel respondent identifies as evangelical protestant (e.g., Adventist, Baptist)

Panel respondent identifies as Black protestant (e.g., African Methodist)

Panel respondent identifies as non-traditional fund. (e.g., Jehovah's Witnesses)

Panel respondent identifies as Catholic (e.g., Roman Catholic, Orthodox)

Panel respondent identifies as Jewish

Panel respondent identifies as Christian, non-denominational

Panel respondent identifies as other religious group (e.g., Buddhist, Hindu)

Panel respondent identifies as Atheist or Agnostic

Panel respondent's religious group is not listed

Panel respondent does not identify with any religious group

Don't know or prefer not to say religious affiliation

Refused to answer

How religious do you consider yourself to be?

$\begin{array}{ccccc}40.59 \% & --- & --- & --- & 740 \\ 45.58 \% & --- & --- & --- & 831 \\ 2.24 \% & --- & --- & --- & 41 \\ 0.87 \% & --- & --- & --- & 16 \\ 84.26 \% & -- & -- & -- & 1823 \\ 2.53 & 1.47 & 1 & 12 & 1823 \\ & & & & \\ 64.56 \% & --- & --- & --- & 1177 \\ 10.09 \% & --- & --- & --- & 184 \\ 22.11 \% & --- & --- & -- & 403 \\ 2.91 \% & --- & --- & --- & 53 \\ 0.33 \% & --- & --- & -- & 6 \\ & & & & \\ 64.95 \% & --- & --- & --- & 1184 \\ 31.98 \% & --- & --- & -- & 583 \\ 3.07 \% & --- & --- & --- & 56 \\ & & & & \\ 87.22 \% & --- & --- & --- & 1590 \\ 12.78 \% & --- & --- & --- & 233 \\ & & & & \\ 18.16 \% & --- & --- & --- & 331 \\ 20.95 \% & --- & --- & --- & 382 \\ 45.15 \% & --- & --- & --- & 823 \\ 15.74 \% & --- & --- & --- & 287 \\ 2.45 & 2.34 & 0 & 8 & 1806 \\ 3.73 & 1.09 & 0 & 5 & 1823 \\ & & & & \\ 12.72 \% & --- & --- & --- & 232 \\ 6.14 \% & --- & --- & --- & 112 \\ 26.22 \% & --- & --- & --- & 478 \\ 1.59 \% & --- & --- & --- & 29 \\ 2.30 \% & --- & --- & --- & 42 \\ 13.16 \% & --- & --- & --- & 240 \\ 1.48 \% & --- & --- & -- & 27 \\ 7.67 \% & --- & --- & --- & 140 \\ 1.15 \% & --- & --- & --- & 21 \\ 4.22 \% & -- & --- & -- & 77 \\ 2.08 \% & --- & --- & --- & 38 \\ 13.11 \% & --- & --- & --- & 239 \\ 7.40 \% & --- & --- & --- & 135 \\ 0.71 \% & --- & --- & --- & 13 \\ & & & & \\ 12.61 \% & --- & --- & --- & 230 \\ 15.85 \% & --- & --- & -- & 289 \\ 40.09 \% & --- & --- & --- & 731\end{array}$


Very religious

DKPNS

Don't know or prefer not to say

Refused to answer

How often do you attend religious services?

Religious attendance

Never (omitted)

Once a year or less

A few times a year

Once or twice a month

Once a week

More than once a week

DKPNS

Don't know or prefer not to say

Refused

Refused to answer

Note: 1,823 GfK panel members each assessed 10 vignettes yielding 18,230 observations.

\begin{tabular}{ccccc}
$24.30 \%$ & --- & --- & -- & 443 \\
$6.47 \%$ & --- & --- & --- & 118 \\
$0.66 \%$ & --- & --- & -- & 12 \\
& & & & \\
$22.00 \%$ & --- & --- & -- & 401 \\
$15.80 \%$ & --- & -- & -- & 288 \\
$18.65 \%$ & & & & 340 \\
$8.83 \%$ & --- & --- & -- & 161 \\
$20.84 \%$ & --- & --- & -- & 380 \\
$13.17 \%$ & & & & 240 \\
$0.33 \%$ & --- & --- & --- & 6 \\
$0.38 \%$ & --- & --- & -- & 7 \\
\hline
\end{tabular}



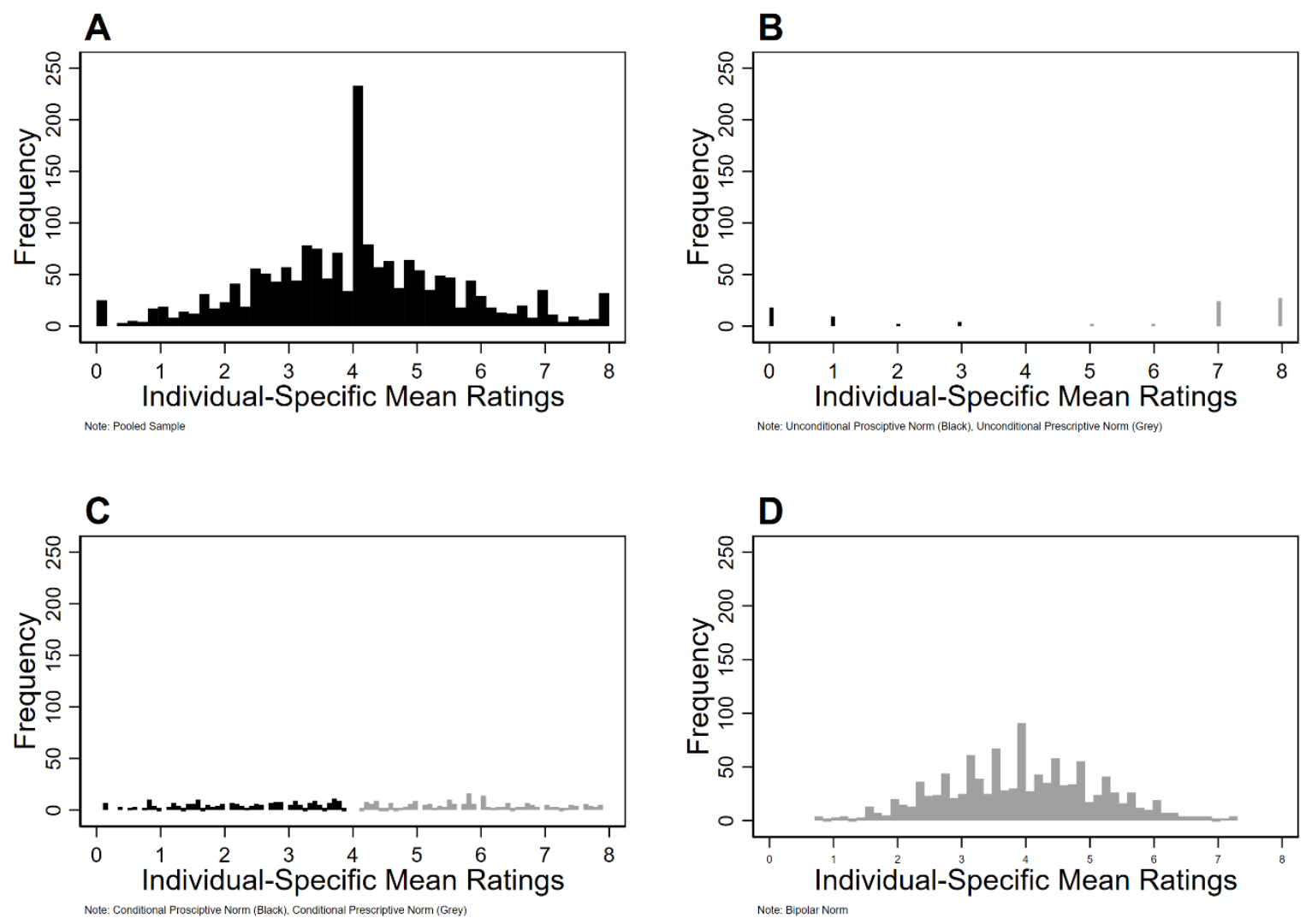

Figure A1. Frequency Distribution of Individual-Specific Mean Ratings of the Norm to Marry for the Pooled Sample (Panel A), Unconditional Norms (Panel B), Conditional Norms (Panel C), and Bipolar Norms (Panel D)

Note: In Panels B and C, black distributions indicate a proscriptive norm, grey distributions indicate a prescriptive norm. 


\section{References}

Anderson, Elijah 1999. Code of The Street: Decency, Violence, and The Moral Life of The Inner City. W. W. Norton and Company

Auspurg, Katrin and Thomas Hinz. 2015. Factorial Survey Experiments. Los Angeles, CA: Sage.

Autor, David and Melanie Wasserman. 2013. "Wayward Sons: The Emerging Gender Gap in Labor Markets and Education.” Third Way.

Barber, Jennifer S., Jennifer Eckerman Yarger, and Heather H. Gatny. 2015. "Black-White Differences in Attitudes Related to Pregnancy among Young Women.” Demography 52: 751-786.

Bicchieri, Cristina. 2006. The Grammar of Society: The Nature and Dynamics of Social Norms. Cambridge University Press.

Bicchieri, Cristina. 2016. Norms in the Wild: How to Diagnose, Measure, and Change Social Norms. Oxford University Press.

Brown, S. L. 2004. "Union Transitions among Cohabitors: The Significance of Relationship Assessments and Expectations.” Journal of Marriage and Family 62: 833-846.

Bulcroft, Richard A. and Kris A. Bulcroft. 1993. "Race Differences in Attitudinal and Motivational Factors in the Decision to Marry.” Journal of Marriage and Family 55: 338355.

Carlson, Marcia, Sara McLanahan, and Paula England. 2004. "Union Formation in Fragile Families.” Demography 41: 237-261.

Cherlin, Andrew J. 2004. “The Deinstitutionalization of American Marriage.” Journal of Marriage and Family 66: 848-861.

Cherlin, Andrew. 2010. The Marriage-Go-Round: The State of Marriage and the Family in America Today. Vintage.

Cherlin, Andrew. 2020. "Degrees of Change: An Assessment of the Deinstitutionalization of Marriage Thesis.” Journal of Marriage and Family 82: 62-80.

Cherlin, Andrew, Caitlin Cross-Barnet, Linda M. Burton, and Raymond Garrett-Peters. 2008. "Promises They Can Keep: Low-Income Women's Attitudes Toward Motherhood, Marriage, and Divorce.” Journal of Marriage and Family 70: 919-933.

Coleman, James. 1990. Foundations of Social Theory. Harvard University Press.

Coontz, Stephanie. 2005. Marriage, A History: How Love Conquered Marriage. Penguin.

Cott, Nancy F. 2002. Public Vows: A History of Marriage and the Nation. Harvard University Press.

Daugherty, Jill and Casey Copen. 2016. "Trends in Attitudes about Marriage, Childbearing, and Sexual Behavior: Unites States, 2002, 2006-2010, and 2011-2013.” National Health Statistics Reports 92: 1-10.

DeNavas, Carmen, Bernadette D. Proctor, and Jessica C. Smith. 2012. "Income, Poverty, and Health Insurance Coverage in the United States: 2011.” United States Census Bureau.

Diefenbach, Heike and Karl-Dieter Opp. 2007. "When and Why Do People Think There Should Be a Divorce? An Application of the Factorial Survey.” Rationality and Society 19: 485-517.

Edin, Kathryn. 2000. "What do Low-Income Single Mothers say about Marriage?” Social Problems 47: 112-133.

Edin, Kathryn and Maria J. Kefalas. 2005. Promises I Can Keep: Why Poor Women Put Motherhood Before Marriage. University of California Press. 
Erikson, Robert, and John H. Goldthorpe. 1992. The Constant Flux: A Study of Class Mobility in Industrial Revolutions. Clarendon Press.

Estacion, Angela and Andrew Cherlin. 2010. "Gender Distrust and Intimate Unions among LowIncome Hispanic and African-American Women.” Journal of Family Issues 31: 475-498.

Gassman-Pines, Anna, Christina M. Gibson-Davis, Corey Vernot, Maggie Butler, Natalie Hall, Lauren Taylor, Katherine Eastwood, and Xinri Zhang. 2017. “They should say "I Don’t”: Norms about Midpregnancy Marriage and Job Loss.” Journal of Marriage and Family 79: 405-418.

Gibson-Davis, Christina M. 2009. "Money, Marriage, and Children: Testing the Financial Expectations and Family Formation Theory.” Journal of Marriage and Family 71: 146-161.

Gibson-Davis, Christina M., Elizabeth O. Ananat, and Anna Gassman-Pines. 2016.

"Midpregnancy Marriage and Divorce: Why the Death of Shotgun Marriage has been Greatly Exaggerated.” Demography 53: 1693-1715.

Gibson-Davis, Christina M., Kathryn Edin, and Sara McLanahan. 2005. "High Hopes but Even Higher Expectations: The Retreat from Marriage Among Low-Income Couples.” Journal of Marriage and Family 67: 1301-1312

Gibson-Davis, Christina M., Anna Gassman-Pines, and Rebecca Lehrman. 2018. “'His’ and 'Hers': Meeting the Economic Bar to Marriage.” Demography 55: 2321-2343.

Gubernskaya, Zoya. 2010. "Changing Attitudes toward Marriage and Children in Six Countries.” Sociological Perspectives 53: 179-200.

Hechter, Michael and Karl-Dieter Opp (eds.). 2001. Social Norms. Russell Sage

Horne, Christine. 2009. The Rewards of Punishment: A Relational Theory of Norm Enforcement. Stanford University Press.

Horne, Christine, F. Nii-Amoo Dodoo, and Naa Dodua Dodoo. 2013. “The Shadow of Indebtedness: Bridewealth and Norms Constraining Female Reproductive Autonomy.” American Sociological Review 78: 503-520.

Horne, Christine, Naa Dodua Dodoo, and F. Nii-Amoo Dodoo. 2018. "The Conditionality of Norms: The Case of Bridewealth.” Social Psychology Quarterly 81: 319-339.

Ishizuka, Patrick. 2018. “The Economic Foundations of Cohabiting Couples’ Union Transitions.” Demography 55: 535-557.

Jackson, Jay. 1966. “A Conceptual and Measurement Model for Norms and Roles.” The Pacific Sociological Review 9: 35-47.

Jasso, Guillermina. 2006. "Factorial Survey Methods for Studying Beliefs and Judgments.” Sociological Methods \& Research 34: 334-90.

Jasso, Guillermina and Karl-Dieter Opp, 1997. "Probing the Character of Norms: A Factorial Survey Analysis of the Norms of Political Action.” American Sociological Review 62: 947964.

Knapp, Stan J. and Greg Wurm. 2019. “Theorizing Family Change: A Review and Reconceptualization.” Journal of Family Theory and Review 11: 212-229.

Kuo, Janet Chen-Lan and R. Kelly Raley. 2016. "Diverging Patterns of Union Transition among Cohabitors by Race-Ethnicity and Education: Trends and Marital Intentions.” Demography 53: 921-935.

Lauer, Sean and Carrie Yodanis. 2010. "The Deinstitutionalization of Marriage Revisited: A New Institutional Approach to Marriage.” Journal of Family Theory and Review 2: 58-72.

Lesthaeghe, Ron. 2014. "The Second Demographic Transition: A Concise Overview of Its Development” Proceedings of the National Academy of Sciences 111: 18112-18115. 
Lichter, Daniel T., Diane K. McLaughlin, George Kephart, and David J. Landry. 1992. "Race and the Retreat from Marriage: A Shortage of Marriageable Men?” American Sociological Review 57: 781-799.

Lundberg, Shelly and Robert A. Pollak. 2007. “The American Family and Family Economics.” Journal of Economic Perspectives 21.

Lundberg, Shelly, Robert A. Pollak, and Jenna Stearns. 2016. "Family Inequality: Diverging Patterns in Marriage, Cohabitation, and Childbearing.” Journal of Economic Perspectives 30: 79-102.

Manning, Wendy D., Susan L. Brown, and Bart Stykes. 2015. Trends in Births to Single and Cohabiting Mothers, 1980-2013. National Center for Family and Marriage Research Family Profile FP-15-03.

Opp, Karl-Dieter. 2013. “Norms and Rationality. Is Moral Behavior a Form of Rational Action?” Theory and Decision 74: 389-409.

Pagnini, Deanna L. and S. Philip Morgan. 1996. "Racial Differences in Marriage and Childbearing: Oral History Evidence from the South in the Early Twentieth Century.” American Journal of Sociology 101: 1694-1718.

Powell, Brian, Catherine Bolzendahl, Claudia Geist, and Lala Carr Steelman. 2010. Counted Out: Same-Sex Relations and Americans’ Definitions of Family. Russell Sage Foundation.

Rackin, Heather M. and Christina M. Gibson-Davis. 2017. "Low Income Childless Young Adults’ Marriage and Fertility Frameworks.” Journal of Marriage and Family 79: 10961110.

Raley, R. Kelly, Megan M. Sweeney, and Danielle Wondra. 2015. “The Growing Racial and Ethnic Divide in U.S. Marriage Patterns.” Future of Children 25: 89-109.

Rauhut, Heiko and Fabian Winter. 2010. “A Sociological Perspective on Measuring Social Norms by Means of Strategy Method Experiments.” Social Science Research 39: 1181-1194.

Rosenfeld, Michael J. 2007. The Age of Independence: Interracial Unions, Same-Sex Unions, and the Changing American Family. Harvard University Press.

Rossi, Peter H. and Richard A. Berk. 1985. "Varieties of Normative Consensus.” American Sociological Review 50: 333-347.

Ruggles, Steven. 1994. “The Origins of African-American Family Structure.” American Sociological Review 59: 136-151.

Sassler, Sharon and Robert Schoen. 1999. "The Effect of Attitudes and Economic Activity on Marriage.” Journal of Marriage and Family 61: 147-159.

Schneider, Daniel. 2011. "Wealth and the Marital Divide." American Journal of Sociology 117: 627-667.

Schoen, Robert and James R. Kluegal. 1988. “The Widening Gap in Black and White Marriage Rates: The Impact of Population Composition and Differential Marriage Propensities.” American Sociological Review 53: 893-907.

Smock, Pamela J., Wendy D. Manning, and Meredith Porter. 2005. “"Everything’s There Except Money’: How Money Shapes Decisions to Marry among Cohabitors.” Journal of Marriage and Family 67: 680-696.

South, Scott J. 1993. "Racial and Ethnic Differences in the Desire to Marry.” Journal of Marriage and Family 55: 357-370.

Sweeney, Megan M. 2002. "Two Decades of Family Change: The Shifting Economic Foundations of Marriage.” American Sociological Review 67: 132-147. 
Thornton, Arland and L. Young-DeMarco. 2001. "Four Decades of Trends in Attitudes toward Family Issues in the United States: The 1960s through the 1990s.” Journal of Marriage and Family 63: 1009-1037.

Thornton, Arland, William G. Axinn, and Yu Xie. 2007. Marriage and Cohabitation. University of Chicago Press.

Torr, Berna M. 2011. "The Changing Relationship between Education and Marriage in the United States, 1940-2000.” Journal of Family History 36: 483-503.

Treas, Judith, Jonathan Lui, and Zoya Gubernskaya. 2014. “Attitudes on Marriage and New Relationships: Cross-National Evidence on the Deinstitutionalization of Marriage.” Demographic Research 30: 1495-1526.

Tucker, M. Belinda and Claudia Mitchell-Kernan (eds.). 1995. The Decline in Marriage among African Americans: Causes, Consequences, and Policy Implications. Russell Sage.

Tzioumis, Konstantinos. 2018. "Data Descriptor: Demographic Aspects of First Names.” Scientific Data 5: 180025.

U.S. National Center for Health Statistics. 2018. Births: Final Data for 2016. Retrieved from https://www.cdc.gov/nchs/data/nvsr/nvsr66/nvsr66_01.pdf

Wallander, Lisa. 2009. "25 Years of Factorial Surveys in Sociology: A Review.” Social Science Research 38: 505-520.

Waller, Maureen R. 2002. My Baby’s Father: Unmarried Parents and Parental Responsibility. Cornell University Press.

Waller, Maureen R. and Sara S. McLanahan. 2005. “'His’ and 'Her’ Marriage Expectations: Determinants and Consequences.” Journal of Marriage and Family 67: 53-67.

Watson, Tara and Sara McLanahan. 2011. "Marriage Meets the Joneses: Relative Income, Identity, and Marital Status.” The Journal of Human Resources 46: 482-517.

Wilcox, W. Bradford and Nicholas H. Wolfinger. 2016. Soul Mates: Religion, Sex, Love, and Marriage among African Americans and Latinos. Oxford University Press.

Wilcox, W. Bradford and Steven L. Nock. 2006. "What's Love Got to Do with It? Equality, Equity, Commitment and Women’s Marital Quality.” Social Forces 84: 1321-1345.

Wilson, William Julius. 1987. The Truly Disadvantaged: The Inner City, the Underclass and Public Policy. University of Chicago Press

Wilson, William Julius. 1996. When Work Disappears: The World of the New Urban Poor. A. Knop

Wilson, William Julius. 2009. More than Just Race: Being Black and Poor in the Inner City. W. W. Norton and Company. 
Table 1. Norm to Marry Vignette Dimensions and Levels

\begin{tabular}{|c|c|c|}
\hline Dimension & Level & Text \\
\hline \multirow[t]{3}{*}{ Mike's education } & 1 & Mike does not have a high school diploma. \\
\hline & 2 & Mike has a high school diploma. \\
\hline & 3 & Mike has a 4-year college degree. \\
\hline \multirow{3}{*}{ Mike's earnings and employment } & 1 & He has been unemployed for 2 years. \\
\hline & 2 & He has a full-time job and earns about $\$ 20,000$ a year. \\
\hline & 3 & He has a full-time job and earns about $\$ 50,000$ a year. \\
\hline \multirow[t]{3}{*}{ Jessica's education } & 1 & Jessica does not have a high school diploma. \\
\hline & 2 & Jessica has a high school diploma. \\
\hline & 3 & Jessica has a 4-year college degree. \\
\hline \multirow[t]{3}{*}{ Jessica's earnings and employment } & 1 & She has been unemployed for 2 years. \\
\hline & 2 & She has a full-time job and earns about $\$ 20,000$ a year. \\
\hline & 3 & She has a full-time job and earns about $\$ 50,000$ a year. \\
\hline \multirow[t]{2}{*}{ Assets } & 1 & BLANK (i.e., respondent shown nothing). \\
\hline & 2 & Mike and Jessica recently inherited $\$ 5,000$ each from a mutual, elderly friend. \\
\hline \multirow[t]{2}{*}{ Relationship quality } & 1 & $\begin{array}{l}\text { Mike and Jessica are attracted to one another and treat each other well. But when they have disagreements with each other they argue and } \\
\text { feel hurt and misunderstood afterward. }\end{array}$ \\
\hline & 2 & $\begin{array}{l}\text { Mike and Jessica are attracted to one another and treat each other well. They have disagreements with each other but they talk it out and try } \\
\text { to understand each other better. }\end{array}$ \\
\hline \multirow[t]{2}{*}{ Pregnancy status } & 1 & Mike and Jessica are not thinking of having a child at this time. \\
\hline & 2 & Mike and Jessica were not thinking of having a child at this time, but they found out that Jessica is pregnant. \\
\hline
\end{tabular}


Table 2. Polarity and Conditionality of the Norm to Marry

\begin{tabular}{lcc}
\hline Norm to Marry & Number & $\begin{array}{c}\% \text { of } \\
\text { Sample }\end{array}$ \\
\hline Polarity & & \\
$\quad$ Nonexistent $(R=4)$ & 145 & 8.16 \\
Prescriptive $(R>4 ; r \geq 4)$ & 268 & 15.08 \\
Proscriptive $(R<4 ; r \leq 4)$ & 248 & 13.96 \\
Bipolar $(0<R<8 ; R \neq 4 ; 0 \leq r \leq 8)$ & 1116 & 62.80 \\
Total & 1777 & 100 \\
Conditionality & & \\
$\quad$ Nonexistent $(R=4)$ & 145 & 8.16 \\
Unconditional $(R=r ; r \neq 4)$ & 88 & 4.95 \\
Conditional $(V A R(r) \neq 0)$ & 1544 & 86.89 \\
Total & 1777 & 100 \\
\hline
\end{tabular}

Note: Polarity and conditionality are defined by the numerical pattern of each respondent's individual-specific mean $(R)$ of the norm to marry ratings $(r)$. Polarity: If a respondent assigns a rating of 4 (neutral value) to all $N$ vignettes, this indicates that the respondent does not subscribe to a norm to marry (nonexistent norm to marry). If all $N$ of a given respondent's ratings are both 4 and greater than 4 , this indicates that the respondent subscribes to a prescriptive norm to marry. If all $N$ of a given respondent's ratings are both 4 and less than 4 , this indicates that the respondent subscribes to a proscriptive norm to marry. If the respondent's ratings span values less than 4 and values greater than 4 , this indicates that the respondent subscribes to a bipolar norm to marry. Conditionality: if a respondent assigns the same non-neutral (i.e., 4) rating to all $N$ vignettes, this indicates that the respondent subscribes to an unconditional norm to marry; in all other cases, the norm is regarded as a conditional norm to marry. 
Table 3. Consensus and Conditionality of the Norm to Marry, Two-Level Hierarchical Linear Models

\begin{tabular}{|c|c|c|c|c|}
\hline & \multicolumn{2}{|c|}{ Model 1} & \multicolumn{2}{|c|}{ Model 2} \\
\hline & $b$ & $S E$ & $b$ & SE \\
\hline \multicolumn{5}{|l|}{ Vignette dimensions } \\
\hline \multicolumn{5}{|l|}{ Mike's education } \\
\hline \multicolumn{5}{|l|}{ No HS diploma (omitted) } \\
\hline HS diploma & $0.113^{* *}$ & 0.037 & $0.113^{* *}$ & 0.035 \\
\hline 4-year college degree & $0.191^{* * *}$ & 0.039 & $0.205^{* * *}$ & 0.036 \\
\hline \multicolumn{5}{|l|}{ Mike's earnings and employment } \\
\hline \multicolumn{5}{|l|}{ Unemployed 2 years (omitted) } \\
\hline Full-time job, $\$ 20,000$ a year & $1.059 * * *$ & 0.040 & $1.047 * * *$ & 0.039 \\
\hline Full-time job, $\$ 50,000$ a year & $1.555^{* * *}$ & 0.046 & $1.550 * * *$ & 0.045 \\
\hline \multicolumn{5}{|l|}{ Jessica's education } \\
\hline \multicolumn{5}{|l|}{ No HS diploma (omitted) } \\
\hline HS diploma & $0.097 *$ & 0.040 & $0.114^{* *}$ & 0.037 \\
\hline 4-year college degree & $0.170 * * *$ & 0.039 & $0.170 * * *$ & 0.036 \\
\hline \multicolumn{5}{|l|}{ Jessica's earnings and employment } \\
\hline \multicolumn{5}{|l|}{ Unemployed 2 years (omitted) } \\
\hline Full-time job, $\$ 20,000$ a year & $0.649 * * *$ & 0.036 & $0.649 * * *$ & 0.034 \\
\hline Full-time job, $\$ 50,000$ a year & $0.896 * * *$ & 0.040 & $0.905^{* * *}$ & 0.039 \\
\hline \multicolumn{5}{|l|}{ Mike and Jessica's assets } \\
\hline \multicolumn{5}{|l|}{ Blank (omitted) } \\
\hline Inherited $\$ 5,000$ & $0.086^{* *}$ & 0.032 & $0.076^{*}$ & 0.030 \\
\hline \multicolumn{5}{|l|}{ Relationship quality } \\
\hline \multicolumn{5}{|l|}{ Bad (omitted) } \\
\hline Good & $1.259 * * *$ & 0.044 & $1.247 * * *$ & 0.043 \\
\hline \multicolumn{5}{|l|}{ Pregnancy status } \\
\hline \multicolumn{5}{|l|}{ Not pregnant (omitted) } \\
\hline Pregnant & $0.696 * * *$ & 0.042 & $0.705^{* * *}$ & 0.041 \\
\hline Intercept & $1.548 * * *$ & 0.087 & $1.552 * * *$ & 0.084 \\
\hline sd(intercept) & \multicolumn{2}{|c|}{1.427} & \multicolumn{2}{|c|}{1.396} \\
\hline sd(residuals) & \multicolumn{2}{|c|}{1.940} & \multicolumn{2}{|c|}{1.642} \\
\hline sd(Mike HS diploma) & & & \multicolumn{2}{|c|}{0.155} \\
\hline sd(Mike 4-year degree) & & & \multicolumn{2}{|c|}{0.264} \\
\hline sd(Mike $\$ 20,000$ a year) & & & \multicolumn{2}{|c|}{0.204} \\
\hline sd(Mike $\$ 50,000$ a year) & & & \multicolumn{2}{|c|}{0.763} \\
\hline sd(Jessica HS diploma) & & & 0.237 & \\
\hline sd(Jessica 4-year degree) & & & 0.140 & \\
\hline sd(Jessica $\$ 20,000$ a year) & & & 0.000 & \\
\hline sd(Jessica $\$ 50,000$ a year) & & & 0.412 & \\
\hline sd(Inherited \$5,000) & & & 0.282 & \\
\hline sd(Good relationship quality) & & & 1.128 & \\
\hline
\end{tabular}


sd(Pregnant)

1.243

Vignette dummies

Yes

Individual-level variables and controls

Yes

No

Observations

No

16804

Individuals

16804

1777

*** $p<0.001,{ }^{* *} p<0.01, * p<0.05, \dagger p<0.10$ (two-tailed)

Note: $b=$ unstandardized slopes, $S E=$ robust standard errors. Model 1 familywise tests include Mike's education, $\chi^{2}(2)=24.78, p<.001$; Mike's earnings and employment, $\chi^{2}(2)=11134.24, p<$ .001 ; Jessica's education, $\chi^{2}(2)=18.89, p<.001$; Jessica's earnings and employment, $\chi^{2}(2)=524.61$, $p<.001$. Model 1 pairwise tests include Mike's HS diploma vs 4-year college degree, $\chi^{2}(1)=4.01, p$ $<.05$; Mike earning $\$ 20,000$ vs $\$ 50,000, \chi^{2}(1)=173.14, p<.001$; Jessica's HS diploma vs 4-year college degree, $\chi^{2}(1)=3.57, p=.058$; Jessica earning $\$ 20,000$ vs $\$ 50,000, \chi^{2}(1)=48.48, p<.001$. 
Table 4. Select Linear Predictions of the Norm to Marry

\begin{tabular}{lllll}
\multicolumn{2}{c}{ Bad Relationship Quality } & & \multicolumn{2}{c}{ Good Relationship Quality } \\
Not Pregnant & Pregnant & & Not Pregnant & Pregnant
\end{tabular}

Low Economic Standing

Mike and Jessica No HS Diploma

1.548

2.244

2.808

3.504

Mike and Jessica Unemployed

$(1.375,1.720) \quad(2.065,2.424)$

(2.642, 2.974)

(3.330, 3.678)

No Assets

Moderate Economic Standing

Mike and Jessica HS Diploma

3.554

4.251

4.814

5.511

Mike and Jessica \$20,000 a year

$(3.403,3.706)$

(4.086, 4.416)

(4.667, 4.961)

(5.350, 5.671)

Assets

High Economic Standing

Mike and Jessica 4-year College Degree

4.448

5.145

5.708

6.405

Mike and Jessica $\$ 50,000$ a year

$(4.292,4.605) \quad(4.976,5.314)$

(5.559, 5.858)

(6.242, 6.568)

Assets

Note: Linear predictions based on model 1 in Table 3 using the delta method (95 percent CIs in parentheses). 
Table 5. Consensus of the Norm to Marry across Subpopulations, TwoLevel Hierarchical Linear Model

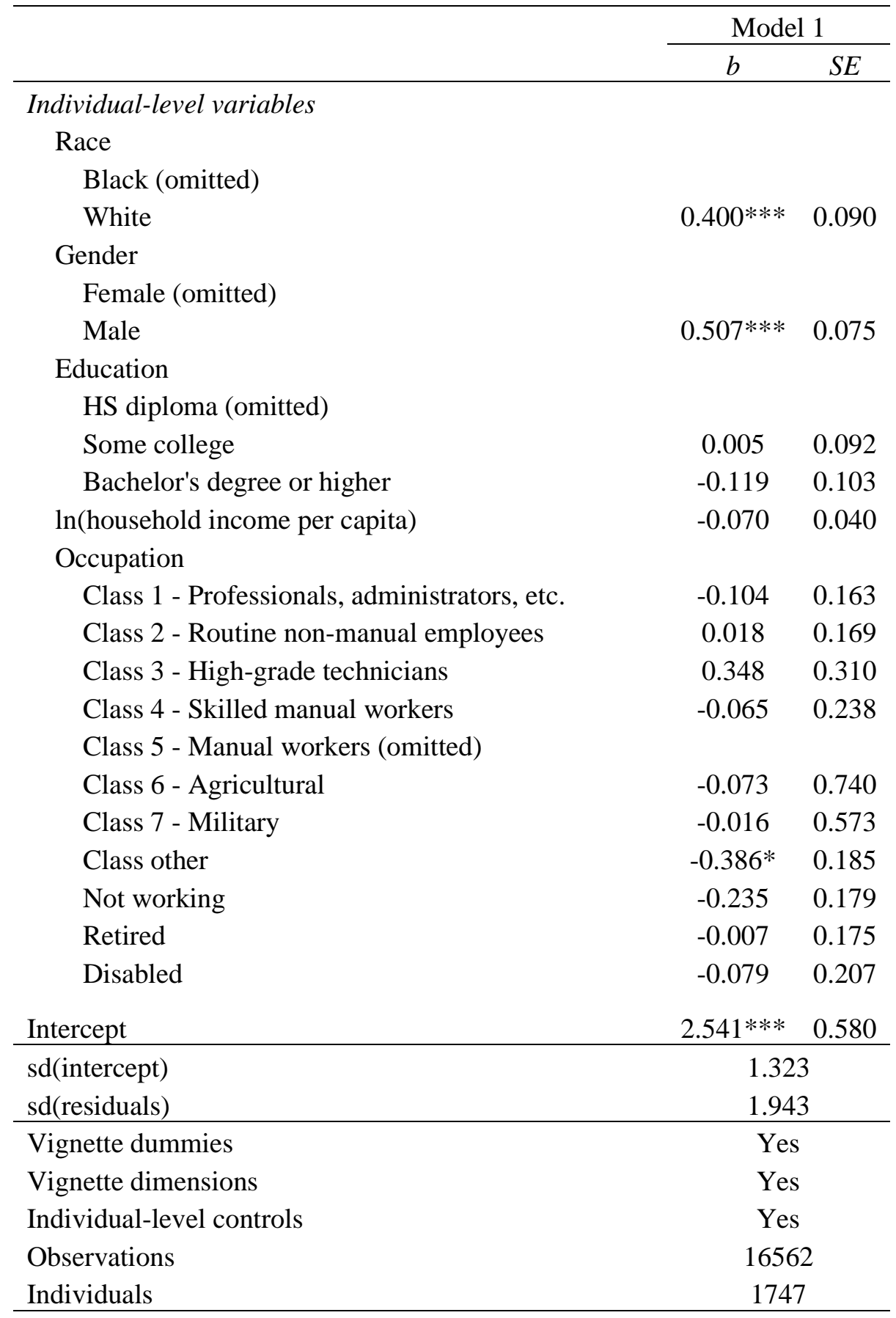

$* * * p<0.001,{ }^{* *} p<0.01, * p<0.05$ (two-tailed)

Note: $b=$ unstandardized slopes, $S E=$ robust standard errors. Control variables included age, marital status, cohabitation status, housing type, ownership of living quarters, MSA status, region, religious affiliation, religiosity, religious attendance, a short-form GSS vocabulary test, and marriage judgments. 
Table 6. Consensus of Conditionality of the Norm to Marry across Subpopulations, Two-Level Hierarchical Linear Model with Higher Level Moderation of Lower Level Effects

\begin{tabular}{|c|c|c|}
\hline & Mode & \\
\hline & $b$ & $S E$ \\
\hline Vignette dimensions & & \\
\hline Mike's education & & \\
\hline No HS diploma (omitted) & & \\
\hline HS diploma & 0.123 & 0.082 \\
\hline 4-year college degree & 0.167 & 0.086 \\
\hline Mike's earnings and employment & & \\
\hline Unemployed 2 years (omitted) & & \\
\hline Full-time job, $\$ 20,000$ a year & $1.097 * * *$ & 0.092 \\
\hline Full-time job, $\$ 50,000$ a year & $1.621^{* * *}$ & 0.111 \\
\hline Jessica's education & & \\
\hline No HS diploma (omitted) & & \\
\hline HS diploma & 0.101 & 0.093 \\
\hline 4-year college degree & 0.100 & 0.085 \\
\hline Jessica's earnings and employme & & \\
\hline Unemployed 2 years (omitted) & & \\
\hline Full-time job, $\$ 20,000$ a year & $0.740 * * *$ & 0.080 \\
\hline Full-time job, $\$ 50,000$ a year & $0.983^{* * *}$ & 0.089 \\
\hline Mike and Jessica's assets & & \\
\hline Blank (omitted) & & \\
\hline Inherited $\$ 5,000$ & $0.162 *$ & 0.068 \\
\hline Relationship quality & & \\
\hline Bad (omitted) & & \\
\hline Good & $1.013^{* * *}$ & 0.097 \\
\hline Pregnancy status & & \\
\hline Not pregnant (omitted) & & \\
\hline Pregnant & $0.456 * * *$ & 0.089 \\
\hline Individual-level variables & & \\
\hline Race & & \\
\hline Black (omitted) & & \\
\hline White & 0.141 & 0.154 \\
\hline Gender & & \\
\hline Female (omitted) & & \\
\hline Male & $0.855^{* * *}$ & 0.142 \\
\hline Education & & \\
\hline HS diploma (omitted) & & \\
\hline Some college & -0.105 & 0.176 \\
\hline
\end{tabular}


Bachelor's degree or higher

$-0.472^{* *} \quad 0.181$

Cross-level interactions

White $\times$ Mike HS diploma

$\begin{array}{ll}0.013 & 0.071\end{array}$

White $\times$ Mike 4-year degree

$0.086 \quad 0.073$

White $\times$ Mike $\$ 20,000$ a year

$\begin{array}{ll}-0.018 & 0.079\end{array}$

White $\times$ Mike $\$ 50,000$ a year

$-0.050 \quad 0.091$

White $\times$ Jessica HS diploma

$0.057 \quad 0.075$

White $\times$ Jessica 4-year degree

$\begin{array}{ll}-0.064 & 0.073\end{array}$

White $\times$ Jessica $\$ 20,000$ a year

$\begin{array}{ll}-0.004 & 0.069\end{array}$

White $\times$ Jessica $\$ 50,000$ a year

$\begin{array}{ll}-0.024 & 0.078\end{array}$

White $\times$ Inherited \$5,000

$\begin{array}{ll}-0.052 & 0.060\end{array}$

White $\times$ Good relationship quality

$0.235 * * \quad 0.086$

White $\times$ Pregnant

$0.453 * * * \quad 0.082$

Male $\times$ Mike HS diploma

$\begin{array}{ll}-0.027 & 0.071\end{array}$

Male $\times$ Mike 4-year degree

$\begin{array}{ll}-0.022 & 0.073\end{array}$

Male $\times$ Mike $\$ 20,000$ a year

$-0.191 * \quad 0.079$

Male $\times$ Mike $\$ 50,000$ a year

$-0.211^{*} \quad 0.091$

Male $\times$ Jessica HS diploma

$0.084 \quad 0.075$

Male $\times$ Jessica 4-year degree

$0.114 \quad 0.073$

Male $\times$ Jessica \$20,000 a year

$-0.163 * \quad 0.069$

Male $\times$ Jessica $\$ 50,000$ a year

$-0.130 \quad 0.078$

Male $\times$ Inherited \$5,000

$\begin{array}{ll}-0.010 & 0.059\end{array}$

Male $\times$ Good relationship quality

$-0.243 * *$

0.086

Male $\times$ Pregnant

$-0.060$

0.082

Some college $\times$ Mike HS diploma

$-0.003 \quad 0.088$

Some college $\times$ Mike 4-year degree

$-0.040 \quad 0.092$

Bachelor's $\times$ Mike HS diploma

$0.004 \quad 0.086$

Bachelor's $\times$ Mike 4-year degree

$0.062 \quad 0.091$

Some college $\times$ Mike $\$ 20,000$ a year

$0.076 \quad 0.098$

Some college $\times$ Mike $\$ 50,000$ a year

$0.024 \quad 0.115$

Bachelor's $\times$ Mike $\$ 20,000$ a year

$0.120 \quad 0.097$

Bachelor's $\times$ Mike $\$ 50,000$ a year

0.204

0.113

Some college $\times$ Jessica HS diploma

$-0.079$

0.093

$0.133 \quad 0.093$

Some college $\times$ Jessica 4-year degree

$-0.081$

0.090

$0.015 \quad 0.088$

Bachelor's $\times$ Jessica 4-year degree

$-0.040$

0.085

$0.002 \quad 0.096$

Some college $\times$ Jessica $\$ 50,000$ a year

$0.027 \quad 0.085$

Bachelor's $\times$ Jessica \$20,000 a year

$0.011 \quad 0.095$

Bachelor's $\times$ Jessica \$50,000 a year

$-0.139 \quad 0.074$

Some college $\times$ Inherited $\$ 5,000$

$\begin{array}{ll}-0.024 & 0.072\end{array}$

Some college $\times$ Good relationship quality

$0.378^{* * *} \quad 0.107$ 


\begin{tabular}{lcc}
\multicolumn{1}{c}{ Bachelor's $\times$ Good relationship quality } & $0.355^{* *}$ & 0.104 \\
\multicolumn{1}{c}{ Some college $\times$ Pregnant } & -0.023 & 0.099 \\
Bachelor's $\times$ Pregnant & 0.182 & 0.102 \\
Intercept & $3.248^{* * *}$ & 0.633 \\
\hline sd(intercept) & 1.272 \\
sd(residuals) & 1.636 \\
sd(Mike HS diploma) & 0.174 \\
sd(Mike 4-year degree) & 0.267 \\
sd(Mike \$20,000 a year) & 0.242 \\
sd(Mike \$50,000 a year) & 0.781 \\
sd(Jessica HS diploma) & 0.273 \\
sd(Jessica 4-year degree) & 0.098 \\
sd(Jessica \$20,000 a year) & 0.000 \\
sd(Jessica \$50,000 a year) & 0.421 \\
sd(Inherited \$5,000) & 0.264 \\
sd(Good relationship quality) & 1.103 \\
sd(Pregnant) & 1.229 \\
\hline Vignette dummies & Yes \\
Individual-level controls & Yes \\
Observations & 16562 \\
Individuals & 1747 \\
\hline
\end{tabular}

*** $p<0.001,{ }^{* *} p<0.01, * p<0.05$ (two-tailed)

Note: $b=$ unstandardized slopes, $S E=$ robust standard errors. Joint test of significance for cross-level interactions, $\chi^{2}(44)=110.09, p<.001$. Control variables included age, marital status, cohabitation status, housing type, ownership of living quarters, MSA status, region, religious affiliation, religiosity, religious attendance, a short-form GSS vocabulary test, and marriage judgments. 
Table 7. Select Linear Predictions of the Norm to Marry by Race and Gender

\begin{tabular}{|c|c|c|c|c|c|c|c|}
\hline \multicolumn{4}{|c|}{ Black Female } & \multicolumn{4}{|c|}{ White Female } \\
\hline \multicolumn{2}{|c|}{ Bad Relationship Quality } & \multicolumn{2}{|c|}{ Good Relationship Quality } & \multicolumn{2}{|c|}{ Bad Relationship Quality } & \multicolumn{2}{|c|}{ Good Relationship Quality } \\
\hline Not Pregnant & Pregnant & Not Pregnant & Pregnant & Not Pregnant & Pregnant & Not Pregnant & Pregnant \\
\hline Not Pregnant & Pregnant & Not Pregnant & Pregnant & Not Pregnant & Pregnant & Not Pregnant & Pregnant \\
\hline $\begin{array}{c}3.561 \\
(2.578,4.545)\end{array}$ & $\begin{array}{c}3.957 \\
(2.967,4.947)\end{array}$ & $\begin{array}{c}4.331 \\
(3.357,5.306)\end{array}$ & $\begin{array}{c}4.727 \\
(3.744,5.709)\end{array}$ & $\begin{array}{c}3.703 \\
(2.731,4.675)\end{array}$ & $\begin{array}{c}4.552 \\
(3.572,5.532)\end{array}$ & $\begin{array}{c}4.709 \\
(3.741,5.676)\end{array}$ & $\begin{array}{c}5.558 \\
(4.583,6.533)\end{array}$ \\
\hline
\end{tabular}

Note: Linear predictions based on model 1 in Table 6 using the delta method (95 percent CIs in parentheses). All continuous covariates constrained to their minimum value, all factor-variable covariates constrained to their base level, and all pecuniary vignette dimensions constrained to their lowest level (Mike and Jessica no HS diploma, Mike and Jessica unemployed, and no assets). 

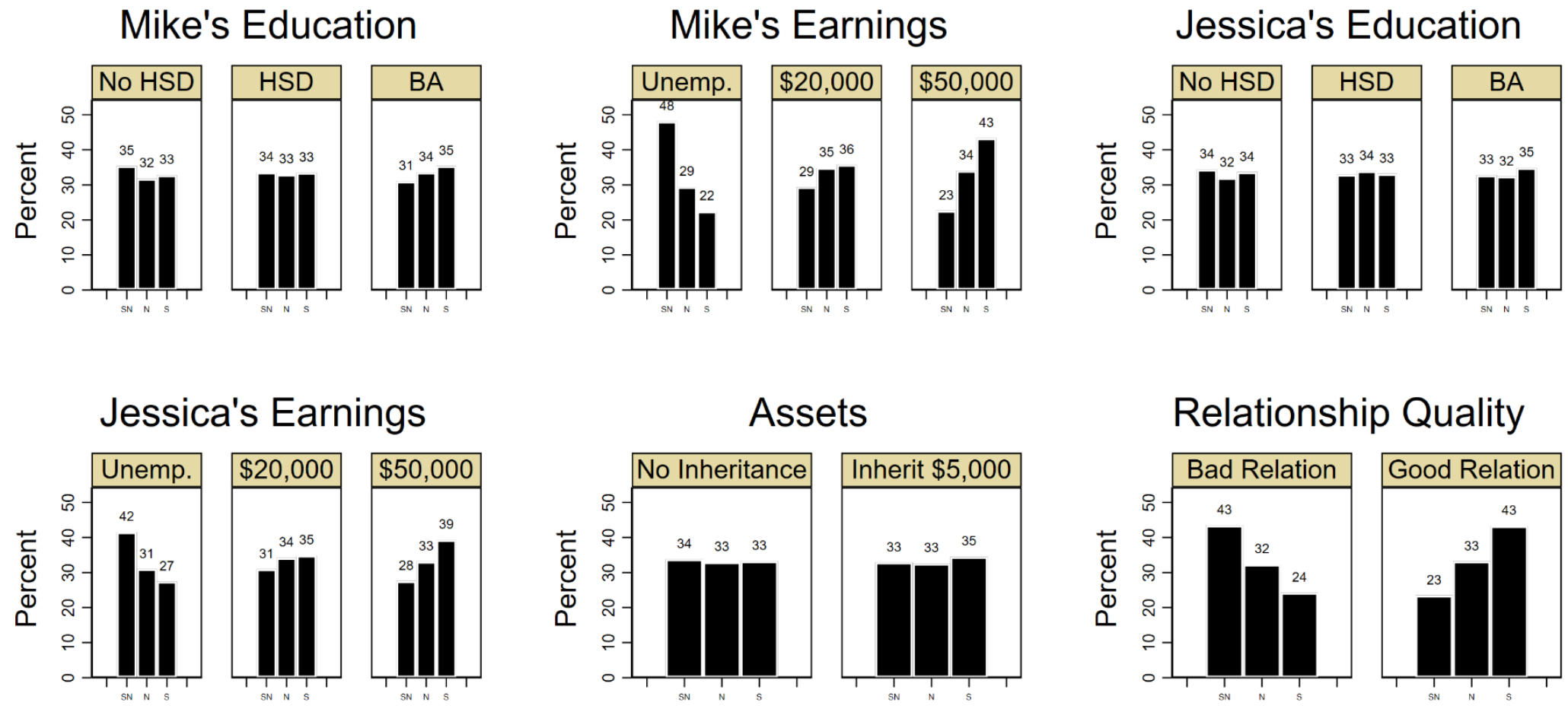

\section{Pregnancy Status}

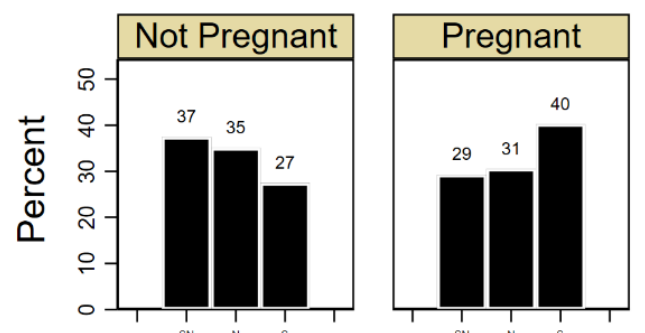

Figure 1. Histograms of the Norm to Marry by Vignette Dimensions

Note. Percent of total evaluations on the $y$-axis. 9-point rating task collapsed into three categories on the $x$-axis: $S N$ (not strong at all, not very strong, somewhat strong, and very strong should not marry), $N$ (neutral or nonexistent), and $S$ (not strong at all, not very strong, somewhat strong, and very strong should marry). HSD = HS diploma, BA = 4-year college degree. 


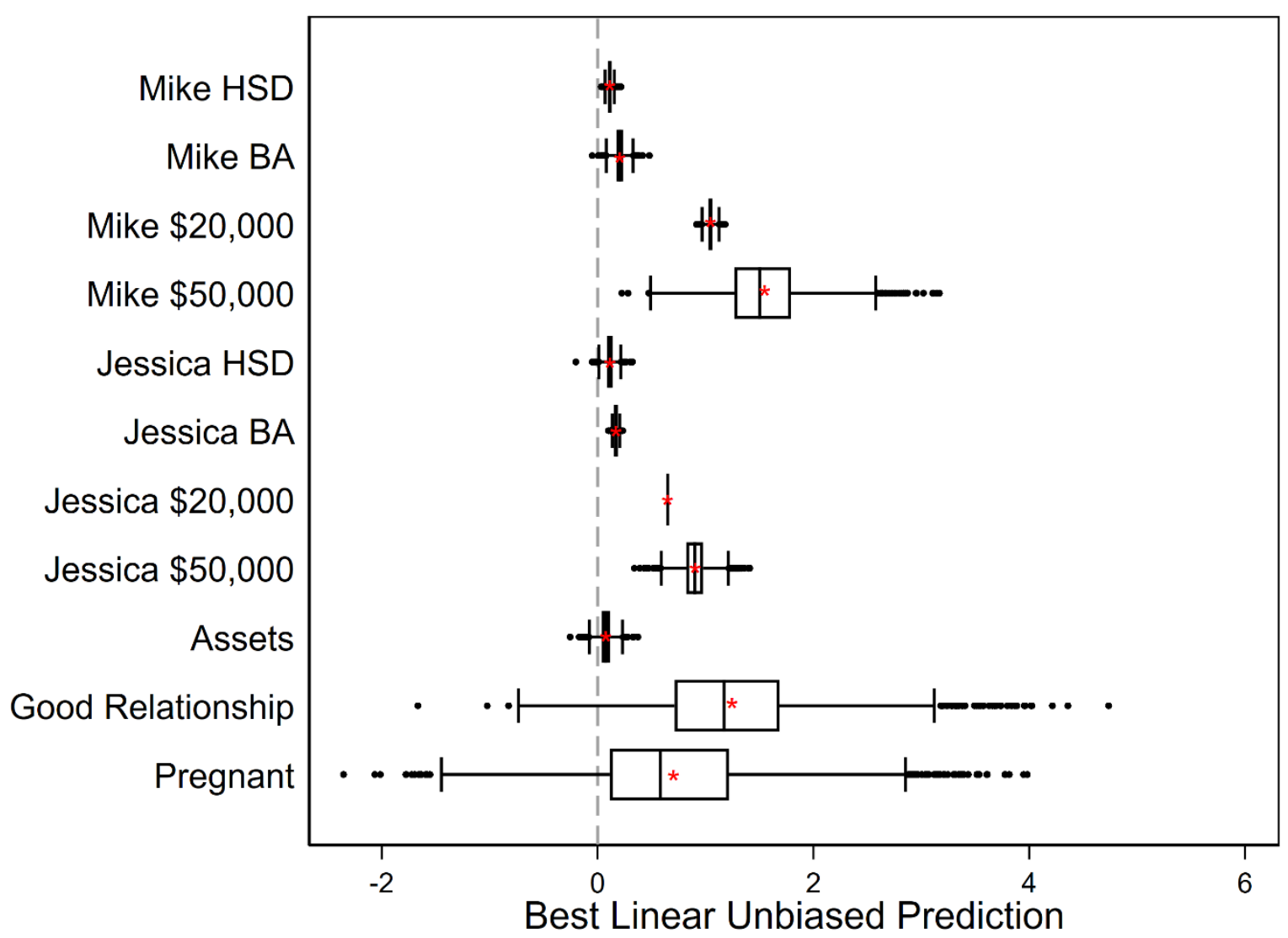

Figure 2. Boxplots of Best Linear Unbiased Predictions of Random Slopes

Note: boxplots show the distributions of magnitudes of each random slope at the individual level. Red stars in each boxplot represent the population-average coefficients estimated from Table 3, model 2. HSD = HS diploma, BA = 4-year college degree. 

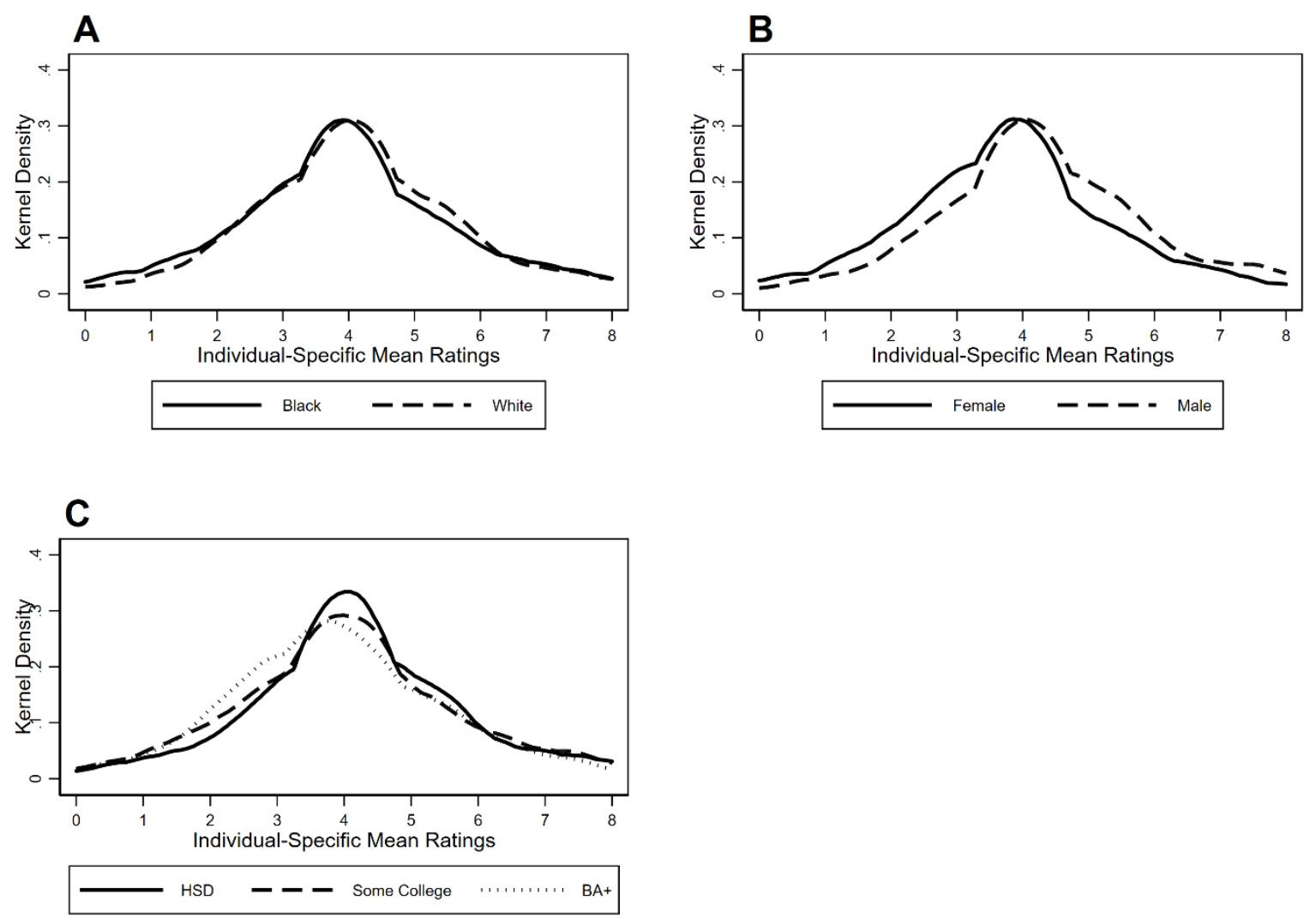

Figure 3. Kernel Density Plots of Individual-Specific Mean Ratings of the Norm to Marry by Race (Panel A), Gender (Panel B), and Education (Panel C) Note: HSD = HS diploma, BA+ = Bachelor's degree or higher. 

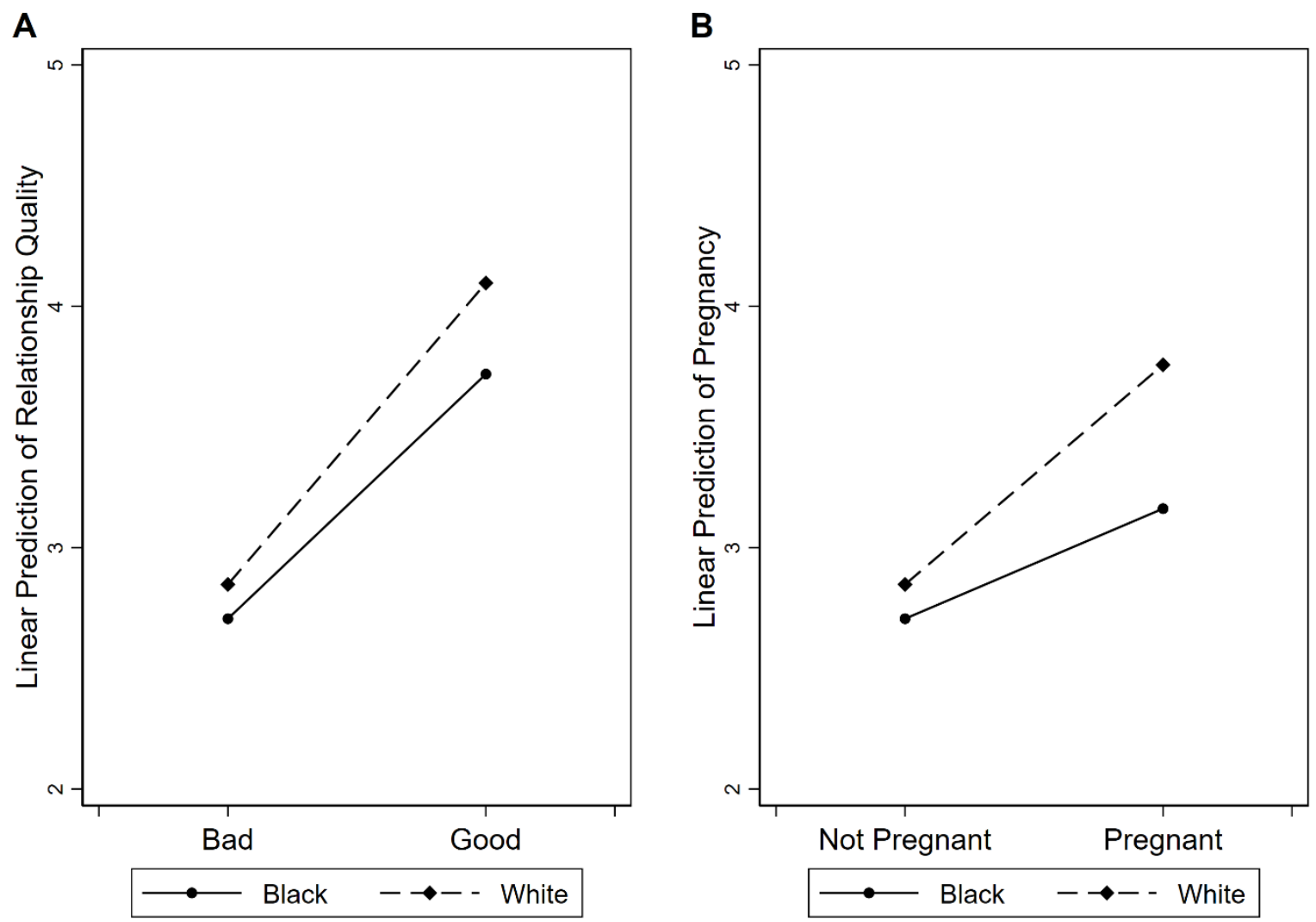

Figure 4. Cross-Level Interaction Effects between Race and Relationship Quality (Panel A) and Race and Pregnancy Status (Panel B) on the Norm to Marry (Table 6)

Note: All continuous covariates constrained to their minimum value and all factor-variable covariates constrained to their base level. 


\section{Supplemental Material}

Assessing the Deinstitutionalization of Marriage Thesis:

An Experimental Test

\section{Contents}

\section{Statistical models and estimation}

1.1. Ordinary least squares regression and hierarchical linear models .......................................2

2. Modeling assumptions

2.1. First-order serial autocorrelation, heteroskedasticity, etc.

3. Tests of assumptions for unbiased causal identification and inference

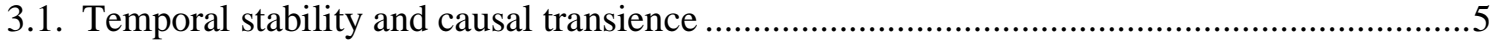

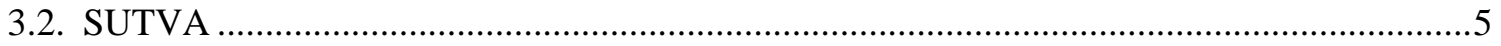

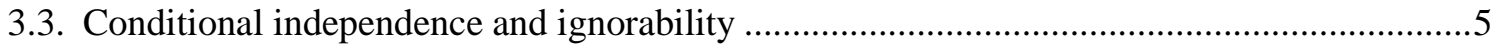

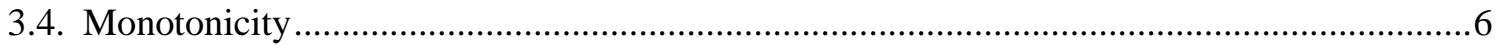

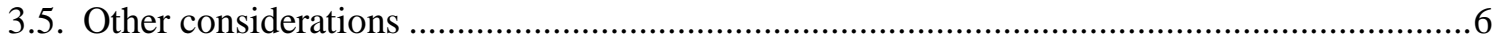

4. References

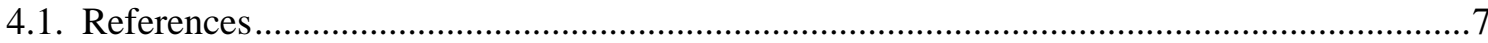

5. Randomized block design

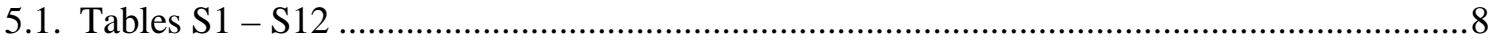

6. Robustness and sensitivity checks, part 1

6.1. Table S13. Consensus of the Norm across Subpopulations, Control Variables Shown .........20

6.2. Table S14. Cross-Level Interactions for Income and Vignette Dimensions ...........................23

6.3. Table S15. Cross-Level Interactions for Occupation and Vignette Dimensions .....................26

6.4. Table S16. Model Comparisons of Higher-Order Interactions, Vignette Dimensions ............31

6.5. Table S17. Interactions Effects Between Respondent's Race, Gender, and SES ...................32

6.6. Table S18. Model Comparisons of Higher-Order Interactions, Respondents x Vignette........33

6.7. Table S19. Ordered Logit Model, Effects of Vignette Dimensions........................................34

6.8. Table S20. Ordered Logit Model, Effects of Individual-Level Variables ...............................35

6.9. Table S21. Ordered Logit Model, Cross-Level Interactions ..................................................36

7. Robustness and sensitivity checks, part 2

7.1. Table S22. Multinomial Logit Model, Effects of Vignette Dimensions.................................39

7.2. Table S23. Multinomial Logit Model, Effects of Individual-Level Variables.........................40

7.3. Table S24. Consensus and Conditionality without Nonexistent Norm Followers..................41

7.4. Table S25. Consensus across Subpopulations without Nonexistent Norm Followers.............42

7.5. Table S26. Cross-Level Interactions without Nonexistent Norm Followers ..........................43

7.6. Table S27. Consensus and Conditionality, All Ten Vignettes Evaluated................................46

7.7. Table S28. Consensus across Subpopulations, All Ten Vignettes Evaluated..........................47

7.8. Table S29. Cross-Level Interactions, All Ten Vignettes Evaluated .......................................48

8. Robustness and sensitivity checks, part 3

8.1. Table S30. Character of the Norm with Survey Weights.......................................................51

8.2. Table S31. Consensus and Conditionality with Survey Weights..........................................52

8.3. Table S32. Consensus across Subpopulations with Survey Weights......................................53

8.4. Table S33. Consensus of Conditionality across Subpopulations with Survey Weights ..........54

9. Cross-Level Interaction Plots

9.1. Figure S1. Cross-Level Interactions between Gender and Select Vignette Dimensions .........57

9.2. Figure S2. Cross-Level Interactions between Education and Select Vignette Dimensions....58 


\section{Statistical Models and Estimation}

The research design yields panel data in which $i$ vignettes $(i=1, \ldots, 10)$ are nested within $j$ individuals $(j=1, \ldots, 1823)$. As a result, we estimated a series nested ordinary least squares and two-level hierarchical linear models (HLM) with and without higher level moderation of lower level effects. The various models we estimated in the main text can be found below.

To begin, we assumed that all respondents could be characterized by a single regression equation. In other words, all respondents had the same tendency to prescribe or proscribe marriage and that all respondents placed the same weight on the pecuniary and non-pecuniary circumstances governing the norm to marry (i.e., fixed intercept and fixed slopes model). The single equation we specify was a classic ordinary least squares regression with robust standard errors given by:

$$
Y_{i}=\beta_{0}+\beta_{k} X_{k i}+\delta_{i} V_{i}+\varepsilon_{i},
$$

where $Y$ denotes the norm rating, $X_{k}$ represent the vector of regressors (i.e., vignette dimensions and levels), $V_{i}$ denote the vector of vignette dummy variables for vignettes 2 through 10 (vignette 1 is the referent category), $\beta_{0}$ denotes the intercept, $\beta_{k}$ denote slope coefficients for $X_{k}$, $\delta_{i}$ denote slopes coefficients for $V_{i}, \varepsilon$ denotes the error term (i.i.d.), and $i$ indexes the vignette. Although not shown in the main text, the results suggest a reasonable fit to the data $\left(N=16804, \chi^{2}(20)=\right.$ 3152.53, $p<.001)$.

Next, we relaxed the assumption that respondents had the same tendency to prescribe or proscribe marriage by estimating a two-level random intercept and fixed slopes HLM. This model allowed each respondent to have a unique intercept for the ten evaluated vignettes, but retained the restriction that a single slope for each respective regressor characterized all respondents. The two equations specified were given by:

$$
Y_{i j}=\beta_{0 j}+\beta_{k} X_{k i j}+\delta_{i} V_{i}+r_{i j},
$$

where Equation 2 was a level-1 (or within-level) model that paralleled Equation 1 except for the addition of $j$, which indexes individual respondents, and the use of $r_{i j}$, which denotes a random error term (i.i.d) that varies over the population of vignettes. We also specified a level-2 model of between-individual variation in ratings by modeling the intercept, $\beta_{0 j}$, from Equation 2:

$$
\beta_{0 j}=\gamma_{00}+\gamma_{0 k} W_{k j}+u_{0 j},
$$

where $\gamma_{00}$ refers to the overall population intercept for ratings of the norm to marry (which is the grand mean of ratings across all individuals), $W_{k j}$ denotes a vector of individual-level regressors, $\gamma_{0 k}$ refers to slope coefficients for $W_{k j}$, and $u_{0 j}$ denotes a random error term (i.i.d) for the deviation of the intercept of an individual from the overall population intercept $\gamma_{00}$.

Next, we relaxed the assumption of fixed slopes, so that each respondent had both a unique intercept and a unique slope for each vignette dimension (i.e., a two-level random intercept and 
random slopes HLM). To accomplish this task, we included an additional equation to the model specified in Equations 2 and 3:

$$
\beta_{k j}=\gamma_{k 0}+\gamma_{k k} W_{k j}+u_{k j}
$$

where $\beta_{k j}$ denotes a vector of slope coefficients for $X_{k i j}$ in respondent $j, \gamma_{k 0}$ is a vector of overall population slope coefficients for $X_{k i j}, W_{k j}$ refers to a vector of individual-level regressors, $\gamma_{k k}$ denotes slope coefficients for $W_{k j}$, and $u_{k j}$ is a vector of random error terms (i.i.d) for the deviation of the slopes of individual $j$ from the overall population slopes $\gamma_{k 0}$.

Note that when we probed the character of the norm to marry in the main text (e.g., polarity and intensity), we constrained $\gamma_{0 k}$ in Equation 3 and $\gamma_{k k}$ in Equation 4 to zero. These two parameters were freed when we investigated whether the norm to marry and the conditions governing the norm to marry varied across subpopulations (see Tables 5 and 6 in the main text). 


\section{Modeling Assumptions}

Tests revealed that the estimates presented in the results section were neither unduly influenced by outliers (results available upon request) nor first-order serial autocorrelation of the level-1 disturbance terms (Woolridge test for first-order autocorrelation, $F(1,1729)=0.482, p=.487$ ), but that heteroscedastic level-1 errors were observed (Breusch-Pagan test for heteroscedasticity, $\left.\chi^{2}(1)=8.73, p<.01\right)$. As a result, robust standard errors were used throughout.

To test for possible fatigue effects and other issues related to repeated measures (e.g., unobserved effects that might influence all cases to the same degree for a specified ith vignette), we regressed marriage norm ratings on dummy variables for vignette number with the first vignette serving as the referent category. A Wald test for the joint significance of the vignette dummy variables rejected the null hypothesis that the vignette dummy variables were identical across the 10 vignettes, $\chi^{2}(9)=17.43, p=.042$. As a result, we include a vector of vignette dummy variables in the level-1 model (see Equation 1).

Because we randomly assigned levels of each dimension to vignettes and randomly assigned respondents to design-based experimental treatments, we assume that the vignette dimensions are orthogonal to the level-1 and level-2 errors terms (see Equations 1 through 4). While we cannot explicitly test the former, we can test whether vignette dimensions are orthogonal to the level-2 random error term with a classic Hausman specification test estimating fixed- and randomeffects econometric models for panel data. In doing so, we failed to reject the null hypothesis of no systematic differences in coefficients, $\left.\chi^{2}(11)=17.03, p=.106\right)$. In support of this evidence, the correlation between the vignette dimensions and the level-2 error term was negligible $(r=-$ 0.002). 


\section{Assumptions for Unbiased Causal Identification and Inference}

Temporal stability and causal transience. First, under two weak assumptions, the assessment of ten vignettes per respondent allows us to estimate unit causal effects in a counterfactual framework and not merely treatment effects on the treated. The two assumptions-temporal stability and causal transience-state that potential outcomes are unaffected by the anticipation of treatments administered in the future (sometimes referred to anticipation effects) and that potential outcomes in one period are unaffected by treatments administered in prior periods (sometimes referred to as spillover effects) (see Holland 1986; Hainmueller et al. 2014; Morgan and Winship 2007).

To test these assumptions, we estimated (a) two-level models in which each vignette dimension interacted with dummy variables for vignette number, and (b) two-level models with vignette dimensions and lagged $t$ - 1 vignette dimensions. We found that (a) Wald tests for the joint significance of the interaction terms failed to reject the null hypothesis that the vignette dimensions were identical across the 10 vignettes, $\chi^{2}(99)=107.29, p=.267$, and (b) $\chi^{2}$ tests for the joint significance of the lagged $\mathrm{t}-1$ vignette dimensions failed to reject the null hypothesis, $\chi^{2}(11)=13.85, p=.241$. Given the results, we can assume temporal stability and causal transience, and restricting our analysis to the first vignette assessed-even though we lose statistical power-generated substantive findings similar to those presented in the main document.

SUTVA. The stable unit treatment value assumption (SUTVA) states that unit A's potential outcome is solely a function of whether he or she receives the treatment; assignments or treatments applied to units B through $\mathrm{Z}$ have no effect on unit A's potential outcome. A given outcome then is unaffected by treatments assigned to or received by other units. SUTVA, in other words, implies non-interference between units. This assumption is generally maintained in laboratory settings but should be assessed for experimental methods with less control, such as web-based experiments, field experiments, and natural experiments.

We assess SUTVA by exploring the date in which respondents completed the study. The idea here is that respondents who completed the study at a later date could have been influenced by respondents who completed the study at an earlier date. Wald tests failed to reject the null hypothesis that dummy variables for the date in which respondents completed the study were jointly equal to zero, $\chi^{2}(15)=20.37, p=.158$; these results also imply an absence of history effects. Furthermore, a Wald test failed to reject the null hypothesis that interaction terms between vignette dimensions and a continuous measure for date of study completion were jointly equal to zero, $\chi^{2}(11)=18.45, p=.071$.

Conditional independence and ignorability. Conditional independence-sometimes referred to as ignorability - is the assumption that values assigned to treatment conditions are independent of potential outcomes (i.e., values taken by dependent variables), where "assigning values" describes the process by which treatments obtain their particular values. By manipulating and randomly assigning vignette dimensions to respondents, we satisfy the assumption of conditional independence as well as three other assumptions that underlie conditional independence: (1) treatment assignment is independent of potential outcomes and values of the dependent variables 
(i.e., no simultaneity or reflection problems), (2) selection bias is absent, and (3) omitted variable bias is also absent.

To test the assumption of conditional independence we conducted randomization checks. The goal was to look for unexpected correlations between experimental manipulations and observed covariates (e.g., gender). Our randomization checks consisted of regressing each vignette dimension-either logistic or multinomial logistic regression depending on the number of levels per dimension — on the individual-level covariates presented in the main document. We found that the observed covariates were jointly non-significant ( $p$-values $>.05$ ) for five of the seven vignette dimensions, indicating support for the assumption of conditional independence and that five of the seven vignette dimensions were jointly balanced. However, two other dimensionsassets and relationship quality_yielded statistically significant joint tests $(p<.05)$, indicating that two of the vignette dimensions were conditionally dependent on two observed covariates (i.e., marital status and religious attendance). A common method for dealing with imbalance is by statistically controlling for observed covariates correlated with experimental manipulations (Gerber and Green 2012). This is what we do in the main text.

Monotonicity. The assumption of monotonicity states that there are no units that receive a treatment if assigned to the control group (Angrist et al. 1996; Gerber and Green 2012); or, more generally, that respondents do not do the opposite of his or her assignment, no matter what the assignment. Angrist et al. (1996) classify four types of subjects: (1) compliers: subjects who take the treatment if assigned to the treatment condition; (2) never-takers: subjects who avoid the treatment if assigned to the treatment condition; (3) always-takers: subjects who take the treatment if assigned to the control condition; and (4) defiers: subjects who do the opposite of their assignment; they avoid the treatment if assigned to it, and they take the treatment if assigned to the control group. Angrist et al. (1996) refer to never-takers, always-takers, and defiers jointly as noncompliers. The presence of noncompliers - and defiers in particular — can downwardly bias average treatment effects. In some experimental designs (e.g., natural experiments like the Vietnam War draft) and in most observational studies, the assumption of monotonicity is frequently violated. But, like classic laboratory experiments, our research design rules out noncompliers by making treatment unavailable to those in the control group and the control unavailable to those in the treatment group. Thus, our assumption of monotonicity is likely valid.

Other considerations. First, none of the dimension combinations produced atypical or unrealistic vignettes (Faia 1980), which heightens concerns about external validity when present since unrealistic combinations deem counterfactuals meaningless. Implausible combinations of vignette dimensions are also known to downwardly bias parameter estimates and foster response biases (Auspurg and Hinz 2015). Since none of the dimensions produced unrealistic combinations, this issue is of little concern. 


\section{References}

Angrist, Joshua D., Guido W. Imbens, and Donald B. Rubin. 1996. "Identification of Causal Effects Using Instrumental Variables.” Journal of the American Statistical Association 91: 444-455.

Auspurg, Katrin and Thomas Hinz. 2015. Factorial Survey Experiments. Los Angeles, CA: Sage. Faia, Michael A. 1980. "The Vagaries of the Vignette World: A Comment on Alves and Rossi." American Journal of Sociology 85: 951-954.

Gerber, Alan S. and Donald P. Green. 2012. Field Experiments: Design, Analysis, and Interpretation. New York, NY: W. W. Norton \& Company.

Hainmueller, Jens, Daniel J. Hopkins, and Teppei Yamamoto. 2014. “Causal Inference in Conjoint Analysis: Understanding Multidimensional Choices via Stated Preference Experiments.” Political Analysis 22: 1-30.

Holland, Paul W. 1986. "Statistics and Causal Inference." Journal of the American Statistical Association 81: 945-960.

Morgan, Stephen L. and Christopher Winship. 2007. Counterfactuals and Causal Inference: Methods and Principles for Social Research. Cambridge, MA: Cambridge University Press. 


\section{Randomized Block Design}

Table S1. Number of Vignettes in each Vignette Condition for White Male Respondents with a HS Diploma

\begin{tabular}{|c|c|c|c|c|c|c|c|c|c|}
\hline \multirow[b]{2}{*}{ Pregnancy Status } & \multicolumn{3}{|c|}{ Jessica Unemployed } & \multicolumn{3}{|c|}{ Jessica $\$ 20,000$} & \multicolumn{3}{|c|}{ Jessica $\$ 50,000$} \\
\hline & Mike Unemp. & Mike $\$ 20,000$ & Mike $\$ 50,000$ & Mike Unemp. & Mike $\$ 20,000$ & Mike $\$ 50,000$ & Mike Unemp. & Mike $\$ 20,000$ & Mike $\$ 50,000$ \\
\hline Not pregnant & 90 & 83 & 84 & 87 & 84 & 103 & 84 & 79 & 87 \\
\hline Pregnant & 90 & 69 & 87 & 89 & 77 & 83 & 82 & 85 & 77 \\
\hline
\end{tabular}


Table S2. Number of Vignettes in each Vignette Condition for White Male Respondents with Some College

\begin{tabular}{|c|c|c|c|c|c|c|c|c|c|}
\hline \multirow[b]{2}{*}{ Pregnancy Status } & \multicolumn{3}{|c|}{ Jessica Unemployed } & \multicolumn{3}{|c|}{ Jessica $\$ 20,000$} & \multicolumn{3}{|c|}{ Jessica $\$ 50,000$} \\
\hline & Mike Unemp. & Mike $\$ 20,000$ & Mike $\$ 50,000$ & Mike Unemp. & Mike $\$ 20,000$ & Mike $\$ 50,000$ & Mike Unemp. & Mike $\$ 20,000$ & Mike $\$ 50,000$ \\
\hline Not pregnant & 81 & 89 & 94 & 79 & 81 & 87 & 84 & 88 & 83 \\
\hline Pregnant & 82 & 74 & 80 & 76 & 92 & 82 & 85 & 103 & 80 \\
\hline
\end{tabular}


Table S3. Number of Vignettes in each Vignette Condition for White Male Respondents with a Bachelor's Degree or Higher

\begin{tabular}{|c|c|c|c|c|c|c|c|c|c|}
\hline \multirow[b]{2}{*}{ Pregnancy Status } & \multicolumn{3}{|c|}{ Jessica Unemployed } & \multicolumn{3}{|c|}{ Jessica $\$ 20,000$} & \multicolumn{3}{|c|}{ Jessica $\$ 50,000$} \\
\hline & Mike Unemp. & Mike $\$ 20,000$ & Mike $\$ 50,000$ & Mike Unemp. & Mike $\$ 20,000$ & Mike $\$ 50,000$ & Mike Unemp. & Mike $\$ 20,000$ & Mike $\$ 50,000$ \\
\hline Not pregnant & 81 & 76 & 83 & 84 & 87 & 93 & 84 & 71 & 83 \\
\hline Pregnant & 91 & 89 & 74 & 84 & 87 & 82 & 81 & 86 & 84 \\
\hline
\end{tabular}


Table S4. Number of Vignettes in each Vignette Condition for Black Male Respondents with a HS Diploma

\begin{tabular}{|c|c|c|c|c|c|c|c|c|c|}
\hline \multirow[b]{2}{*}{ Pregnancy Status } & \multicolumn{3}{|c|}{ Jessica Unemployed } & \multicolumn{3}{|c|}{ Jessica $\$ 20,000$} & \multicolumn{3}{|c|}{ Jessica $\$ 50,000$} \\
\hline & Mike Unemp. & Mike $\$ 20,000$ & Mike $\$ 50,000$ & Mike Unemp. & Mike $\$ 20,000$ & Mike $\$ 50,000$ & Mike Unemp. & Mike $\$ 20,000$ & Mike $\$ 50,000$ \\
\hline Not pregnant & 81 & 85 & 82 & 96 & 90 & 90 & 71 & 77 & 92 \\
\hline Pregnant & 79 & 78 & 94 & 82 & 102 & 76 & 78 & 91 & 86 \\
\hline
\end{tabular}


Table S5. Number of Vignettes in each Vignette Condition for Black Male Respondents with Some College

\begin{tabular}{|c|c|c|c|c|c|c|c|c|c|}
\hline \multirow[b]{2}{*}{ Pregnancy Status } & \multicolumn{3}{|c|}{ Jessica Unemployed } & \multicolumn{3}{|c|}{ Jessica $\$ 20,000$} & \multicolumn{3}{|c|}{ Jessica $\$ 50,000$} \\
\hline & Mike Unemp. & Mike $\$ 20,000$ & Mike $\$ 50,000$ & Mike Unemp. & Mike $\$ 20,000$ & Mike $\$ 50,000$ & Mike Unemp. & Mike $\$ 20,000$ & Mike $\$ 50,000$ \\
\hline Not pregnant & 88 & 84 & 82 & 92 & 84 & 88 & 87 & 78 & 81 \\
\hline Pregnant & 80 & 92 & 78 & 85 & 96 & 88 & 78 & 84 & 75 \\
\hline
\end{tabular}


Table S6. Number of Vignettes in each Vignette Condition for Black Male Respondents with Bachelor's Degree or Higher

\begin{tabular}{|c|c|c|c|c|c|c|c|c|c|}
\hline \multirow[b]{2}{*}{ Pregnancy Status } & \multicolumn{3}{|c|}{ Jessica Unemployed } & \multicolumn{3}{|c|}{ Jessica $\$ 20,000$} & \multicolumn{3}{|c|}{ Jessica $\$ 50,000$} \\
\hline & Mike Unemp. & Mike $\$ 20,000$ & Mike $\$ 50,000$ & Mike Unemp. & Mike $\$ 20,000$ & Mike $\$ 50,000$ & Mike Unemp. & Mike $\$ 20,000$ & Mike $\$ 50,000$ \\
\hline Not pregnant & 82 & 81 & 76 & 84 & 76 & 94 & 82 & 81 & 89 \\
\hline Pregnant & 91 & 94 & 86 & 89 & 85 & 79 & 89 & 82 & 80 \\
\hline
\end{tabular}


Table S7. Number of Vignettes in each Vignette Condition for White Female Respondents with a HS Diploma

\begin{tabular}{|c|c|c|c|c|c|c|c|c|c|}
\hline \multirow[b]{2}{*}{ Pregnancy Status } & \multicolumn{3}{|c|}{ Jessica Unemployed } & \multicolumn{3}{|c|}{ Jessica $\$ 20,000$} & \multicolumn{3}{|c|}{ Jessica $\$ 50,000$} \\
\hline & Mike Unemp. & Mike $\$ 20,000$ & Mike $\$ 50,000$ & Mike Unemp. & Mike $\$ 20,000$ & Mike $\$ 50,000$ & Mike Unemp. & Mike $\$ 20,000$ & Mike $\$ 50,000$ \\
\hline Not pregnant & 84 & 86 & 85 & 88 & 77 & 87 & 78 & 84 & 79 \\
\hline Pregnant & 84 & 85 & 74 & 93 & 99 & 90 & 92 & 80 & 75 \\
\hline
\end{tabular}


Table S8. Number of Vignettes in each Vignette Condition for White Female Respondents with Some College

\begin{tabular}{|c|c|c|c|c|c|c|c|c|c|}
\hline \multirow[b]{2}{*}{ Pregnancy Status } & \multicolumn{3}{|c|}{ Jessica Unemployed } & \multicolumn{3}{|c|}{ Jessica $\$ 20,000$} & \multicolumn{3}{|c|}{ Jessica $\$ 50,000$} \\
\hline & Mike Unemp. & Mike $\$ 20,000$ & Mike $\$ 50,000$ & Mike Unemp. & Mike $\$ 20,000$ & Mike $\$ 50,000$ & Mike Unemp. & Mike $\$ 20,000$ & Mike $\$ 50,000$ \\
\hline Not pregnant & 78 & 77 & 76 & 78 & 92 & 94 & 84 & 80 & 82 \\
\hline Pregnant & 80 & 84 & 105 & 77 & 94 & 85 & 92 & 79 & 83 \\
\hline
\end{tabular}


Table S9. Number of Vignettes in each Vignette Condition for White Female Respondents with a Bachelor's Degree or Higher

\begin{tabular}{|c|c|c|c|c|c|c|c|c|c|}
\hline \multirow[b]{2}{*}{ Pregnancy Status } & \multicolumn{3}{|c|}{ Jessica Unemployed } & \multicolumn{3}{|c|}{ Jessica $\$ 20,000$} & \multicolumn{3}{|c|}{ Jessica $\$ 50,000$} \\
\hline & Mike Unemp. & Mike $\$ 20,000$ & Mike $\$ 50,000$ & Mike Unemp. & Mike $\$ 20,000$ & Mike $\$ 50,000$ & Mike Unemp. & Mike $\$ 20,000$ & Mike $\$ 50,000$ \\
\hline Not pregnant & 82 & 81 & 81 & 77 & 89 & 89 & 78 & 81 & 92 \\
\hline Pregnant & 95 & 87 & 86 & 88 & 89 & 76 & 90 & 75 & 80 \\
\hline
\end{tabular}


Table S10. Number of Vignettes in each Vignette Condition for Black Female Respondents with a HS Diploma

\begin{tabular}{|c|c|c|c|c|c|c|c|c|c|}
\hline \multirow[b]{2}{*}{ Pregnancy Status } & \multicolumn{3}{|c|}{ Jessica Unemployed } & \multicolumn{3}{|c|}{ Jessica $\$ 20,000$} & \multicolumn{3}{|c|}{ Jessica $\$ 50,000$} \\
\hline & Mike Unemp. & Mike $\$ 20,000$ & Mike $\$ 50,000$ & Mike Unemp. & Mike $\$ 20,000$ & Mike $\$ 50,000$ & Mike Unemp. & Mike $\$ 20,000$ & Mike $\$ 50,000$ \\
\hline Not pregnant & 85 & 73 & 87 & 76 & 75 & 86 & 81 & 90 & 96 \\
\hline Pregnant & 92 & 68 & 89 & 71 & 81 & 89 & 90 & 94 & 97 \\
\hline
\end{tabular}


Table S11. Number of Vignettes in each Vignette Condition for Black Female Respondents with Some College

\begin{tabular}{|c|c|c|c|c|c|c|c|c|c|}
\hline \multirow[b]{2}{*}{ Pregnancy Status } & \multicolumn{3}{|c|}{ Jessica Unemployed } & \multicolumn{3}{|c|}{ Jessica $\$ 20,000$} & \multicolumn{3}{|c|}{ Jessica $\$ 50,000$} \\
\hline & Mike Unemp. & Mike $\$ 20,000$ & Mike $\$ 50,000$ & Mike Unemp. & Mike $\$ 20,000$ & Mike $\$ 50,000$ & Mike Unemp. & Mike $\$ 20,000$ & Mike $\$ 50,000$ \\
\hline Not pregnant & 82 & 89 & 87 & 85 & 80 & 87 & 83 & 81 & 83 \\
\hline Pregnant & 88 & 73 & 92 & 86 & 89 & 78 & 90 & 94 & 73 \\
\hline
\end{tabular}


Table S12. Number of Vignettes in each Vignette Condition for Black Female Respondents with a Bachelor's Degree or Higher

\begin{tabular}{|c|c|c|c|c|c|c|c|c|c|}
\hline \multirow[b]{2}{*}{ Pregnancy Status } & \multicolumn{3}{|c|}{ Jessica Unemployed } & \multicolumn{3}{|c|}{ Jessica $\$ 20,000$} & \multicolumn{3}{|c|}{ Jessica $\$ 50,000$} \\
\hline & Mike Unemp. & Mike $\$ 20,000$ & Mike $\$ 50,000$ & Mike Unemp. & Mike $\$ 20,000$ & Mike $\$ 50,000$ & Mike Unemp. & Mike $\$ 20,000$ & Mike $\$ 50,000$ \\
\hline Not pregnant & 81 & 79 & 86 & 89 & 83 & 100 & 86 & 79 & 92 \\
\hline Pregnant & 79 & 79 & 88 & 91 & 79 & 83 & 81 & 77 & 88 \\
\hline
\end{tabular}




\section{Robustness and Sensitivity Checks, Part 1}

Table S13. Consensus of the Norm to Marry across Subpopulations, TwoLevel Hierarchical Linear Model with Control Variables Shown

\begin{tabular}{|c|c|c|}
\hline \multirow{3}{*}{ Individual-level variables } & \multicolumn{2}{|c|}{ Model 1} \\
\hline & \multirow[t]{2}{*}{$b$} & \multirow[t]{2}{*}{$S E$} \\
\hline & & \\
\hline \multicolumn{3}{|l|}{ Race } \\
\hline \multicolumn{3}{|l|}{ Black (omitted) } \\
\hline White & $0.400 * * *$ & 0.090 \\
\hline \multicolumn{3}{|l|}{ Gender } \\
\hline \multicolumn{3}{|l|}{ Female (omitted) } \\
\hline Male & $0.507 * * *$ & 0.075 \\
\hline \multicolumn{3}{|l|}{ Education } \\
\hline \multicolumn{3}{|l|}{ HS diploma (omitted) } \\
\hline Some college & 0.005 & 0.092 \\
\hline Bachelor's degree or higher & -0.119 & 0.103 \\
\hline ln(household income per capita) & -0.070 & 0.040 \\
\hline \multicolumn{3}{|l|}{ Occupation } \\
\hline Class 1 - Professionals, administrators, etc. & -0.104 & 0.163 \\
\hline Class 2 - Routine non-manual employees & 0.018 & 0.169 \\
\hline Class 3 - High-grade technicians & 0.348 & 0.310 \\
\hline Class 4 - Skilled manual workers & -0.065 & 0.238 \\
\hline \multicolumn{3}{|l|}{ Class 5 - Manual workers (omitted) } \\
\hline Class 6 - Agricultural & -0.073 & 0.740 \\
\hline Class 7 - Military & -0.016 & 0.573 \\
\hline Class other & $-0.386^{*}$ & 0.185 \\
\hline Not working & -0.235 & 0.179 \\
\hline Retired & -0.007 & 0.175 \\
\hline Disabled & -0.079 & 0.207 \\
\hline \multicolumn{3}{|l|}{ Individual-level variables } \\
\hline Age & $-0.006^{*}$ & 0.003 \\
\hline \multicolumn{3}{|l|}{ Marital status } \\
\hline \multicolumn{3}{|l|}{ Married (omitted) } \\
\hline Widowed & -0.323 & 0.169 \\
\hline Divorced & -0.177 & 0.125 \\
\hline Separated & -0.249 & 0.235 \\
\hline Never married & -0.219 & 0.113 \\
\hline \multicolumn{3}{|l|}{ Cohabitation status } \\
\hline \multicolumn{3}{|l|}{ Present cohabitation (omitted) } \\
\hline Married cohabitation & -0.221 & 0.229 \\
\hline Past cohabitation & -0.255 & 0.142 \\
\hline Never cohabitation & -0.155 & 0.140 \\
\hline DKPNS & 0.156 & 0.243 \\
\hline
\end{tabular}


Head of household

$-0.180 \quad 0.118$

Housing type

One-family house, detached (omitted)

One-family house, attached

$\begin{array}{ll}-0.036 & 0.123\end{array}$

Apartment building

$-0.080 \quad 0.123$

A mobile home

$-0.094 \quad 0.242$

Boat, RV, van, etc.

$0.372 \quad 0.440$

Ownership status of living quarters

Owned or being bought (omitted)

Rented for cash

$0.249 * \quad 0.113$

Occupied without payment of rent

$0.180 \quad 0.246$

MSA Status

Metro (omitted)

Non-metro

$-0.047 \quad 0.115$

Region

Northeast

$0.042 \quad 0.127$

Midwest

$0.088 \quad 0.125$

South

0.146

0.111

West (omitted)

Marriage judgments

$0.047 * * \quad 0.017$

GSS vocabulary test

Zero correct (omitted)

One correct

$\begin{array}{ll}-0.080 & 0.357\end{array}$

Two correct

0.070

0.351

Three correct

$-0.191 \quad 0.306$

Four correct

$\begin{array}{ll}-0.192 & 0.302\end{array}$

Five correct

$-0.214 \quad 0.310$

Religious affiliation

Mainline protestant (omitted)

Pentecostal $\quad 0.070$

0.185

Evangelical protestant

0.065

0.129

Black protestant

$-0.648 \quad 0.337$

Non-traditional fundamentalist

$-0.118 \quad 0.320$

Catholic

$-0.282 * \quad 0.133$

Jewish

$-0.352 \quad 0.283$

Christian, non-denominational

$-0.319 \quad 0.174$

Other denomination

$-0.020 \quad 0.332$

Atheist-agnostic

$-0.436 * 0.208$

Affiliation not listed

$-0.265 \quad 0.270$

Religiously unaffiliated (i.e., none)

$-0.281 \quad 0.154$

DKPNS

$-0.237 \quad 0.166$

Religiosity

Not at all religious (omitted)

Not very religious

$-0.118 \quad 0.145$

Somewhat religious

$-0.074 \quad 0.153$ 


\begin{tabular}{lcc} 
Very religious & 0.229 & 0.181 \\
DKPNS & 0.077 & 0.207 \\
Religious attendance & & \\
$\quad$ Never (omitted) & & \\
Once a year or less & $0.246^{*}$ & 0.122 \\
A few times a year & -0.053 & 0.124 \\
Once or twice a month & 0.034 & 0.165 \\
Once a week & $0.399 * *$ & 0.146 \\
More than once a week & 0.255 & 0.178 \\
DKPNS & 0.175 & 0.355 \\
Intercept & $2.541^{* * *}$ & 0.580 \\
\hline sd(intercept) & 1.323 \\
sd(residuals) & 1.943 \\
\hline Vignette dummies & Yes \\
Vignette dimensions & Yes \\
Observations & 16562 \\
Individuals & 1747 \\
\hline$* * * p<0.001, * * p<0.01, * p<0.05$ (two-tailed) & & \\
Note: $b=$ unstandardized slopes, $S E=$ robust standard errors. &
\end{tabular}


Table S14. Two-Level Hierarchical Linear Model of the Norm to Marry, Cross-Level Interactions

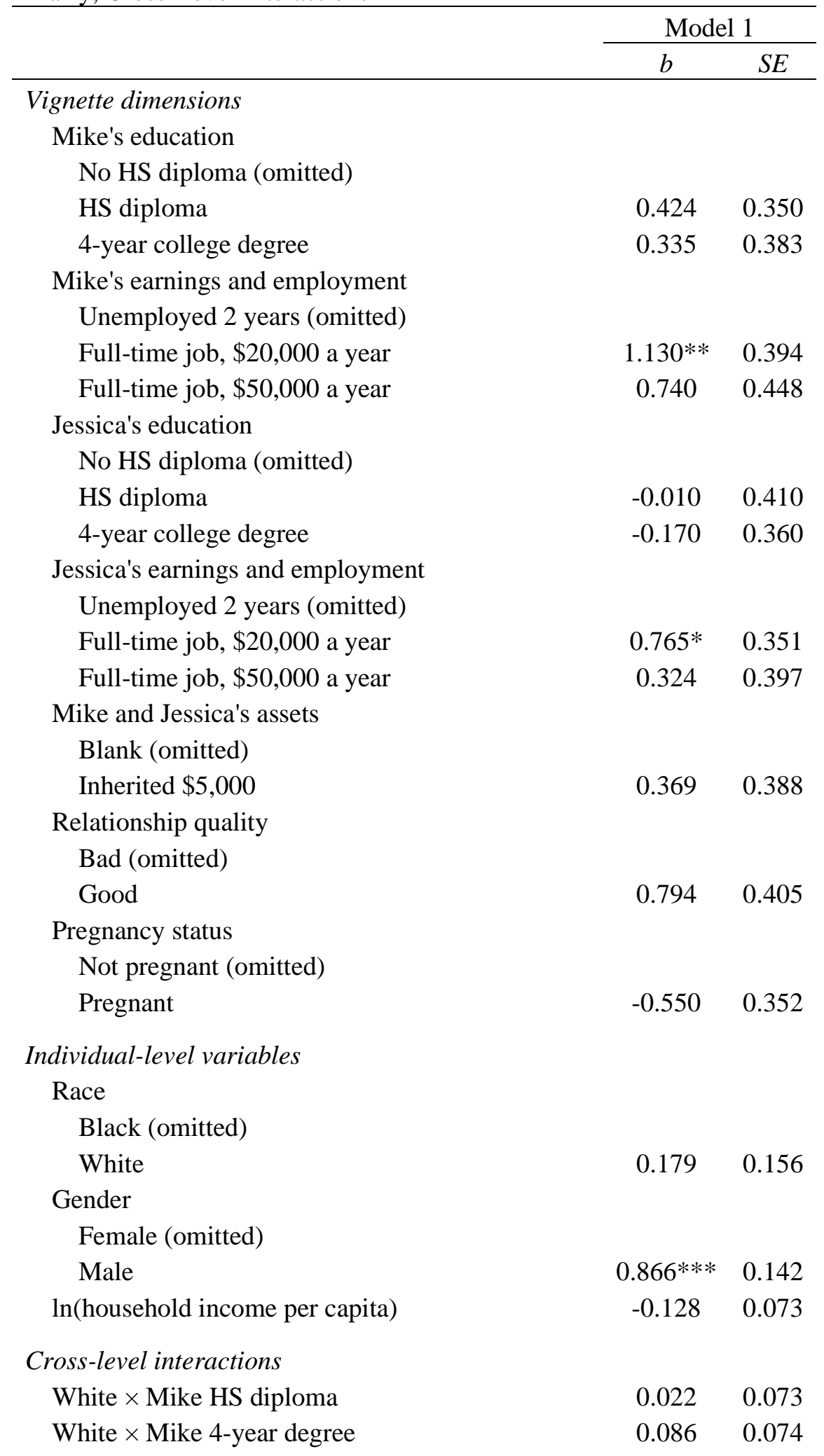




\begin{tabular}{|c|c|c|}
\hline White $\times$ Mike $\$ 20,000$ a year & -0.027 & 0.079 \\
\hline White $\times$ Mike $\$ 50,000$ a year & -0.097 & 0.092 \\
\hline White $\times$ Jessica HS diploma & 0.055 & 0.075 \\
\hline White $\times$ Jessica 4-year degree & -0.083 & 0.074 \\
\hline White $\times$ Jessica $\$ 20,000$ a year & -0.001 & 0.070 \\
\hline White $\times$ Jessica $\$ 50,000$ a year & -0.052 & 0.079 \\
\hline White $\times$ Inherited $\$ 5,000$ & -0.043 & 0.061 \\
\hline White $\times$ Good relationship quality & $0.212^{*}$ & 0.089 \\
\hline White $\times$ Pregnant & $0.404^{* * *}$ & 0.083 \\
\hline Male $\times$ Mike HS diploma & -0.029 & 0.071 \\
\hline Male $\times$ Mike 4-year degree & -0.026 & 0.074 \\
\hline Male $\times$ Mike $\$ 20,000$ a year & $-0.187^{*}$ & 0.078 \\
\hline Male $\times$ Mike $\$ 50,000$ a year & $-0.224 *$ & 0.091 \\
\hline Male $\times$ Jessica HS diploma & 0.080 & 0.074 \\
\hline Male $\times$ Jessica 4-year degree & 0.110 & 0.073 \\
\hline Male $\times$ Jessica $\$ 20,000$ a year & $-0.158^{*}$ & 0.069 \\
\hline Male $\times$ Jessica $\$ 50,000$ a year & -0.137 & 0.078 \\
\hline Male $\times$ Inherited \$5,000 & -0.007 & 0.060 \\
\hline Male $\times$ Good relationship quality & $-0.251^{* *}$ & 0.086 \\
\hline Male $\times$ Pregnant & -0.075 & 0.083 \\
\hline Income $\times$ Mike HS diploma & -0.030 & 0.035 \\
\hline Income $\times$ Mike 4-year degree & -0.015 & 0.038 \\
\hline Income $\times$ Mike $\$ 20,000$ a year & 0.003 & 0.038 \\
\hline Income $\times$ Mike $\$ 50,000$ a year & $0.097 *$ & 0.043 \\
\hline Income $\times$ Jessica HS diploma & 0.006 & 0.040 \\
\hline Income $\times$ Jessica 4-year degree & 0.033 & 0.035 \\
\hline Income $\times$ Jessica $\$ 20,000$ a year & -0.003 & 0.034 \\
\hline Income $\times$ Jessica $\$ 50,000$ a year & 0.067 & 0.039 \\
\hline Income $\times$ Inherited $\$ 5,000$ & -0.026 & 0.028 \\
\hline Income $\times$ Good relationship quality & 0.047 & 0.040 \\
\hline Income $\times$ Pregnant & $0.108^{* *}$ & 0.035 \\
\hline Intercept & $3.801^{* * *}$ & 0.866 \\
\hline sd(intercept) & \multicolumn{2}{|c|}{1.272} \\
\hline sd(residuals) & \multicolumn{2}{|c|}{1.636} \\
\hline sd(Mike HS diploma) & \multicolumn{2}{|c|}{0.149} \\
\hline sd(Mike 4-year degree) & \multicolumn{2}{|c|}{0.268} \\
\hline sd(Mike $\$ 20,000$ a year) & \multicolumn{2}{|c|}{0.250} \\
\hline sd(Mike $\$ 50,000$ a year) & \multicolumn{2}{|c|}{0.779} \\
\hline sd(Jessica HS diploma) & \multicolumn{2}{|c|}{0.265} \\
\hline sd(Jessica 4-year degree) & \multicolumn{2}{|c|}{0.119} \\
\hline sd(Jessica $\$ 20,000$ a year) & \multicolumn{2}{|c|}{0.000} \\
\hline sd(Jessica $\$ 50,000$ a year) & \multicolumn{2}{|c|}{0.414} \\
\hline sd(Inherited \$5,000) & \multicolumn{2}{|c|}{0.277} \\
\hline
\end{tabular}


$\operatorname{sd(Good~relationship~quality)~} \quad 1.114$

sd(Pregnant) $\quad 1.228$

Vignette dummies $\quad$ Yes

Individual-level controls $\quad$ Yes

Observations 16562

Individuals 1747

*** $p<0.001,{ }^{* *} p<0.01, * p<0.05$ (two-tailed)

Note: $b=$ unstandardized slopes, $S E=$ robust standard errors. Joint test of significance for cross-level interactions, $\chi^{2}(33)=95.82, p<.001$. Control variables included age, marital status, cohabitation status, housing type, ownership of living quarters, MSA status, region, religious affiliation, religiosity, religious attendance, a short-form GSS vocabulary test, and marriage judgments. 
Table S15. Two-Level Hierarchical Linear Model of the Norm to Marry, Cross-Level Interactions

\begin{tabular}{|c|c|c|}
\hline & \multicolumn{2}{|c|}{ Model 1} \\
\hline & $b$ & $S E$ \\
\hline \multicolumn{3}{|l|}{ Vignette dimensions } \\
\hline \multicolumn{3}{|l|}{ Mike's education } \\
\hline \multicolumn{3}{|l|}{ No HS diploma (omitted) } \\
\hline HS diploma & 0.226 & 0.157 \\
\hline 4-year college degree & 0.156 & 0.157 \\
\hline \multicolumn{3}{|l|}{ Mike's earnings and employment } \\
\hline \multicolumn{3}{|l|}{ Unemployed 2 years (omitted) } \\
\hline Full-time job, $\$ 20,000$ a year & $1.137 * * *$ & 0.152 \\
\hline Full-time job, $\$ 50,000$ a year & $1.439 * * *$ & 0.176 \\
\hline \multicolumn{3}{|l|}{ Jessica's education } \\
\hline \multicolumn{3}{|l|}{ No HS diploma (omitted) } \\
\hline HS diploma & -0198 & 0.172 \\
\hline 4-year college degree & 0.016 & 0.174 \\
\hline \multicolumn{3}{|l|}{ Jessica's earnings and employment } \\
\hline \multicolumn{3}{|l|}{ Unemployed 2 years (omitted) } \\
\hline Full-time job, $\$ 20,000$ a year & $0.599 * * *$ & 0.133 \\
\hline Full-time job, $\$ 50,000$ a year & $1.003 * * *$ & 0.164 \\
\hline \multicolumn{3}{|l|}{ Mike and Jessica's assets } \\
\hline \multicolumn{3}{|l|}{ Blank (omitted) } \\
\hline Inherited \$5,000 & -0.082 & 0.128 \\
\hline \multicolumn{3}{|l|}{ Relationship quality } \\
\hline \multicolumn{3}{|l|}{ Bad (omitted) } \\
\hline Good & $1.291 * * *$ & 0.203 \\
\hline \multicolumn{3}{|l|}{ Pregnancy status } \\
\hline \multicolumn{3}{|l|}{ Not pregnant (omitted) } \\
\hline Pregnant & $0.643^{* * *}$ & 0.172 \\
\hline \multicolumn{3}{|l|}{ Individual-level variables } \\
\hline \multicolumn{3}{|l|}{ Race } \\
\hline \multicolumn{3}{|l|}{ Black (omitted) } \\
\hline White & 0.149 & 0.154 \\
\hline \multicolumn{3}{|l|}{ Gender } \\
\hline \multicolumn{3}{|l|}{ Female (omitted) } \\
\hline Male & 0.800 & 0.144 \\
\hline \multicolumn{3}{|l|}{ Education } \\
\hline Class 1 - Professionals, administrators, etc. & -0.021 & 0.318 \\
\hline Class 2 - Routine non-manual employees & -0.299 & 0.343 \\
\hline
\end{tabular}


Class 3 - High-grade technicians

$\begin{array}{ll}0.311 & 0.666 \\ 0.050 & 0.485 \\ & \\ 0.066 & 1.366 \\ 0.795 & 0.673 \\ -0.773 & 0.397 \\ -0.671 & 0.366 \\ -0.247 & 0.328 \\ -0.652 & 0.437\end{array}$

Cross-level interactions

White $\times$ Mike HS diploma

$0.013 \quad 0.071$

White $\times$ Mike 4-year degree

$0.071 \quad 0.073$

White $\times$ Mike $\$ 20,000$ a year

$-0.030 \quad 0.079$

White $\times$ Mike $\$ 50,000$ a year

$-0.075 \quad 0.091$

White $\times$ Jessica HS diploma

$0.058 \quad 0.074$

White $\times$ Jessica 4-year degree

$-0.065 \quad 0.073$

White $\times$ Jessica $\$ 20,000$ a year

$-0.005 \quad 0.069$

White $\times$ Jessica $\$ 50,000$ a year

$-0.034 \quad 0.078$

White $\times$ Inherited \$5,000

$-0.044 \quad 0.060$

White $\times$ Good relationship quality

$0.248 * * \quad 0.088$

White $\times$ Pregnant

$0.451 * * * \quad 0.082$

Male $\times$ Mike HS diploma

$-0.041 \quad 0.073$

Male $\times$ Mike 4-year degree

$-0.052 \quad 0.076$

Male $\times$ Mike $\$ 20,000$ a year

$-0.180 * \quad 0.081$

Male $\times$ Mike $\$ 50,000$ a year

$-0.185 * \quad 0.093$

Male $\times$ Jessica HS diploma

$0.115 \quad 0.076$

Male $\times$ Jessica 4-year degree

$0.128 \quad 0.076$

Male $\times$ Jessica $\$ 20,000$ a year

$-0.090 \quad 0.070$

Male $\times$ Jessica $\$ 50,000$ a year

$-0.112 \quad 0.080$

Male $\times$ Inherited \$5,000

$0.024 \quad 0.061$

Male $\times$ Good relationship quality

$-0.236 * * \quad 0.089$

Male $\times$ Pregnant

$-0.089 \quad 0.084$

Class $1 \times$ Mike HS diploma

$-0.121 \quad 0.155$

Class $1 \times$ Mike 4-year degree

$0.068 \quad 0.157$

Class $2 \times$ Mike HS diploma

$-0.151 \quad 0.176$

Class $2 \times$ Mike 4-year degree

$-0.115 \quad 0.173$

Class $3 \times$ Mike HS diploma

$-0.367 \quad 0.279$

Class $3 \times$ Mike 4-year degree

$\begin{array}{ll}-0.203 & 0.292\end{array}$

Class $4 \times$ Mike HS diploma

$-0.190 \quad 0.281$

Class $4 \times$ Mike 4-year degree

$0.234 \quad 0.265$

Class $6 \times$ Mike HS diploma

$\begin{array}{ll}-0.335 & 0.381\end{array}$

Class $6 \times$ Mike 4-year degree

$0.467 \quad 0.310$

Class $7 \times$ Mike HS diploma

$0.774 \quad 0.455$ 


\begin{tabular}{|c|c|c|}
\hline Class $7 \times$ Mike 4-year degree & 0.902 & 0.533 \\
\hline Class other $\times$ Mike HS diploma & -0.002 & 0.191 \\
\hline Class other $\times$ Mike 4-year degree & 0.193 & 0.198 \\
\hline Not working $\times$ Mike HS diploma & -0.021 & 0.188 \\
\hline Not working $\times$ Mike 4 -year degree & 0.137 & 0.192 \\
\hline Retired $\times$ Mike HS diploma & -0.130 & 0.161 \\
\hline Retired $\times$ Mike 4-year degree & 0.023 & 0.164 \\
\hline Disabled $\times$ Mike HS diploma & -0.015 & 0.207 \\
\hline Disabled $\times$ Mike 4-year degree & -0.025 & 0.211 \\
\hline Class $1 \times$ Mike $\$ 20,000$ a year & -0.008 & 0.155 \\
\hline Class $1 \times$ Mike $\$ 50,000$ a year & 0.222 & 0.178 \\
\hline Class $2 \times$ Mike $\$ 20,000$ a year & 0.062 & 0.174 \\
\hline Class $2 \times$ Mike $\$ 50,000$ a year & 0.330 & 0.201 \\
\hline Class $3 \times$ Mike $\$ 20,000$ a year & 0.161 & 0.297 \\
\hline Class $3 \times$ Mike $\$ 50,000$ a year & 0.367 & 0.366 \\
\hline Class $4 \times$ Mike $\$ 20,000$ a year & -0.299 & 0.263 \\
\hline Class $4 \times$ Mike $\$ 50,000$ a year & -0.104 & 0.325 \\
\hline Class $6 \times$ Mike $\$ 20,000$ a year & -0.014 & 0.478 \\
\hline Class $6 \times$ Mike $\$ 50,000$ a year & 0.702 & 0.851 \\
\hline Class $7 \times$ Mike $\$ 20,000$ a year & $-1.105^{* *}$ & 0.366 \\
\hline Class $7 \times$ Mike $\$ 50,000$ a year & $-1.050 * *$ & 0.426 \\
\hline Class other $\times$ Mike $\$ 20,000$ a year & 0.072 & 0.200 \\
\hline Class other $\times$ Mike $\$ 50,000$ a year & 0.279 & 0.230 \\
\hline Not working $\times$ Mike $\$ 20,000$ a year & -0.048 & 0.194 \\
\hline Not working $\times$ Mike $\$ 50,000$ a year & 0.223 & 0.221 \\
\hline Retired $\times$ Mike $\$ 20,000$ a year & 0.141 & 0.157 \\
\hline Retired $\times$ Mike $\$ 50,000$ a year & $0.479 *$ & 0.185 \\
\hline Disabled $\times$ Mike $\$ 20,000$ a year & -0.036 & 0.241 \\
\hline Disabled $\times$ Mike $\$ 50,000$ a year & -0.086 & 0.257 \\
\hline Class $1 \times$ Jessica HS diploma & 0.251 & 0.168 \\
\hline Class $1 \times$ Jessica 4-year degree & 0.097 & 0.172 \\
\hline Class $2 \times$ Jessica HS diploma & 0.188 & 0.191 \\
\hline Class $2 \times$ Jessica 4-year degree & 0.117 & 0.188 \\
\hline Class $3 \times$ Jessica HS diploma & 0.173 & 0.348 \\
\hline Class $3 \times$ Jessica 4 -year degree & 0.205 & 0.377 \\
\hline Class $4 \times$ Jessica HS diploma & 0.151 & 0.258 \\
\hline Class $4 \times$ Jessica 4 -year degree & 0.088 & 0.264 \\
\hline Class $6 \times$ Jessica HS diploma & 0.351 & 0.659 \\
\hline Class $6 \times$ Jessica 4 -year degree & $1.278^{*}$ & 0.579 \\
\hline Class $7 \times$ Jessica HS diploma & -0.197 & 0.405 \\
\hline Class $7 \times$ Jessica 4-year degree & 0.349 & 0.410 \\
\hline Class other $\times$ Jessica HS diploma & 0.191 & 0.207 \\
\hline Class other $\times$ Jessica 4-year degree & 0.214 & 0.208 \\
\hline
\end{tabular}


Not working $\times$ Jessica HS diploma

Not working $\times$ Jessica 4-year degree

Retired $\times$ Jessica HS diploma

Retired $\times$ Jessica 4-year degree

Disabled $\times$ Jessica HS diploma

Disabled $\times$ Jessica 4-year degree

Class $1 \times$ Jessica $\$ 20,000$ a year

Class $1 \times$ Jessica $\$ 50,000$ a year

Class $2 \times$ Jessica $\$ 20,000$ a year

Class $2 \times$ Jessica $\$ 50,000$ a year

Class $3 \times$ Jessica $\$ 20,000$ a year

Class $3 \times$ Jessica $\$ 50,000$ a year

Class $4 \times$ Jessica $\$ 20,000$ a year

Class $4 \times$ Jessica $\$ 50,000$ a year

Class $6 \times$ Jessica $\$ 20,000$ a year

Class $6 \times$ Jessica $\$ 50,000$ a year

Class $7 \times$ Jessica $\$ 20,000$ a year

Class $7 \times$ Jessica $\$ 50,000$ a year

Class other $\times$ Jessica $\$ 20,000$ a year

Class other $\times$ Jessica $\$ 50,000$ a year

Not working $\times$ Jessica $\$ 20,000$ a year

Not working $\times$ Jessica $\$ 50,000$ a year

Retired $\times$ Jessica $\$ 20,000$ a year

Retired $\times$ Jessica $\$ 50,000$ a year

Disabled $\times$ Jessica $\$ 20,000$ a year

Disabled $\times$ Jessica $\$ 50,000$ a year

Class $1 \times$ Inherited $\$ 5,000$

Class $2 \times$ Inherited \$5,000

Class $3 \times$ Inherited $\$ 5,000$

Class $4 \times$ Inherited $\$ 5,000$

Class $6 \times$ Inherited $\$ 5,000$

Class $7 \times$ Inherited $\$ 5,000$

Class other $\times$ Inherited $\$ 5,000$

Not working $\times$ Inherited \$5,000

Retired $\times$ Inherited $\$ 5,000$

Disabled $\times$ Inherited \$5,000

Class $1 \times$ Good relationship quality

Class $2 \times$ Good relationship quality

Class $3 \times$ Good relationship quality

Class $4 \times$ Good relationship quality

Class $6 \times$ Good relationship quality

Class $7 \times$ Good relationship quality

Class other $\times$ Good relationship quality

$\begin{array}{cc}0.576 * * & 0.201 \\ 0.382 & 0.208 \\ 0.131 & 0.171 \\ 0.063 & 0.177 \\ 0.559 * & 0.219 \\ 0.128 & 0.222 \\ 0.058 & 0.137 \\ -0.100 & 0.166 \\ 0.443 * * & 0.158 \\ 0.214 & 0.186 \\ 0.080 & 0.217 \\ -0.171 & 0.304 \\ -0.125 & 0.230 \\ 0.151 & 0.292 \\ 0.320 & 0.387 \\ -0.337 & 0.230 \\ -1.070 * * * & 0.303 \\ -0.573 & 0.231 \\ 0.035 & 0.184 \\ -0.073 & 0.205 \\ 0.070 & 0.177 \\ -0.207 & 0.204 \\ 0.050 & 0.140 \\ 0.003 & 0.172 \\ 0.139 & 0.192 \\ 0.084 & 0.213 \\ 0.089 & 0.125 \\ 0.276 * & 0.140 \\ 0.216 & 0.193 \\ 0.041 & 0.211 \\ 0.160 & 0.675 \\ -0.262 & 0.239 \\ 0.377 * & 0.166 \\ 0.209 & 0.152 \\ 0.142 & 0.133 \\ 0.510 * * & 0.182 \\ -0.136 & 0.199 \\ 0.065 & 0.220 \\ -0.013 & 0.405 \\ -0.076 & 0.341 \\ -1.360 & 0.765 \\ -0.530 & 0.311 \\ 0.104 & 0.253\end{array}$

$\begin{array}{cc}0.576^{* *} & 0.201 \\ 0.382 & 0.208\end{array}$

$0.131 \quad 0.171$

$0.063 \quad 0.177$

$0.559 *-0.219$

$0.058 \quad 0.137$

$-0.100 \quad 0.166$

$0.443 * * \quad 0.158$

$0.080 \quad 0.217$

$-0.171 \quad 0.304$

$-0.125-0.230$

$0.151 \quad 0.292$

$-0.337 \quad 0.230$

$\begin{array}{ll}-1.070 * * * & 0.303\end{array}$

$0.573-0.231$
$0.035-0.184$

$\begin{array}{ll}-0.073 & 0.205 \\ 0.070 & 0.177\end{array}$

$\begin{array}{ll}0.070 & 0.177\end{array}$

$\begin{array}{cc}-0.207 & 0.204 \\ 0.050 & 0.140\end{array}$

$0.003 \quad 0.172$

$0.139 \quad 0.192$

$\begin{array}{ll}0.084 & 0.213\end{array}$

$0.276 * \quad 0.140$

$0.216-0.193$

$0.041 \quad 0.211$

$0.160-0.675$
$-0.262-0.239$

$0.377^{*} \quad 0.166$

$0.209 \quad 0.152$

$0.142 \quad 0.133$

$0.510 * * \quad 0.182$

$\begin{array}{ll}-0.136 & 0.199\end{array}$

$0.065 \quad 0.220$

$\begin{array}{ll}-0.076 & 0.341\end{array}$

$-1.360 \quad 0.765$

$0.104 \quad 0.253$ 


\begin{tabular}{|c|c|c|}
\hline Not working $\times$ Good relationship quality & -0.022 & 0.229 \\
\hline Retired $\times$ Good relationship quality & -0.041 & 0.203 \\
\hline Disabled $\times$ Good relationship quality & 0.096 & 0.276 \\
\hline Class $1 \times$ Pregnant & -0.239 & 0.174 \\
\hline Class $2 \times$ Pregnant & $-0.393 *$ & 0.196 \\
\hline Class $3 \times$ Pregnant & -0.301 & 0.312 \\
\hline Class $4 \times$ Pregnant & -0.084 & 0.285 \\
\hline Class $6 \times$ Pregnant & 0.171 & 0.870 \\
\hline Class $7 \times$ Pregnant & 0.236 & 0.543 \\
\hline Class other $\times$ Pregnant & -0.241 & 0.205 \\
\hline Not working $\times$ Pregnant & -0.090 & 0.207 \\
\hline Retired $\times$ Pregnant & 0.186 & 0.181 \\
\hline Disabled $\times$ Pregnant & -0.048 & 0.233 \\
\hline Intercept & 3.379 & 0.676 \\
\hline sd(intercept) & \multicolumn{2}{|c|}{1.274} \\
\hline sd(residuals) & \multicolumn{2}{|c|}{1.633} \\
\hline sd(Mike HS diploma) & \multicolumn{2}{|c|}{0.126} \\
\hline sd(Mike 4-year degree) & \multicolumn{2}{|c|}{0.264} \\
\hline sd(Mike $\$ 20,000$ a year) & \multicolumn{2}{|c|}{0.246} \\
\hline sd(Mike $\$ 50,000$ a year) & \multicolumn{2}{|c|}{0.767} \\
\hline sd(Jessica HS diploma) & \multicolumn{2}{|c|}{0.240} \\
\hline sd(Jessica 4-year degree) & \multicolumn{2}{|c|}{0.123} \\
\hline sd(Jessica $\$ 20,000$ a year) & \multicolumn{2}{|c|}{0.000} \\
\hline sd(Jessica $\$ 50,000$ a year) & \multicolumn{2}{|c|}{0.417} \\
\hline sd(Inherited \$5,000) & \multicolumn{2}{|c|}{0.266} \\
\hline sd(Good relationship quality) & \multicolumn{2}{|c|}{1.107} \\
\hline sd(Pregnant) & \multicolumn{2}{|c|}{1.217} \\
\hline Vignette dummies & \multicolumn{2}{|c|}{ Yes } \\
\hline Individual-level controls & \multicolumn{2}{|c|}{ Yes } \\
\hline Observations & \multicolumn{2}{|c|}{16562} \\
\hline Individuals & \multicolumn{2}{|c|}{1747} \\
\hline
\end{tabular}

$* * * p<0.001, * * p<0.01, * p<0.05$ (two-tailed)

Note: $b=$ unstandardized slopes, $S E=$ robust standard errors. Joint test of significance for cross-level interactions, $\chi^{2}(144)=14288.52 p<.001$. Joint tests of significance for cross-level interactions between occupation and vignette dimensions, $\chi^{2}(122)=1767.01, p<.001$. Control variables included age, marital status, cohabitation status, housing type, ownership of living quarters, MSA status, region, religious affiliation, religiosity, religious attendance, a short-form GSS vocabulary test, and marriage judgments. 
Table S16. Model Comparisons of Higher-Order Interactions between Vignette Dimensions

\begin{tabular}{cc} 
BIC & Wald $\chi^{2}$ test \\
\hline 73393 & \\
73710 & $\chi^{2}(51)=180.61, p<.001$ \\
74814 & $\chi^{2}(129)=151.97, p>.05$ \\
76442 & $\chi^{2}(188)=201.98, p>.10$ \\
77941 & $\chi^{2}(168)=162.41, p>.10$ \\
& Did not converge \\
& Did not converge
\end{tabular}

Model 7: seven-way interaction effects Did not converge

Note : model 1 estimated from Table 3 (model 1). All remaining models are nested models. 
Table S17. Two-Level Hierarchical Linear Models of the Norm to Marry, Interaction Effects of Respondents' Race, Gender, and SES

\begin{tabular}{|c|c|c|c|c|c|c|c|c|}
\hline & \multicolumn{2}{|c|}{ Model 1} & \multicolumn{2}{|c|}{ Model 2} & \multicolumn{2}{|c|}{ Model 3} & \multicolumn{2}{|c|}{ Model 4} \\
\hline & $b$ & $S E$ & $b$ & $S E$ & $b$ & $S E$ & $b$ & $S E$ \\
\hline \multicolumn{9}{|l|}{ Race } \\
\hline White & $0.311^{*}$ & 0.155 & 0.260 & 0.184 & 0.163 & 0.667 & -0.358 & 0.900 \\
\hline \multicolumn{9}{|l|}{ Gender } \\
\hline \multicolumn{9}{|l|}{ Female (omitted) } \\
\hline \multicolumn{9}{|l|}{ HS diploma (omitted) } \\
\hline Some college & -0.243 & 0.164 & -0.274 & 0.192 & & & & \\
\hline Bachelor's degree or higher & -0.077 & 0.158 & -0.120 & 0.181 & & & & \\
\hline ln(household income per capita) & & & & & -0.115 & 0.059 & $-0.134 *$ & 0.066 \\
\hline \multicolumn{9}{|l|}{ Individual-level interactions } \\
\hline Male $\times$ some college & 0.099 & 0.177 & 0.162 & 0.262 & & & & \\
\hline Male $\times$ Bachelor's degree & -0.257 & 0.176 & -0.168 & 0.254 & & & & \\
\hline White $\times$ male $\times$ some college & & & -0.123 & 0.351 & & & & \\
\hline White $\times$ male $\times$ Bachelor's degree & & & -0.175 & 0.353 & & & & \\
\hline White $\times \ln ($ household income per capita) & & & & & 0.031 & 0.065 & 0.083 & 0.089 \\
\hline Male $\times \ln ($ household income per capita) & & & & & 0.038 & 0.065 & 0.083 & 0.089 \\
\hline White $\times$ male $\times \ln ($ household income per capita) & & & & & & & -0.111 & 0.133 \\
\hline Intercept & $1.762^{* * *}$ & 0.430 & $1.791 * * *$ & 0.431 & $2.772 * * *$ & 0.701 & $2.966 * * *$ & 0.750 \\
\hline sd(intercept) & \multicolumn{2}{|c|}{1.326} & \multicolumn{2}{|c|}{1.326} & \multicolumn{2}{|c|}{1.329} & \multicolumn{2}{|c|}{1.329} \\
\hline sd(residuals) & \multicolumn{2}{|c|}{1.943} & \multicolumn{2}{|c|}{1.943} & \multicolumn{2}{|c|}{1.943} & \multicolumn{2}{|c|}{1.943} \\
\hline Vignette dummies & \multicolumn{2}{|c|}{ Yes } & \multicolumn{2}{|c|}{ Yes } & \multicolumn{2}{|c|}{ Yes } & \multicolumn{2}{|c|}{ Yes } \\
\hline
\end{tabular}

$* * * p<0.001, * * p<0.01, * p<0.05$ (two-tailed)

Note $: b=$ unstandardized slopes, $S E=$ robust standard errors. Joint tests of significance for interaction effects, model 1: $\chi^{2}(5)=9.44, p=0.0927$; model 2: $\chi^{2}(7)=9.78, p=0.2012$; model 3: $\chi^{2}(3)=1.24, p=0.7432$; model 4: $\chi^{2}(4)=1.81, p=0.7701$. Control variables included age, marital status, cohabitation status, housing type, ownership of living quarters, MSA status, region, religious affiliation, religiosity, religious attendance, a short-form GSS vocabulary test, and marriage judgments. 
Table S18. Model Comparisons of Higher-Order Interactions of Race, Gender, SES, and each Vignette Dimension

Model 1: main effects + random slopes

Respondent's Race, Gender, and Education

Model 2: two-way interaction effects

Model 3: three-way interaction effects

Model 4: four-way interaction effects

Respondent's Race, Gender, and Income

Model 5: two-way interaction effects

Model 6: three-way interaction effects

Model 7: four-way interaction effects

Respondent's Race, Gender, and Occupation

Model 8: two-way interaction effects

Model 9: three-way interaction effects

Model 10: four-way interaction effects
Wald $\chi^{2}$ test

71736

$72045 \quad \chi^{2}(44)=110.09 p<.001$

$72557 \quad \chi^{2}(55)=57.56, p>.10$

$72765 \quad \chi^{2}(22)=22.21, p>.10$

$71945 \quad \chi^{2}(33)=95.82, p<.001$

$72248 \quad \chi^{2}(33)=48.08, p<.05$

$72356 \quad \chi^{2}(11)=7.73, p>.10$

$72793 \quad \chi^{2}(144)=14288.52, p<.001$

Did not converge

Did not converge

Note: model 1 estimated from Table 5 (model 1) but with random slopes for all vignette dimensions. All remaining models are nested models. Two-way interactions are between each vignette dimension and a sociodemographic variable (i.e., dimension $\times$ race, dimension $\times$ gender, and dimension $\times$ SES). Three-way interactions are between each vignette dimension and two sociodemographic variables (i.e., dimension $\times$ race $\times$ gender, dimension $\times$ race $\times$ SES, and dimension $\times$ gender $\times$ SES). Four-way interactions are between each vignette dimension and the three sociodemographic variables (i.e., dimension $\times$ race $\times$ gender $\times$ SES). 
Table S19. Two-Level Ordered Logit Models of the Norm to Marry, Effects of Vignette Dimensions

\begin{tabular}{|c|c|c|}
\hline & \multicolumn{2}{|c|}{ Model 1} \\
\hline & Log-Odds & $S E$ \\
\hline \multicolumn{3}{|l|}{ Vignette dimensions } \\
\hline \multicolumn{3}{|l|}{ Mike's education } \\
\hline \multicolumn{3}{|l|}{ No HS diploma (omitted) } \\
\hline HS diploma & $0.099 * *$ & 0.036 \\
\hline 4-year college degree & $0.169 * * *$ & 0.037 \\
\hline \multicolumn{3}{|l|}{ Mike's earnings and employment } \\
\hline \multicolumn{3}{|l|}{ Unemployed 2 years (omitted) } \\
\hline Full-time job, $\$ 20,000$ a year & $0.992 * * *$ & 0.036 \\
\hline Full-time job, $\$ 50,000$ a year & $1.473^{* * *}$ & 0.037 \\
\hline \multicolumn{3}{|l|}{ Jessica's education } \\
\hline \multicolumn{3}{|l|}{ No HS diploma (omitted) } \\
\hline HS diploma & $0.107 * *$ & 0.037 \\
\hline 4-year college degree & $0.171^{* * *}$ & 0.036 \\
\hline \multicolumn{3}{|l|}{ Jessica's earnings and employment } \\
\hline \multicolumn{3}{|l|}{ Unemployed 2 years (omitted) } \\
\hline Full-time job, $\$ 20,000$ a year & $0.641 * * *$ & 0.036 \\
\hline Full-time job, $\$ 50,000$ a year & $0.883^{* * *}$ & 0.036 \\
\hline \multicolumn{3}{|l|}{ Mike and Jessica's assets } \\
\hline \multicolumn{3}{|l|}{ Blank (omitted) } \\
\hline Inherited $\$ 5,000$ & $0.067 *$ & 0.030 \\
\hline \multicolumn{3}{|l|}{ Relationship quality } \\
\hline \multicolumn{3}{|l|}{ Bad (omitted) } \\
\hline Good & $1.172 * * *$ & 0.031 \\
\hline \multicolumn{3}{|l|}{ Pregnancy status } \\
\hline \multicolumn{3}{|l|}{ Not pregnant (omitted) } \\
\hline Pregnant & $0.680 * * *$ & 0.030 \\
\hline Cut-point 1 & $-0.708 * * *$ & 0.097 \\
\hline Cut-point 2 & $0.782 * * *$ & 0.091 \\
\hline Cut-point 3 & $1.139 * * *$ & 0.090 \\
\hline Cut-point 4 & $1.268 * * *$ & 0.089 \\
\hline Cut-point 5 & $3.354 * * *$ & 0.089 \\
\hline Cut-point 6 & $3.406 * * *$ & 0.089 \\
\hline Cut-point 7 & $3.725 * * *$ & 0.090 \\
\hline Cut-point 8 & $5.576 * * *$ & 0.105 \\
\hline sd(intercept) & \multicolumn{2}{|c|}{1.638} \\
\hline Vignette dummies & \multicolumn{2}{|c|}{ Yes } \\
\hline Individual-level variables and controls & \multicolumn{2}{|c|}{ No } \\
\hline Observations & \multicolumn{2}{|c|}{16804} \\
\hline Individuals & \multicolumn{2}{|c|}{1777} \\
\hline
\end{tabular}

*** $p<0.001, * * p<0.01, * p<0.05$ (two-tailed)

Note $: S E=$ standard errors. A model with random slopes failed to converge. 
Table S20. Two-Level Ordered Logit Model of the Norm to Marry,

Effects of Individual-Level Variables

\begin{tabular}{|c|c|c|}
\hline & \multicolumn{2}{|c|}{ Model 1} \\
\hline & Log-Odds & $S E$ \\
\hline \multicolumn{3}{|l|}{$\begin{array}{l}\text { Individual-level variables } \\
\text { nate }\end{array}$} \\
\hline \multicolumn{3}{|l|}{ Race } \\
\hline \multicolumn{3}{|l|}{ Black (omitted) } \\
\hline White & $0.451^{* * *}$ & 0.101 \\
\hline \multicolumn{3}{|l|}{ Gender } \\
\hline \multicolumn{3}{|l|}{ Female (omitted) } \\
\hline Male & $0.550 * * *$ & 0.085 \\
\hline \multicolumn{3}{|l|}{ Education } \\
\hline \multicolumn{3}{|l|}{ HS diploma (omitted) } \\
\hline Some college & -0.014 & 0.104 \\
\hline Bachelor's degree or higher & -0.136 & 0.114 \\
\hline ln(household income per capita) & -0.066 & 0.047 \\
\hline \multicolumn{3}{|l|}{ Occupation } \\
\hline Class 1 - Professionals, administrators, etc. & -0.167 & 0.186 \\
\hline Class 2 - Routine non-manual employees & -0.005 & 0.193 \\
\hline Class 3 - High-grade technicians & 0.473 & 0.371 \\
\hline Class 4 - Skilled manual workers & -0.109 & 0.271 \\
\hline \multicolumn{3}{|l|}{ Class 5 - Manual workers (omitted) } \\
\hline Class 6 - Agricultural & -0.093 & 0.650 \\
\hline Class 7 - Military & -0.247 & 0.671 \\
\hline Class other & $-0.496 *$ & 0.207 \\
\hline Not working & -0.302 & 0.204 \\
\hline Retired & -0.069 & 0.202 \\
\hline Disabled & -0.189 & 0.234 \\
\hline Cut-point 1 & $-1.647^{*}$ & 0.682 \\
\hline Cut-point 2 & -0.153 & 0.680 \\
\hline Cut-point 3 & 0.202 & 0.680 \\
\hline Cut-point 4 & 0.327 & 0.680 \\
\hline Cut-point 5 & $2.406 * * *$ & 0.680 \\
\hline Cut-point 6 & $2.459 * * *$ & 0.679 \\
\hline Cut-point 7 & $2.781 * * *$ & 0.679 \\
\hline Cut-point 8 & $4.622 * * *$ & 0.680 \\
\hline sd(intercept) & \multicolumn{2}{|c|}{1.516} \\
\hline Vignette dummies & \multicolumn{2}{|c|}{ Yes } \\
\hline Vignette dimensions & \multicolumn{2}{|c|}{ Yes } \\
\hline Individual-level controls & \multicolumn{2}{|c|}{ Yes } \\
\hline Observations & \multicolumn{2}{|c|}{16562} \\
\hline Individuals & \multicolumn{2}{|c|}{1747} \\
\hline
\end{tabular}

$* * * p<0.001, * * p<0.01, * p<0.05$ (two-tailed)

Note $: S E$ = robust standard errors. Control variables included age, marital status, cohabitation status, housing type, ownership of living quarters, MSA status, region, religious affiliation, religiosity, religious attendance, a short-form GSS vocabulary test, and marriage judgments. 
Table S21. Two-Level Ordered Logit Model of the Norm to Marry, Higher Level Moderation of Lower Level Effects

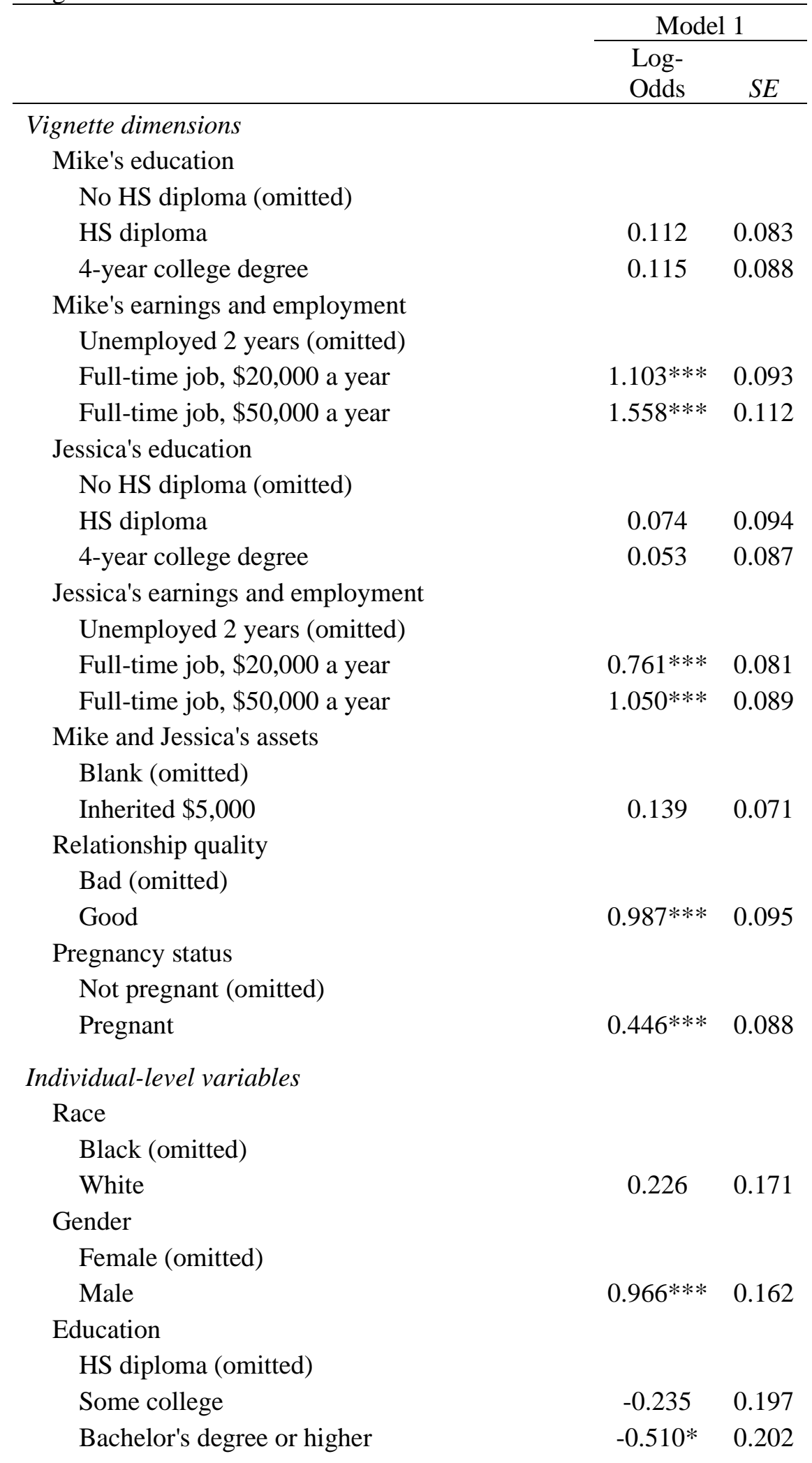




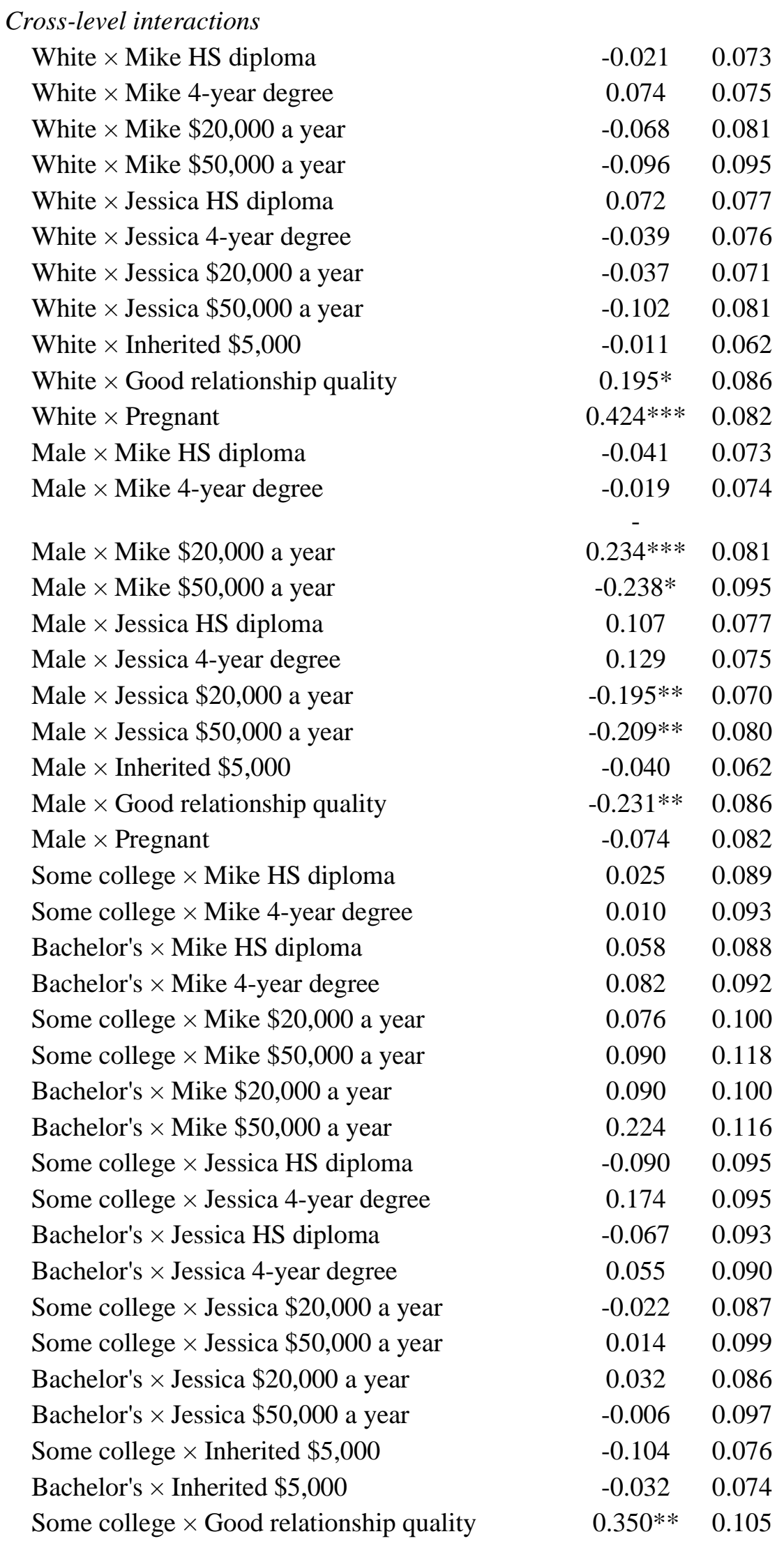




\begin{tabular}{lcc}
\multicolumn{1}{c}{ Bachelor's $\times$ Good relationship quality } & $0.294^{* *}$ & 0.102 \\
Some college $\times$ Pregnant & 0.011 & 0.099 \\
Bachelor's $\times$ Pregnant & 0.166 & 0.100 \\
\hline Cut-point 1 & $-1.754^{* *}$ & 0.700 \\
Cut-point 2 & -0.246 & 0.698 \\
Cut-point 3 & 0.112 & 0.698 \\
Cut-point 4 & 0.238 & 0.698 \\
Cut-point 5 & $2.331^{* * *}$ & 0.698 \\
Cut-point 6 & $2.384^{* * *}$ & 0.698 \\
Cut-point 7 & $2.709^{* * *}$ & 0.697 \\
Cut-point 8 & $4.558^{* * *}$ & 0.698 \\
\hline sd(intercept) & 1.529 \\
Vignette dummies & Yes \\
Individual-level controls & Yes \\
Observations & 16562 \\
Individuals & 1747 \\
\hline$* * *<0.001, * * p<0.01, * p<0.05($ two-tailed) & \multicolumn{2}{c}{} \\
\hline
\end{tabular}

*** $p<0.001, * * p<0.01, * p<0.05$ (two-tailed)

Note: $S E=$ robust standard errors. Joint test of significance for crosslevel interactions, $\chi^{2}(44)=101.80, p<.001$. Control variables included age, marital status, cohabitation status, housing type, ownership of living quarters, MSA status, region, religious affiliation, religiosity, religious attendance, a short-form GSS vocabulary test, and marriage judgments. Model failed to converge with all random slopes freely estimated. 
Table S22. Two-Level Multinomial Logit Model of the Norm to Marry, Effects of Vignette Dimensions

\begin{tabular}{|c|c|c|c|c|c|c|}
\hline & \multicolumn{2}{|c|}{ Should not vs. Neutral } & \multicolumn{2}{|c|}{ Should vs. Neutral } & \multicolumn{2}{|c|}{ Don't know vs. Neutral } \\
\hline & Log-Odds & $S E$ & Log-Odds & $S E$ & Log-Odds & $S E$ \\
\hline \multicolumn{7}{|l|}{ Vignette dimensions } \\
\hline \multicolumn{7}{|l|}{ Mike's education } \\
\hline \multicolumn{7}{|l|}{ No HS diploma (omitted) } \\
\hline HS diploma & $-0.150^{*}$ & 0.059 & 0.043 & 0.059 & -0.239 & 0.127 \\
\hline 4-year college degree & $-0.267 * * *$ & 0.061 & 0.081 & 0.060 & -0.185 & 0.126 \\
\hline \multicolumn{7}{|l|}{ Mike's earnings and employment } \\
\hline \multicolumn{7}{|l|}{ Unemployed 2 years (omitted) } \\
\hline Full-time job, $\$ 20,000$ a year & $-1.139 * * *$ & 0.060 & $0.627 * * *$ & 0.066 & $-0.362 * *$ & 0.118 \\
\hline Full-time job, $\$ 50,000$ a year & $-1.504 * * *$ & 0.069 & $1.066^{* * *}$ & 0.068 & $-0.317 *$ & 0.124 \\
\hline \multicolumn{7}{|l|}{ Jessica's education } \\
\hline \multicolumn{7}{|l|}{ No HS diploma (omitted) } \\
\hline HS diploma & $-0.177 * *$ & 0.061 & -0.030 & 0.062 & -0.181 & 0.132 \\
\hline 4-year college degree & $-0.205^{* *}$ & 0.061 & 0.047 & 0.060 & -0.125 & 0.121 \\
\hline \multicolumn{7}{|l|}{ Jessica's earnings and employment } \\
\hline \multicolumn{7}{|l|}{ Unemployed 2 years (omitted) } \\
\hline Full-time job, $\$ 20,000$ a year & $-0.649 * * *$ & 0.057 & $0.380 * * *$ & 0.061 & 0.107 & 0.118 \\
\hline Full-time job, $\$ 50,000$ a year & $-0.899 * * *$ & 0.062 & $0.610 * * *$ & 0.063 & -0.010 & 0.122 \\
\hline \multicolumn{7}{|l|}{ Mike and Jessica's assets } \\
\hline \multicolumn{7}{|l|}{ Blank (omitted) } \\
\hline Inherited $\$ 5,000$ & -0.028 & 0.050 & $0.131 *$ & 0.051 & 0.112 & 0.103 \\
\hline \multicolumn{7}{|l|}{ Relationship quality } \\
\hline \multicolumn{7}{|l|}{ Bad (omitted) } \\
\hline Good & $-1.124 * * *$ & 0.063 & $1.097 * * *$ & 0.063 & $-0.327 * *$ & 0.113 \\
\hline \multicolumn{7}{|l|}{ Pregnancy status } \\
\hline \multicolumn{7}{|l|}{ Not pregnant (omitted) } \\
\hline Pregnant & $-0.248 * * *$ & 0.058 & $0.961 * * *$ & 0.068 & $0.245^{*}$ & 0.110 \\
\hline Intercept & $1.922 * * *$ & 0.126 & $-2.339 * * *$ & 0.146 & $-5.303 * * *$ & 0.384 \\
\hline sd(intercept) & \multicolumn{2}{|c|}{2.049} & \multicolumn{2}{|c|}{2.202} & \multicolumn{2}{|c|}{5.044} \\
\hline Vignette dummies & \multicolumn{6}{|c|}{ Yes } \\
\hline Individual-level variables and controls & \multicolumn{6}{|c|}{ No } \\
\hline Observations & \multirow{2}{*}{\multicolumn{6}{|c|}{$\begin{array}{c}18230 \\
1823\end{array}$}} \\
\hline Individuals & & & & & & \\
\hline
\end{tabular}

$* * * p<0.001, * * p<0.01, * p<0.05$ (two-tailed)

Note : Log-Odds = relative log-odds; $S E=$ standard errors. A model with random slopes failed to converge. 
Table S23. Two-Level Multinomial Logit Model of the Norm to Marry, Effects of Individual-Level Variables

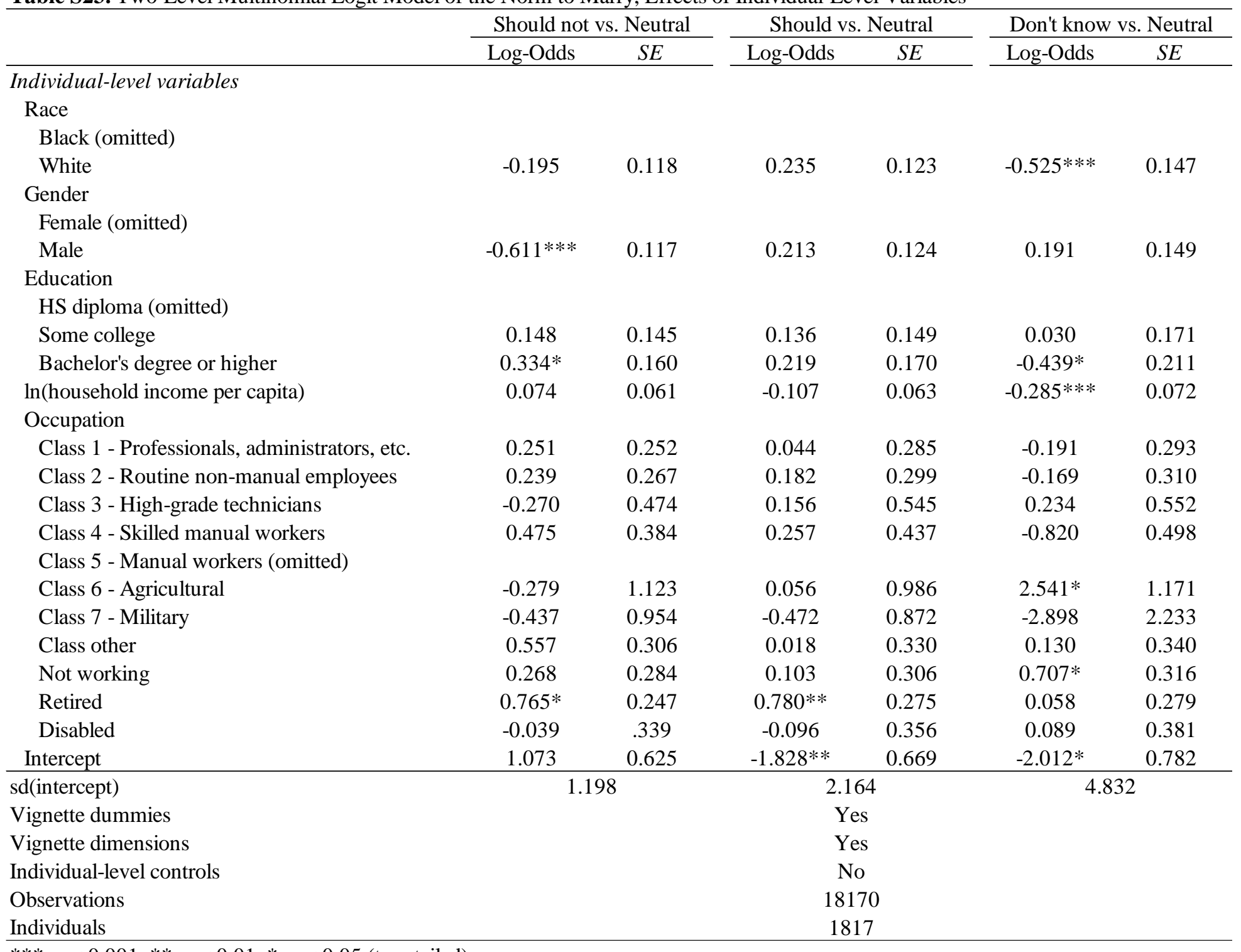

$* * * p<0.001, * * p<0.01$, * $p<0.05$ (two-tailed)

Note : Log-Odds = relative log-odds; $S E$ = standard errors. A model with individual-level control variables failed to converge. 
Table S24. Consensus and Conditionality of the Norm to Marry, Two-Level Hierarchical Linear Models without Nonexistent Norm Followers

\begin{tabular}{|c|c|c|c|c|}
\hline & \multicolumn{2}{|c|}{ Model 1} & \multicolumn{2}{|c|}{ Model 2} \\
\hline & $b$ & $S E$ & $b$ & $S E$ \\
\hline \multicolumn{5}{|l|}{ Vignette dimensions } \\
\hline \multicolumn{5}{|l|}{ Mike's education } \\
\hline \multicolumn{5}{|l|}{ No HS diploma (omitted) } \\
\hline HS diploma & $0.128 * *$ & 0.040 & $0.126^{* *}$ & 0.038 \\
\hline 4-year college degree & $0.214 * * *$ & 0.041 & $0.228 * * *$ & 0.039 \\
\hline \multicolumn{5}{|l|}{ Mike's earnings and employment } \\
\hline \multicolumn{5}{|l|}{ Unemployed 2 years (omitted) } \\
\hline Full-time job, $\$ 20,000$ a year & $1.148^{* * *}$ & 0.043 & $1.136^{* * *}$ & 0.041 \\
\hline Full-time job, $\$ 50,000$ a year & $1.696 * * *$ & 0.049 & $1.690 * * *$ & 0.048 \\
\hline \multicolumn{5}{|l|}{ Jessica's education } \\
\hline \multicolumn{5}{|l|}{ No HS diploma (omitted) } \\
\hline HS diploma & $0.109 *$ & 0.043 & $0.124 * *$ & 0.040 \\
\hline 4-year college degree & $0.189 * * *$ & 0.041 & $0.191 * * *$ & 0.039 \\
\hline \multicolumn{5}{|l|}{ Jessica's earnings and employment } \\
\hline \multicolumn{5}{|l|}{ Unemployed 2 years (omitted) } \\
\hline Full-time job, $\$ 20,000$ a year & $0.697 * * *$ & 0.038 & $0.699 * * *$ & 0.036 \\
\hline Full-time job, $\$ 50,000$ a year & $0.973 * * *$ & 0.043 & $0.984 * * *$ & 0.041 \\
\hline \multicolumn{5}{|l|}{ Mike and Jessica's assets } \\
\hline \multicolumn{5}{|l|}{ Blank (omitted) } \\
\hline Inherited $\$ 5,000$ & $0.096 * *$ & 0.034 & $0.084^{* *}$ & 0.032 \\
\hline \multicolumn{5}{|l|}{ Relationship quality } \\
\hline \multicolumn{5}{|l|}{ Bad (omitted) } \\
\hline Good & $1.370 * * *$ & 0.046 & $1.356^{* * *}$ & 0.046 \\
\hline \multicolumn{5}{|l|}{ Pregnancy status } \\
\hline \multicolumn{5}{|l|}{ Not pregnant (omitted) } \\
\hline Pregnant & $0.759 * * *$ & 0.045 & $0.766^{* * *}$ & 0.044 \\
\hline Intercept & $1.353^{* * *}$ & 0.092 & $1.357^{* * *}$ & 0.088 \\
\hline sd(intercept) & \multicolumn{2}{|c|}{1.488} & \multicolumn{2}{|c|}{1.443} \\
\hline sd(residuals) & \multicolumn{2}{|c|}{1.995} & \multicolumn{2}{|c|}{1.697} \\
\hline sd(Mike HS diploma) & & & \multicolumn{2}{|c|}{0.174} \\
\hline sd(Mike 4-year degree) & & & \multicolumn{2}{|c|}{0.255} \\
\hline sd(Mike $\$ 20,000$ a year) & & & & \\
\hline sd(Mike $\$ 50,000$ a year) & & & & \\
\hline sd(Jessica HS diploma) & & & & \\
\hline sd(Jessica 4-year degree) & & & & \\
\hline sd(Jessica $\$ 20,000$ a year) & & & & \\
\hline sd(Jessica $\$ 50,000$ a year) & & & & \\
\hline sd(Inherited \$5,000) & & & & \\
\hline sd(Good relationship quality) & & & & \\
\hline sd(Pregnant) & & & & \\
\hline Vignette dummies & & & & \\
\hline Individual-level variables and controls & & & & \\
\hline Observations & & & & \\
\hline Individuals & & & & \\
\hline
\end{tabular}

*** $p<0.001, * * p<0.01, * p<0.05$ (two-tailed)

Note $: b=$ unstandardized slopes, $S E=$ robust standard errors. 
Table S25. Consensus of the Norm to Marry across Subpopulations, TwoLevel Hierarchical Linear Model without Nonexistent Norm Followers

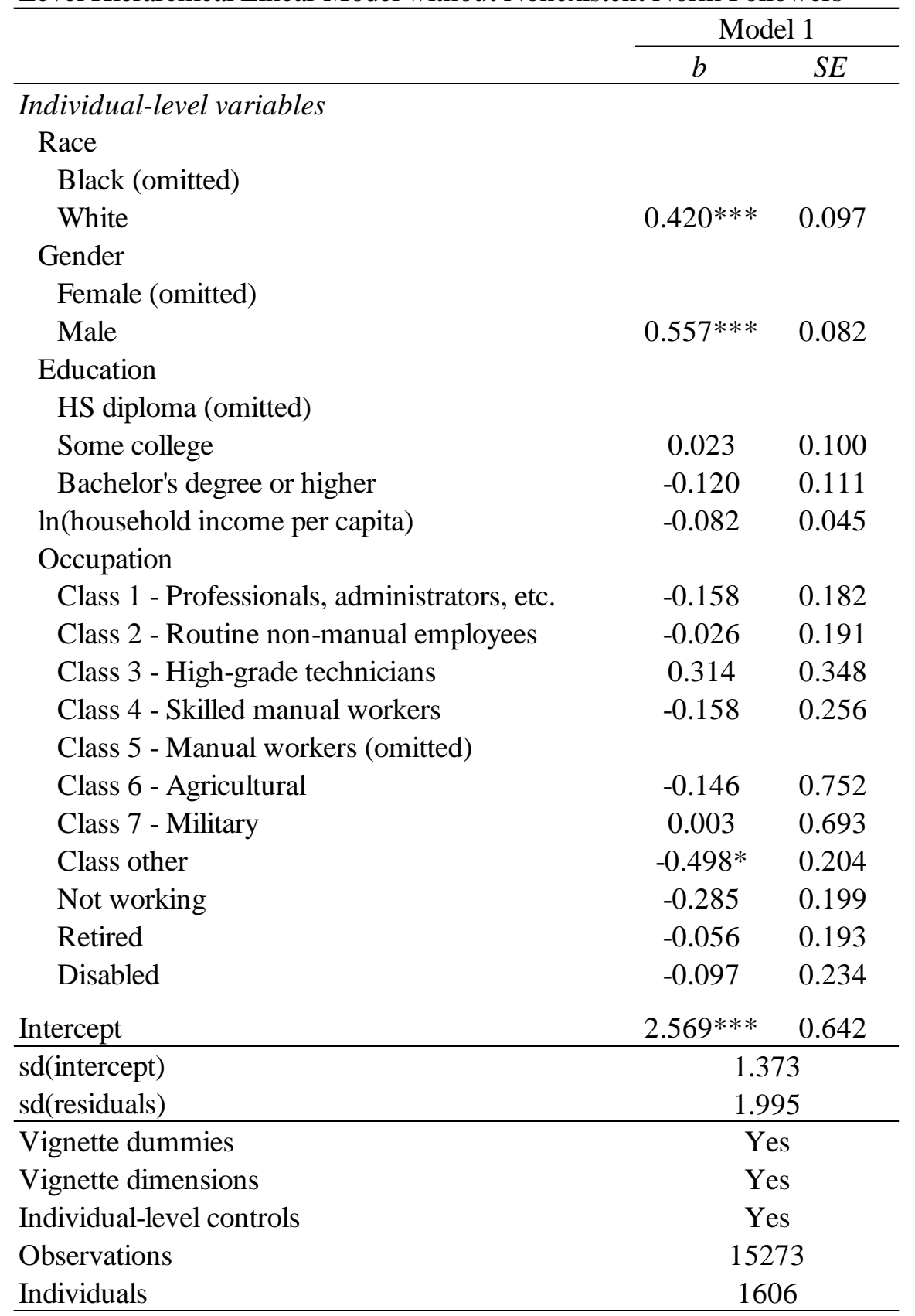

$* * * p<0.001, * * p<0.01, * p<0.05$ (two-tailed)

Note $: b=$ unstandardized slopes, $S E$ = robust standard errors. Control variables included age, marital status, cohabitation status, housing type, ownership of living quarters, MSA status, region, religious affiliation, religiosity, religious attendance, a short-form GSS vocabulary test, and marriage judgments. 
Table S26. Consensus of Conditionality of the Norm to Marry across Subpopulations, Two-Level Hierarchical Linear Model with Higher Level Moderation of Lower Level Effects without Nonexistent Norm Followers

\begin{tabular}{|c|c|c|}
\hline & \multicolumn{2}{|c|}{ Model 1} \\
\hline & $b$ & $S E$ \\
\hline \multicolumn{3}{|l|}{ Vignette dimensions } \\
\hline \multicolumn{3}{|l|}{ Mike's education } \\
\hline \multicolumn{3}{|l|}{ No HS diploma (omitted) } \\
\hline HS diploma & 0.142 & 0.093 \\
\hline 4-year college degree & 0.185 & 0.099 \\
\hline \multicolumn{3}{|l|}{ Mike's earnings and employment } \\
\hline \multicolumn{3}{|l|}{ Unemployed 2 years (omitted) } \\
\hline Full-time job, $\$ 20,000$ a year & $1.231^{* * *}$ & 0.101 \\
\hline Full-time job, $\$ 50,000$ a year & $1.753 * * *$ & 0.119 \\
\hline \multicolumn{3}{|l|}{ Jessica's education } \\
\hline \multicolumn{3}{|l|}{ No HS diploma (omitted) } \\
\hline HS diploma & 0.097 & 0.106 \\
\hline 4-year college degree & 0.083 & 0.097 \\
\hline \multicolumn{3}{|l|}{ Jessica's earnings and employment } \\
\hline \multicolumn{3}{|l|}{ Unemployed 2 years (omitted) } \\
\hline Full-time job, $\$ 20,000$ a year & $0.820 * * *$ & 0.090 \\
\hline Full-time job, $\$ 50,000$ a year & $1.088^{* * *}$ & 0.097 \\
\hline \multicolumn{3}{|l|}{ Mike and Jessica's assets } \\
\hline \multicolumn{3}{|l|}{ Blank (omitted) } \\
\hline Inherited $\$ 5,000$ & $0.162^{*}$ & 0.080 \\
\hline \multicolumn{3}{|l|}{ Relationship quality } \\
\hline \multicolumn{3}{|l|}{ Bad (omitted) } \\
\hline Good & $1.134 * * *$ & 0.105 \\
\hline \multicolumn{3}{|l|}{ Pregnancy status } \\
\hline \multicolumn{3}{|l|}{ Not pregnant (omitted) } \\
\hline Pregnant & $0.516^{* * *}$ & 0.097 \\
\hline \multicolumn{3}{|l|}{ Individual-level variables } \\
\hline \multicolumn{3}{|l|}{ Race } \\
\hline \multicolumn{3}{|l|}{ Black (omitted) } \\
\hline White & 0.033 & 0.163 \\
\hline \multicolumn{3}{|l|}{ Gender } \\
\hline \multicolumn{3}{|l|}{ Female (omitted) } \\
\hline Male & $0.917 * * *$ & 0.153 \\
\hline \multicolumn{3}{|l|}{ Education } \\
\hline \multicolumn{3}{|l|}{ HS diploma (omitted) } \\
\hline Some college & -0.034 & 0.191 \\
\hline
\end{tabular}


Bachelor's degree or higher

$-0.471^{*} \quad 0.193$

Cross-level interactions

White $\times$ Mike HS diploma

White $\times$ Mike 4-year degree

$\begin{array}{ll}-0.007 & 0.080\end{array}$

White $\times$ Mike $\$ 20,000$ a year

$0.067 \quad 0.083$

White $\times$ Mike $\$ 50,000$ a year

$-0.015 \quad 0.086$

White $\times$ Jessica HS diploma

$-0.025 \quad 0.098$

White $\times$ Jessica 4-year degree

$0.092 \quad 0.086$

White $\times$ Jessica $\$ 20,000$ a year

$\begin{array}{ll}-0.050 & 0.084\end{array}$

White $\times$ Jessica $\$ 50,000$ a year

$\begin{array}{ll}-0.011 & 0.077\end{array}$

White $\times$ Inherited \$5,000

$\begin{array}{ll}-0.026 & 0.086\end{array}$

White $\times$ Good relationship quality

$\begin{array}{ll}-0.016 & 0.069\end{array}$

White $\times$ Pregnant

$0.289 * * \quad 0.093$

Male $\times$ Mike HS diploma

$0.490 * * * \quad 0.089$

Male $\times$ Mike 4-year degree

$-0.035$

0.080

$0.006 \quad 0.083$

Male $\times$ Mike $\$ 20,000$ a year

$-0.206 * \quad 0.086$

Male $\times$ Mike $\$ 50,000$ a year

$-0.191 \quad 0.098$

Male $\times$ Jessica HS diploma

$0.096 \quad 0.086$

Male $\times$ Jessica 4-year degree

$0.138 \quad 0.084$

Male $\times$ Jessica $\$ 20,000$ a year

$-0.192 * \quad 0.077$

Male $\times$ Jessica $\$ 50,000$ a year

$-0.174 * \quad 0.086$

Male $\times$ Inherited \$5,000

$\begin{array}{ll}-0.008 & 0.069\end{array}$

Male $\times$ Good relationship quality

$-0.245^{* *} \quad 0.093$

Male $\times$ Pregnant

$\begin{array}{ll}-0.091 & 0.090\end{array}$

Some college $\times$ Mike HS diploma

$0.011 \quad 0.099$

Some college $\times$ Mike 4-year degree

$\begin{array}{ll}-0.064 & 0.105\end{array}$

Bachelor's $\times$ Mike HS diploma

0.038

0.099

Bachelor's $\times$ Mike 4-year degree

0.061

0.104

Some college $\times$ Mike $\$ 20,000$ a year

$0.013 \quad 0.107$

Some college $\times$ Mike $\$ 50,000$ a year

$-0.015$

0.123

Bachelor's $\times$ Mike $\$ 20,000$ a year

0.092

0.107

Bachelor's $\times$ Mike \$50,000 a year

0.213

0.121

Some college $\times$ Jessica HS diploma

$-0.095$

0.106

Some college $\times$ Jessica 4-year degree

0.174

0.106

Bachelor's $\times$ Jessica HS diploma

$-0.127$

0.106

Bachelor's $\times$ Jessica 4-year degree

0.038

0.102

Some college $\times$ Jessica $\$ 20,000$ a year

$-0.058$

0.095

Some college $\times$ Jessica $\$ 50,000$ a year

$-0.007$

0.105

Bachelor's $\times$ Jessica $\$ 20,000$ a year

$0.003 \quad 0.096$

Bachelor's $\times$ Jessica $\$ 50,000$ a year

$-0.014$

0.106

Some college $\times$ Inherited $\$ 5,000$

$-0.140$

0.085

Bachelor's $\times$ Inherited \$5,000

$-0.024 \quad 0.084$

Some college $\times$ Good relationship quality

$0.331 * * \quad 0.115$ 


\begin{tabular}{lcc}
\multicolumn{1}{c}{ Bachelor's $\times$ Good relationship quality } & $0.328^{* *}$ & 0.112 \\
\multicolumn{1}{c}{ Some college $\times$ Pregnant } & -0.052 & 0.108 \\
Bachelor's $\times$ Pregnant & 0.185 & 0.111 \\
Intercept & $2.693^{* * *}$ & 0.660 \\
\hline sd(intercept) & 1.374 \\
sd(residuals) & 1.984 \\
Vignette dummies & Yes \\
Individual-level controls & Yes \\
Observations & 15273 \\
Individuals & 1606 \\
\hline
\end{tabular}

*** $p<0.001, * * p<0.01, * p<0.05$ (two-tailed)

Note: $b=$ unstandardized slopes, $S E=$ robust standard errors. Joint test of significance for cross-level interactions, $\chi^{2}(44)=109.04, p<.001$. Control variables included age, marital status, cohabitation status, housing type, ownership of living quarters, MSA status, region, religious affiliation, religiosity, religious attendance, a short-form GSS vocabulary test, and marriage judgments. Model failed to converge with all random slopes freely estimated. 
Table S27. Consensus and Conditionality of the Norm to Marry, Two-Level Hierarchical Linear Models of Respondents who Rated All Ten Vignettes

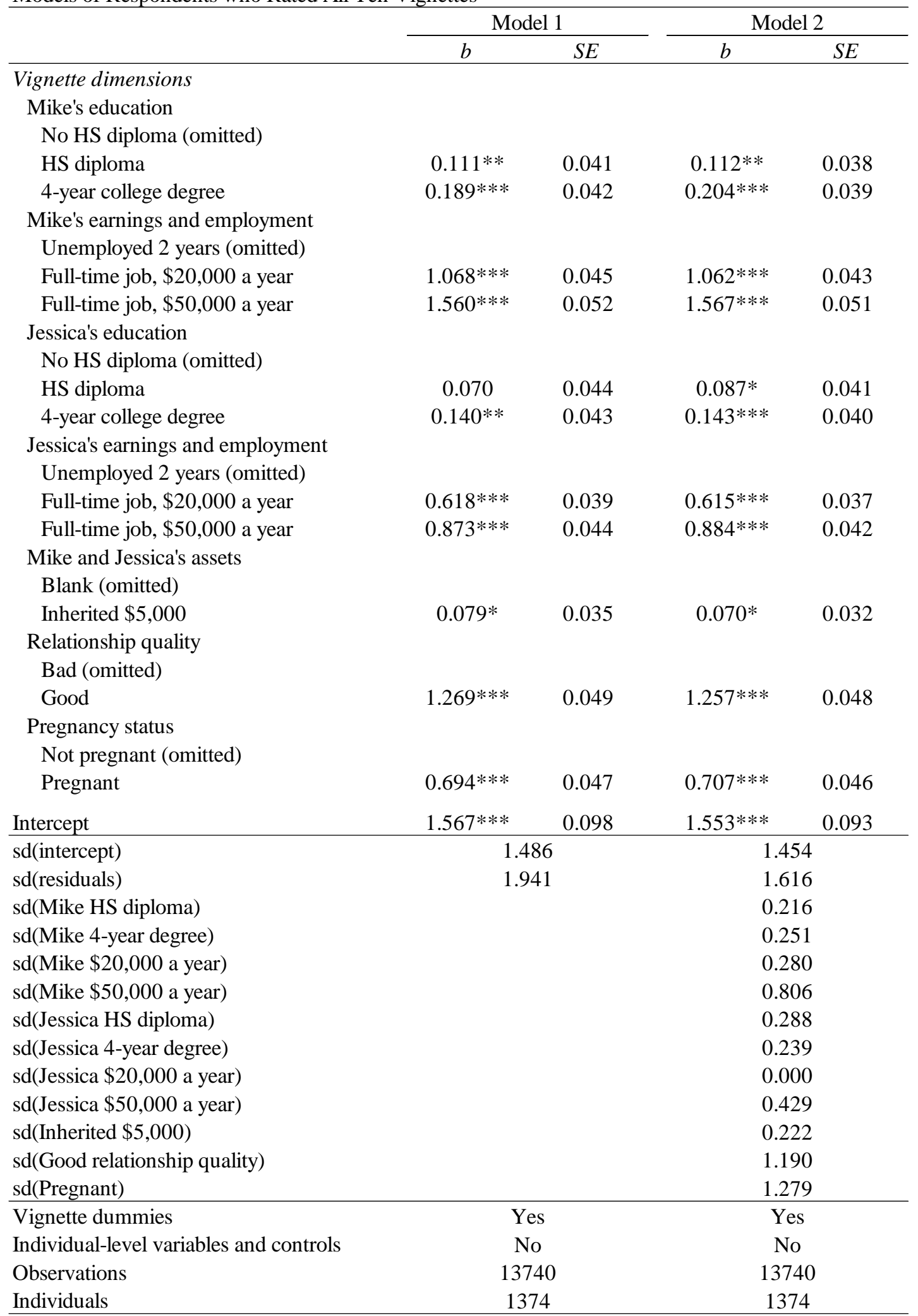

*** $p<0.001, * * p<0.01, * p<0.05$ (two-tailed)

Note $: b=$ unstandardized slopes, $S E=$ robust standard errors. 
Table S28. Consensus of the Norm to Marry across Subpopulations, TwoLevel Hierarchical Linear Model of Respondents who Rated All Ten

Vignettes

\begin{tabular}{|c|c|c|}
\hline & \multicolumn{2}{|c|}{ Model 1} \\
\hline & $b$ & SE \\
\hline \multicolumn{3}{|l|}{ Individual-level variables } \\
\hline \multicolumn{3}{|l|}{ Race } \\
\hline \multicolumn{3}{|l|}{ Black (omitted) } \\
\hline White & $0.486 * * *$ & 0.103 \\
\hline \multicolumn{3}{|l|}{ Gender } \\
\hline \multicolumn{3}{|l|}{ Female (omitted) } \\
\hline Male & $0.531 * * *$ & 0.087 \\
\hline \multicolumn{3}{|l|}{ Education } \\
\hline \multicolumn{3}{|l|}{ HS diploma (omitted) } \\
\hline Some college & -0.053 & 0.109 \\
\hline Bachelor's degree or higher & -0.127 & 0.121 \\
\hline ln(household income per capita) & $-0.109 *$ & 0.049 \\
\hline \multicolumn{3}{|l|}{ Occupation } \\
\hline Class 1 - Professionals, administrators, etc. & -0.095 & 0.199 \\
\hline Class 2 - Routine non-manual employees & -0.037 & 0.210 \\
\hline Class 3 - High-grade technicians & 0.402 & 0.367 \\
\hline Class 4 - Skilled manual workers & -0.350 & 0.264 \\
\hline \multicolumn{3}{|l|}{ Class 5 - Manual workers (omitted) } \\
\hline Class 6 - Agricultural & 0.062 & 0.901 \\
\hline Class 7 - Military & -0.156 & 0.702 \\
\hline Class other & $-0.448 *$ & 0.224 \\
\hline Not working & -0.264 & 0.226 \\
\hline Retired & -0.040 & 0.217 \\
\hline Disabled & -0.036 & 0.252 \\
\hline Intercept & $3.010 * * *$ & 0.728 \\
\hline sd(intercept) & \multicolumn{2}{|c|}{1.376} \\
\hline sd(residuals) & \multicolumn{2}{|c|}{1.944} \\
\hline Vignette dummies & \multicolumn{2}{|c|}{ Yes } \\
\hline Vignette dimensions & \multicolumn{2}{|c|}{ Yes } \\
\hline Individual-level controls & \multicolumn{2}{|c|}{ Yes } \\
\hline Observations & \multicolumn{2}{|c|}{13580} \\
\hline Individuals & \multicolumn{2}{|c|}{1358} \\
\hline
\end{tabular}

$* * * p<0.001, * * p<0.01, * p<0.05$ (two-tailed)

Note $: b=$ unstandardized slopes, $S E=$ robust standard errors. Control variables included age, marital status, cohabitation status, housing type, ownership of living quarters, MSA status, region, religious affiliation, religiosity, religious attendance, a short-form GSS vocabulary test, and marriage judgments. 
Table S29. Consensus of Conditionality of the Norm to Marry across Subpopulations, Two-Level Hierarchical Linear Model with Higher Level Moderation of Lower Level Effects of Respondents who Rated All Ten Vignettes

Model 1

b SE

Vignette dimensions

Mike's education

No HS diploma (omitted)

HS diploma

$0.124 \quad 0.092$

4-year college degree

$0.176 \quad 0.094$

Mike's earnings and employment

Unemployed 2 years (omitted)

Full-time job, $\$ 20,000$ a year

$1.164 * * * \quad 0.104$

Full-time job, $\$ 50,000$ a year

$1.734 * * * \quad 0.129$

Jessica's education

No HS diploma (omitted)

HS diploma

$0.058 \quad 0.106$

4-year college degree

$0.087 \quad 0.095$

Jessica's earnings and employment

Unemployed 2 years (omitted)

Full-time job, $\$ 20,000$ a year

$0.685 * * * \quad 0.088$

Full-time job, $\$ 50,000$ a year

$0.975^{* * *} \quad 0.099$

Mike and Jessica's assets

Blank (omitted)

Inherited \$5,000

$0.167 * \quad 0.075$

Relationship quality

Bad (omitted)

Good

$1.050 * * * \quad 0.109$

Pregnancy status

Not pregnant (omitted)

Pregnant

$0.427 * * * \quad 0.101$

Individual-level variables

Race

Black (omitted)

White

0.393* 0.171

Gender

Female (omitted)

Male

$0.851^{* * *} \quad 0.158$

Education

HS diploma (omitted)

Some college

$-0.128 \quad 0.199$ 
Bachelor's degree or higher

$-0.468 * \quad 0.204$

Cross-level interactions

White $\times$ Mike HS diploma

$\begin{array}{ll}0.020 & 0.077\end{array}$

White $\times$ Mike 4-year degree

$0.066 \quad 0.079$

White $\times$ Mike $\$ 20,000$ a year

$-0.091 \quad 0.088$

White $\times$ Mike $\$ 50,000$ a year

$-0.138 \quad 0.103$

White $\times$ Jessica HS diploma

$0.044 \quad 0.084$

White $\times$ Jessica 4-year degree

$-0.100 \quad 0.082$

White $\times$ Jessica $\$ 20,000$ a year

$-0.029 \quad 0.075$

White $\times$ Jessica $\$ 50,000$ a year

$-0.089 \quad 0.085$

White $\times$ Inherited \$5,000

$-0.066 \quad 0.065$

White $\times$ Good relationship quality

$0.160 \quad 0.097$

White $\times$ Pregnant

$0.443 * * * \quad 0.092$

Male $\times$ Mike HS diploma

$-0.063 \quad 0.077$
0.001

Male $\times$ Mike 4-year degree

$\begin{array}{ll}0.001 & 0.079\end{array}$

Male $\times$ Mike $\$ 20,000$ a year

$-0.164 \quad 0.087$

Male $\times$ Mike $\$ 50,000$ a year

$-0.234 * \quad 0.102$

Male $\times$ Jessica HS diploma

$0.117 \quad 0.083$

Male $\times$ Jessica 4-year degree

$0.126 \quad 0.081$

Male $\times$ Jessica $\$ 20,000$ a year

$\begin{array}{ll}-0.140 & 0.075\end{array}$

Male $\times$ Jessica $\$ 50,000$ a year

$\begin{array}{ll}-0.129 & 0.085\end{array}$

Male $\times$ Inherited \$5,000

$-0.018 \quad 0.064$

Male $\times$ Good relationship quality

$-0.237 * \quad 0.097$

Male $\times$ Pregnant

$-0.041 \quad 0.092$

Some college $\times$ Mike HS diploma

$0.029 \quad 0.097$

Some college $\times$ Mike 4-year degree

$\begin{array}{ll}-0.067 & 0.100\end{array}$

Bachelor's $\times$ Mike HS diploma

$0.006 \quad 0.094$

Bachelor's $\times$ Mike 4-year degree

$0.041 \quad 0.099$

Some college $\times$ Mike $\$ 20,000$ a year

$0.063 \quad 0.111$

Some college $\times$ Mike $\$ 50,000$ a year

$-0.023 \quad 0.131$

Bachelor's $\times$ Mike $\$ 20,000$ a year

$0.058 \quad 0.108$

Bachelor's $\times$ Mike $\$ 50,000$ a year

$0.118 \quad 0.128$

Some college $\times$ Jessica HS diploma

$-0.092 \quad 0.105$

Some college $\times$ Jessica 4-year degree

$0.124 \quad 0.105$

Bachelor's $\times$ Jessica HS diploma

$\begin{array}{ll}-0.057 & 0.100\end{array}$

Bachelor's $\times$ Jessica 4-year degree

$0.016 \quad 0.098$

$-0.010 \quad 0.095$

$0.024 \quad 0.107$

Some college $\times$ Jessica $\$ 50,000$ a year

$0.050 \quad 0.092$

Bachelor's $\times$ Jessica \$20,000 a year

$0.035 \quad 0.103$

Bachelor's $\times$ Jessica \$50,000 a year

$-0.128 \quad 0.081$

Some college $\times$ Inherited $\$ 5,000$

$\begin{array}{ll}-0.029 & 0.078\end{array}$

Some college $\times$ Good relationship quality

$0.380 * * \quad 0.121$ 


\begin{tabular}{lcc}
\multicolumn{1}{c}{ Bachelor's $\times$ Good relationship quality } & $0.350^{* *}$ & 0.116 \\
\multicolumn{1}{c}{ Some college $\times$ Pregnant } & -0.055 & 0.113 \\
\multicolumn{1}{c}{ Bachelor's $\times$ Pregnant } & $0.254^{*}$ & 0.115 \\
Intercept & $3.747^{* * *}$ & 0.782 \\
\hline sd(intercept) & 1.324 \\
sd(residuals) & 1.612 \\
sd(Mike HS diploma) & 0.236 \\
sd(Mike 4-year degree) & 0.260 \\
sd(Mike \$20,000 a year) & 0.291 \\
sd(Mike \$50,000 a year) & 0.820 \\
sd(Jessica HS diploma) & 0.305 \\
sd(Jessica 4-year degree) & 0.213 \\
sd(Jessica \$20,000 a year) & 0.000 \\
sd(Jessica \$50,000 a year) & 0.443 \\
sd(Inherited \$5,000) & 0.190 \\
sd(Good relationship quality) & 1.169 \\
sd(Pregnant) & 1.261 \\
\hline Vignette dummies & Yes \\
Individual-level controls & Yes \\
Observations & 13580 \\
Individuals & 1358 \\
\hline *** $~$
\end{tabular}

*** $p<0.001,{ }^{* *} p<0.01, * p<0.05$ (two-tailed)

Note: $b=$ unstandardized slopes, $S E=$ robust standard errors. Joint test of significance for cross-level interactions, $\chi^{2}(44)=89.98, p<.001$. Control variables included age, marital status, cohabitation status, housing type, ownership of living quarters, MSA status, region, religious affiliation, religiosity, religious attendance, a short-form GSS vocabulary test, and marriage judgments. 
Table S30. Polarity and Conditionality of the Norm to Marry with Survey Weights

\begin{tabular}{lcc}
\hline Norm to Marry & \multicolumn{2}{c}{ Weighted \% of } \\
Polarity & Number & Sample \\
$\quad$ Nonexistent $(R=4)$ & 145 & 8.82 \\
Prescriptive $(R>4, r \geq 4)$ & 268 & 14.92 \\
Proscriptive $(R<4, r \leq 4)$ & 248 & 13.45 \\
Bipolar $(0<R<8,0<r<8)$ & 1116 & 62.82 \\
Total & 1777 & 100 \\
Conditionality & & \\
Nonexistent $(R=4)$ & 145 & 12.02 \\
Unconditional $(R=r, r \neq 4)$ & 88 & 4.69 \\
Conditional $(V A R(r) \neq 0)$ & 1544 & 83.29 \\
Total & 1777 & 100 \\
\hline & & Weighted \\
& Number & Intensity \\
\hline Intensity & & \\
Unconditional proscriptive & 33 & 3.25 \\
Unconditional prescriptive & 55 & 3.28 \\
Conditional proscriptive & 215 & 1.90 \\
Conditional prescriptive & 213 & 1.90 \\
Bipolar & 1116 & 2.34 \\
\hline
\end{tabular}


Table S31. Consensus and Conditionality of the Norm to Marry, TwoLevel Hierarchical Linear Models with Survey Weights

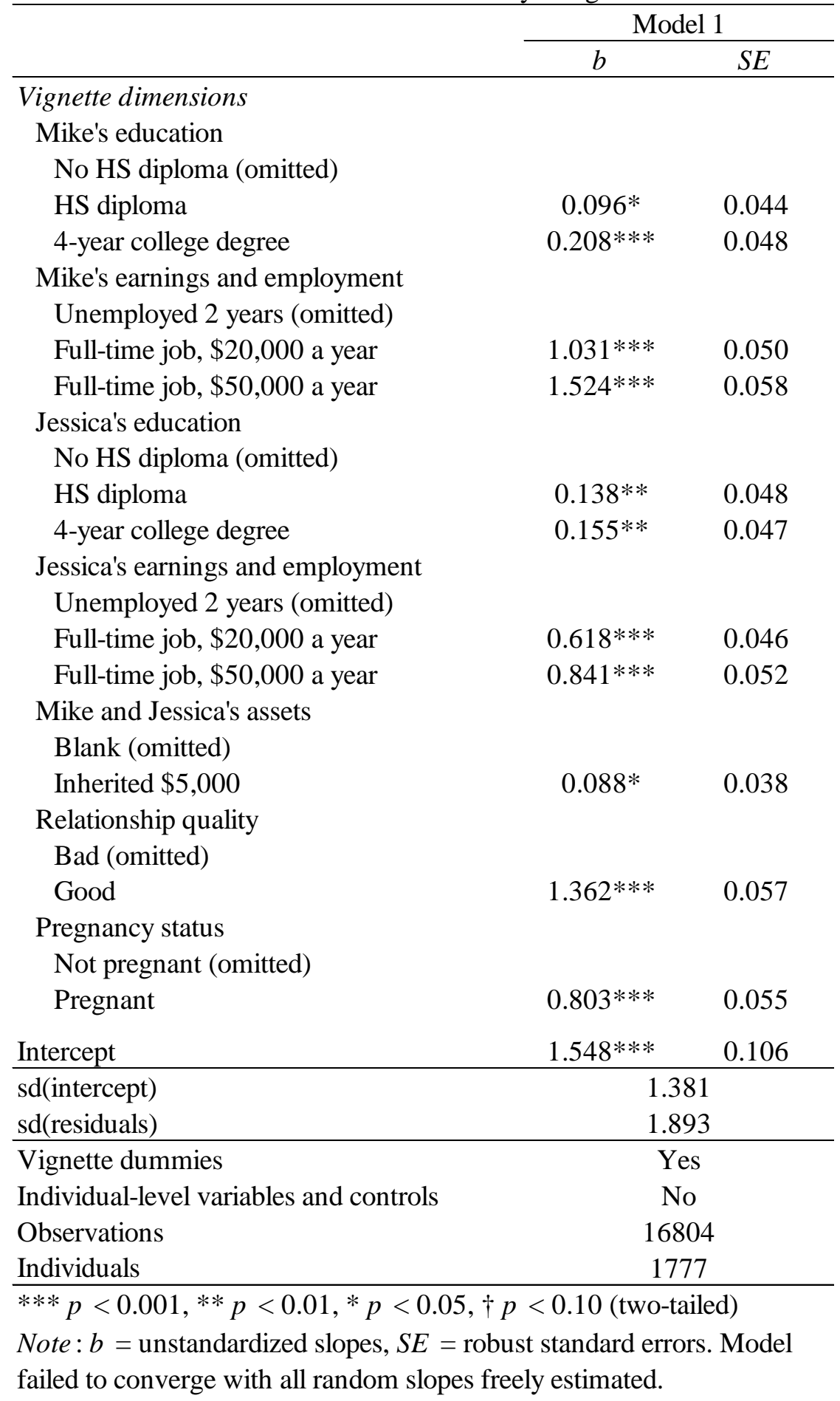


Table S32. Consensus of the Norm to Marry across Subpopulations, TwoLevel Hierarchical Linear Model with Survey Weights

\begin{tabular}{|c|c|c|}
\hline & \multicolumn{2}{|c|}{ Model 1} \\
\hline & $b$ & $S E$ \\
\hline \multicolumn{3}{|l|}{ Individual-level variables } \\
\hline \multicolumn{3}{|l|}{ Race } \\
\hline \multicolumn{3}{|l|}{ Black (omitted) } \\
\hline White & $0.465 * * *$ & 0.100 \\
\hline \multicolumn{3}{|l|}{ Gender } \\
\hline \multicolumn{3}{|l|}{ Female (omitted) } \\
\hline Male & $0.493 * * *$ & 0.091 \\
\hline \multicolumn{3}{|l|}{ Education } \\
\hline \multicolumn{3}{|l|}{ HS diploma (omitted) } \\
\hline Some college & 0.011 & 0.107 \\
\hline Bachelor's degree or higher & -0.171 & 0.127 \\
\hline ln(household income per capita) & -0.035 & 0.050 \\
\hline \multicolumn{3}{|l|}{ Occupation } \\
\hline Class 1 - Professionals, administrators, etc. & 0.026 & 0.178 \\
\hline Class 2 - Routine non-manual employees & 0.160 & 0.191 \\
\hline Class 3 - High-grade technicians & 0.382 & 0.338 \\
\hline Class 4 - Skilled manual workers & 0.020 & 0.287 \\
\hline \multicolumn{3}{|l|}{ Class 5 - Manual workers (omitted) } \\
\hline Class 6 - Agricultural & 0.307 & 0.812 \\
\hline Class 7 - Military & -0.666 & 0.600 \\
\hline Class other & -0.172 & 0.227 \\
\hline Not working & 0.018 & 0.201 \\
\hline Retired & 0.173 & 0.203 \\
\hline Disabled & 0.005 & 0.231 \\
\hline Intercept & $1.483^{*}$ & 0.699 \\
\hline sd(intercept) & \multicolumn{2}{|c|}{1.255} \\
\hline sd(residuals) & \multicolumn{2}{|c|}{1.895} \\
\hline Vignette dummies & \multicolumn{2}{|c|}{ Yes } \\
\hline Vignette dimensions & \multicolumn{2}{|c|}{ Yes } \\
\hline Individual-level controls & \multicolumn{2}{|c|}{ Yes } \\
\hline Observations & \multicolumn{2}{|c|}{16562} \\
\hline Individuals & \multicolumn{2}{|c|}{1747} \\
\hline
\end{tabular}

$* * * p<0.001, * * p<0.01, * p<0.05$ (two-tailed)

Note $: b=$ unstandardized slopes, $S E$ = robust standard errors. Control variables included age, marital status, cohabitation status, housing type, ownership of living quarters, MSA status, region, religious affiliation, religiosity, religious attendance, a short-form GSS vocabulary test, and marriage judgments. 
Table S33. Consensus of Conditionality of the Norm to Marry across Subpopulations, Two-Level Hierarchical Linear Model with Higher Level Moderation of Lower Level Effects with Survey Weights

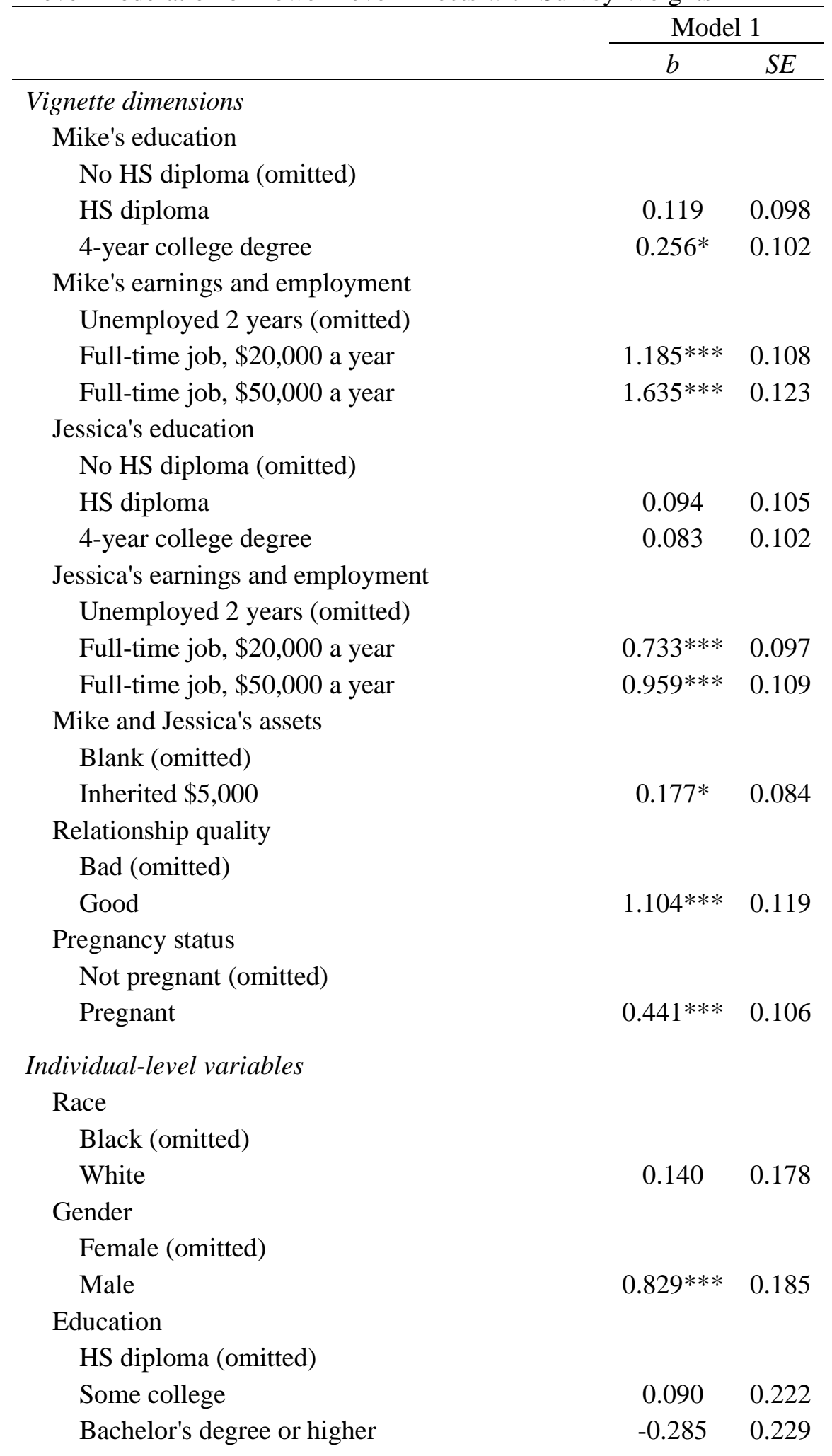




\begin{tabular}{|c|c|c|}
\hline \multicolumn{3}{|c|}{ Cross-level interactions } \\
\hline White $\times$ Mike HS diploma & -0.048 & 0.083 \\
\hline White $\times$ Mike 4-year degree & -0.001 & 0.087 \\
\hline White $\times$ Mike $\$ 20,000$ a year & -0.005 & 0.091 \\
\hline White $\times$ Mike $\$ 50,000$ a year & 0.027 & 0.101 \\
\hline White $\times$ Jessica HS diploma & 0.065 & 0.089 \\
\hline White $\times$ Jessica 4-year degree & -0.040 & 0.088 \\
\hline White $\times$ Jessica $\$ 20,000$ a year & 0.008 & 0.078 \\
\hline White $\times$ Jessica $\$ 50,000$ a year & -0.034 & 0.090 \\
\hline White $\times$ Inherited $\$ 5,000$ & -0.003 & 0.070 \\
\hline White $\times$ Good relationship quality & $0.236^{*}$ & 0.099 \\
\hline White $\times$ Pregnant & $0.437 * * *$ & 0.088 \\
\hline Male $\times$ Mike HS diploma & 0.059 & 0.090 \\
\hline Male $\times$ Mike 4-year degree & -0.075 & 0.097 \\
\hline Male $\times$ Mike $\$ 20,000$ a year & -0.185 & 0.100 \\
\hline Male $\times$ Mike $\$ 50,000$ a year & -0.187 & 0.116 \\
\hline Male $\times$ Jessica HS diploma & 0.063 & 0.098 \\
\hline Male $\times$ Jessica 4-year degree & 0.112 & 0.096 \\
\hline Male $\times$ Jessica $\$ 20,000$ a year & $-0.209 *$ & 0.093 \\
\hline Male $\times$ Jessica $\$ 50,000$ a year & -0.133 & 0.105 \\
\hline Male $\times$ Inherited \$5,000 & -0.045 & 0.077 \\
\hline Male $\times$ Good relationship quality & $-0.232 *$ & 0.111 \\
\hline Male $\times$ Pregnant & -0.029 & 0.111 \\
\hline Some college $\times$ Mike HS diploma & -0.053 & 0.109 \\
\hline Some college $\times$ Mike 4-year degree & -0.124 & 0.120 \\
\hline Bachelor's $\times$ Mike HS diploma & 0.050 & 0.107 \\
\hline Bachelor's $\times$ Mike 4-year degree & 0.110 & 0.119 \\
\hline Some college $\times$ Mike $\$ 20,000$ a year & -0.055 & 0.127 \\
\hline Some college $\times$ Mike $\$ 50,000$ a year & -0.053 & 0.143 \\
\hline Bachelor's $\times$ Mike $\$ 20,000$ a year & -0.099 & 0.121 \\
\hline Bachelor's $\times$ Mike $\$ 50,000$ a year & -0.050 & 0.143 \\
\hline Some college $\times$ Jessica HS diploma & -0.051 & 0.116 \\
\hline Some college $\times$ Jessica 4-year degree & 0.098 & 0.120 \\
\hline Bachelor's $\times$ Jessica HS diploma & -0.098 & 0.113 \\
\hline Bachelor's $\times$ Jessica 4-year degree & 0.061 & 0.121 \\
\hline Some college $\times$ Jessica $\$ 20,000$ a year & -0.006 & 0.115 \\
\hline Some college $\times$ Jessica $\$ 50,000$ a year & 0.055 & 0.128 \\
\hline Bachelor's $\times$ Jessica $\$ 20,000$ a year & -0.041 & 0.112 \\
\hline Bachelor's $\times$ Jessica $\$ 50,000$ a year & -0.095 & 0.126 \\
\hline Some college $\times$ Inherited $\$ 5,000$ & $-0.118^{*}$ & 0.092 \\
\hline Bachelor's $\times$ Inherited $\$ 5,000$ & -0.013 & 0.093 \\
\hline Some college $\times$ Good relationship quality & 0.258 & 0.132 \\
\hline Bachelor's $\times$ Good relationship quality & 0.252 & 0.136 \\
\hline
\end{tabular}




\begin{tabular}{lcc}
\multicolumn{1}{c}{ Some college $\times$ Pregnant } & -0.105 & 0.126 \\
\multicolumn{1}{c}{ Bachelor's $\times$ Pregnant } & 0.093 & 0.139 \\
Intercept & $1.616^{*}$ & 0.717 \\
\hline sd(intercept) & 1.256 \\
sd(residuals) & 1.888 \\
\hline Vignette dummies & Yes \\
Individual-level controls & Yes \\
Observations & 16562 \\
Individuals & 1747 \\
\hline
\end{tabular}

*** $p<0.001, * * p<0.01, * p<0.05$ (two-tailed)

Note: $b=$ unstandardized slopes, $S E=$ robust standard errors. Joint test of significance for cross-level interactions, $\chi^{2}(44)=75.03, p<.01$. Model failed to converge with all random slopes freely estimated. 

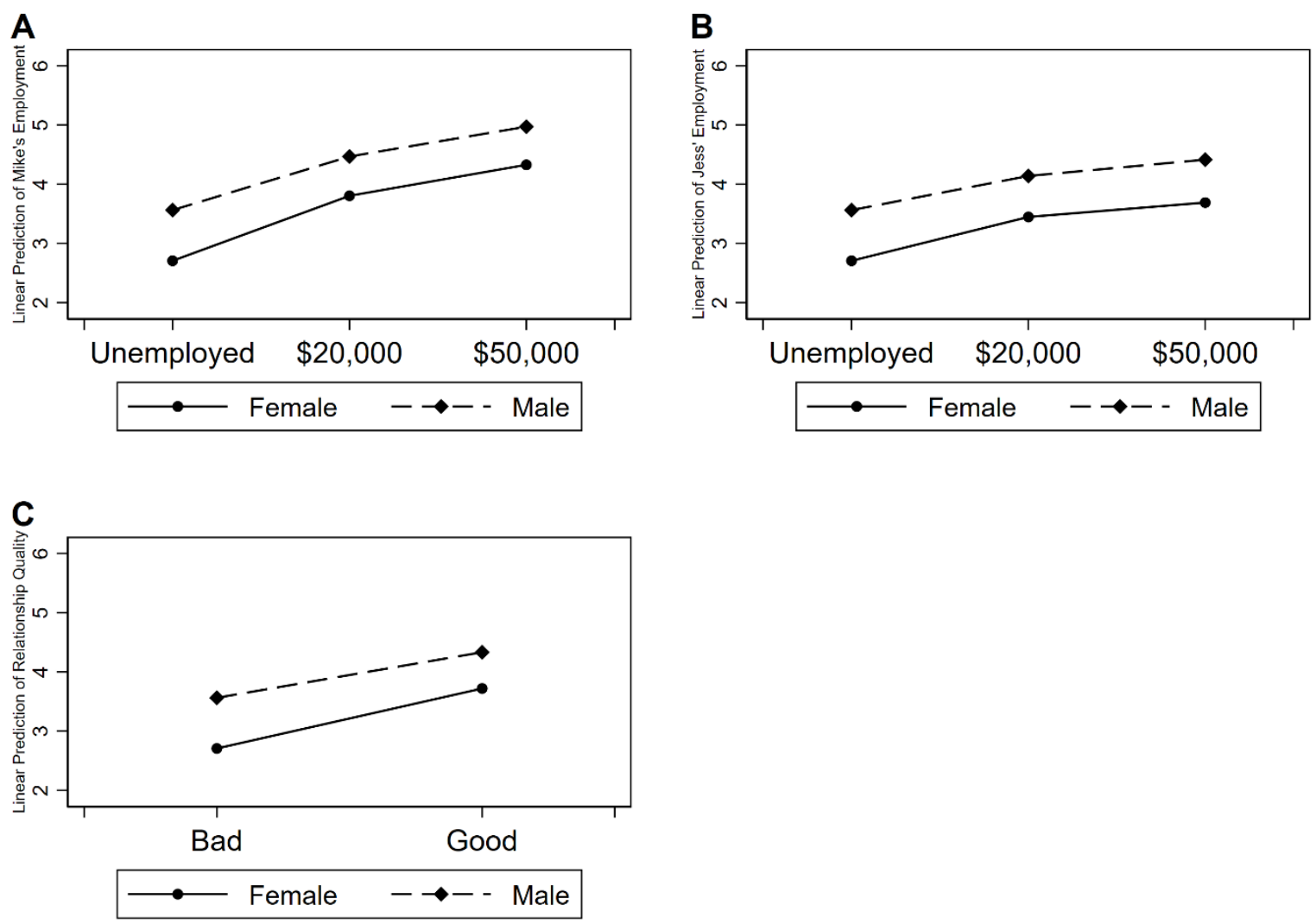

Figure S1. Cross-Level Interaction Effects between Gender and Mike’s Earnings and Employment (Panel A), Gender and Jessica's Earnings and Employment (Panel B), and Gender and Relationship Quality (Panel C) on the Norm to Marry (Table 6)

Note: All continuous covariates constrained to their minimum value and all factor-variable covariates constrained to their base level. 


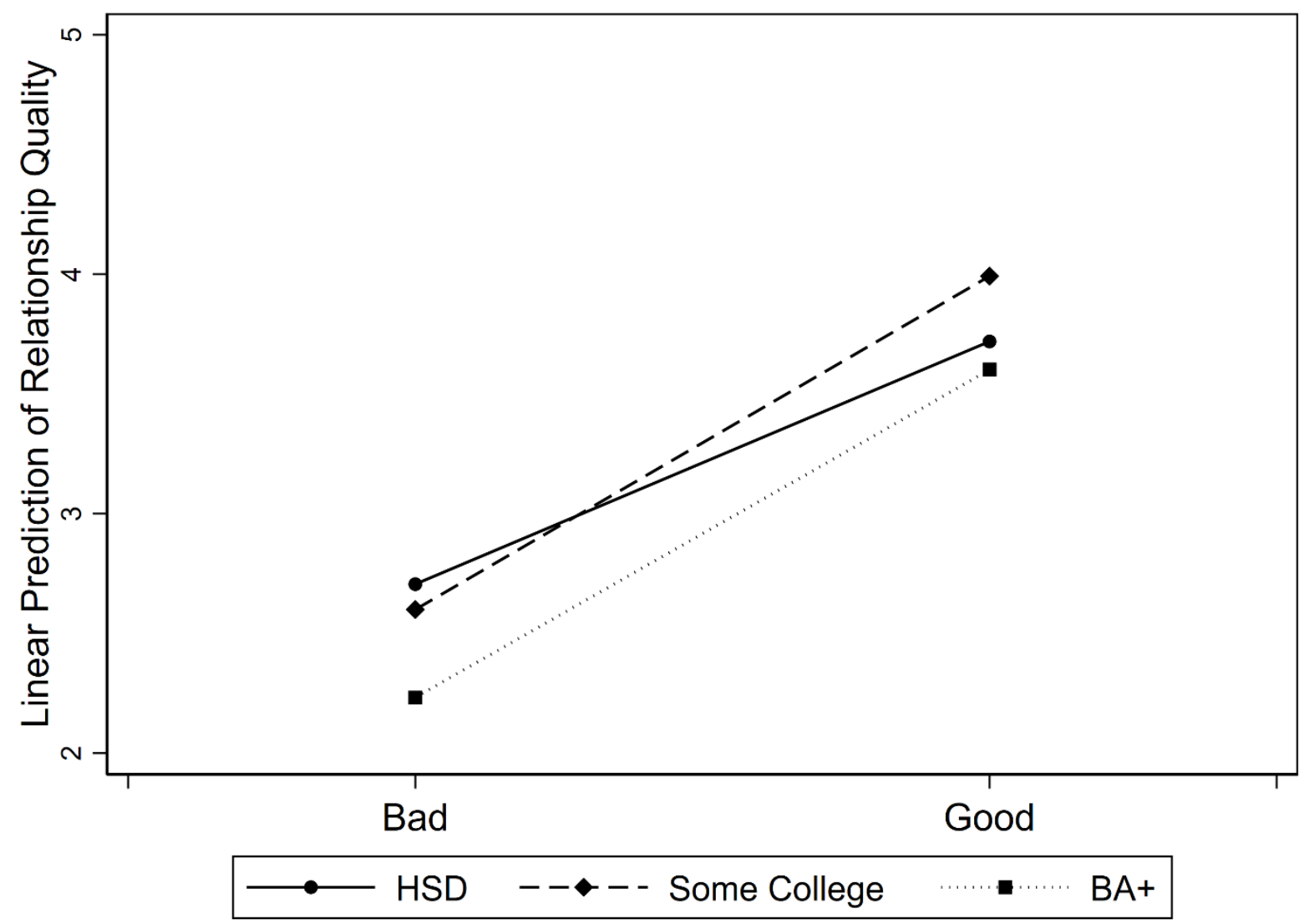

Figure S2. Cross-Level Interaction Effect between Education of Respondent and Relationship Quality on the Norm to Marry (Table 6)

Note: All continuous covariates constrained to their minimum value and all factor-variable covariates constrained to their base level. 